$\mathrm{AD}$

Award Number:W81XWH-10-1-0520

TITLE:Preclinical Studies of Induced Pluripotent Stem Cell-Derived Astrocyte Transplantation in ALS

PRINCIPAL INVESTIGATOR: Nicholas J. Maragakis, M.D.

CONTRACTING ORGANIZATION : Johns Hopkins University School of Medicine \%DQP RHயO ' पि००००

REPORT DATE: December 2014

TYPE OF REPORT: Final

PREPARED FOR: U.S. Army Medical Research and Materiel Command Fort Detrick, Maryland 21702-5012

DISTRIBUTION STATEMENT: Approved for public release; distribution unlimited

The views, opinions and/or findings contained in this report are those of the author(s) and should not be construed as an official Department of the Army position, policy or decision unless so designated by other documentation. 


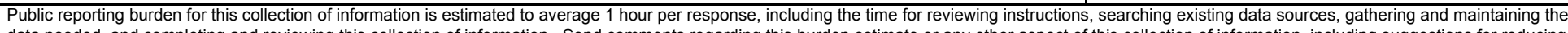

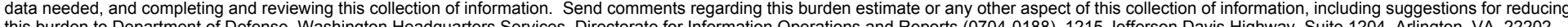

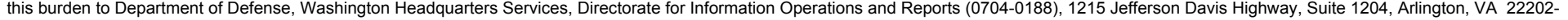

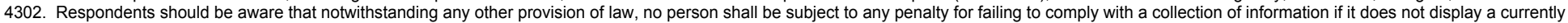
valid OMB control number. PLEASE DO NOT RETURN YOUR FORM TO THE ABOVE ADDRESS.

\begin{tabular}{l|l|l} 
1. REPORT DATE (DD-MM-YYYY) & 2. REPORT TYPE & 3. DATES COVERED (FrOm - To)
\end{tabular}

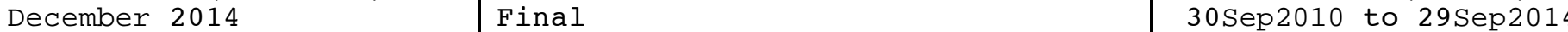

\section{TITLE AND SUBTITLE}

Preclinical Studies of Induced Pluripotent Stem Cell-Derived

Astrocyte Transplantation in ALS

5a. CONTRACT NUMBER

5b. GRANT NUMBER

W81XWH-10-1-0520

5c. PROGRAM ELEMENT NUMBER

\section{AUTHOR(S)}

Nicholas J. Maragakis, M.D., Hongjun Song, Ph.D.

5d. PROJECT NUMBER

5e. TASK NUMBER

FNBJM ONBSBHBL!KINJ EEV

\section{5f. WORK UNIT NUMBER}

\section{PERFORMING ORGANIZATION NAME(S) AND ADDRESS(ES)B}

8. PERFORMING ORGANIZATION REPORT

Johns Hopkins University, NUMBER

School of Medicine

Baltimore, MD, 21205

9. SPONSORING / MONITORING AGENCY NAME(S) AND ADDRESS(ES)

10. SPONSOR/MONITOR'S ACRONYM(S)

U.S. Army Medical Research

And Materifl Command

Fort Detrick, Maryland

$21702-5012$

11. SPONSOR/MONITOR'S REPORT NUMBER(S)

12. DISTRIBUTION / AVAILABILITY STATEMENT

Approved for public release. Distribution unlimited

\section{SUPPLEMENTARY NOTES}

\section{ABSTRACT}

We have now created numerous iPS cell lines from ALS patient samples and have characterized their long-term differentiation into astroglia. We now have data from the in vivo transplantation of these astroglial progenitors into rat spinal cords. We have characterized several controls and an ALS cell line with regard to their survival, differentiation, migration, and phenotypic effects on the host animals. Our data demonstrate that there are differences amongst the cell lines with regard to these properties but we have not appreciated obvious differences with regard to ALS cells when compared with control astroglial cells. Finally, we have demonstrated, in preparation for our therapeutic approaches, that these glial progenitor cells continue to mature into astrocytes following transplantation but that their survival is significantly reduced when compared with previous studies using human glial restricted precursors. Given this poor survival (5\% of transplanted iPSC-derived astrocytes), we have used human fetally-derived glial restricted precursors to understand how the ALS host environment influences transplanted cells. 15. SUBJECT TERMS

Stem Cells, iPS cells, astrocytes, familial ALS

\section{SECURITY CLASSIFICATION OF:}

\begin{tabular}{l|l}
$\begin{array}{l}\text { a. REPORT } \\
\mathrm{U}\end{array}$ & $\begin{array}{l}\text { b. ABSTRACT } \\
\mathrm{U}\end{array}$ \\
\hline
\end{tabular}

17. LIMITATION OF ABSTRACT c. THIS PAGE
18. NUMBER OF PAGES 19a. NAME OF RESPONSIBLE PERSON USAMRMC

19b. TELEPHONE NUMBER (include area code) 
Table of Contents

Page

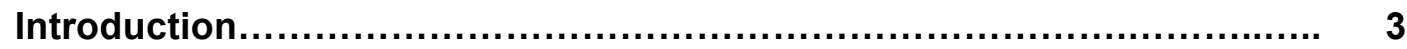

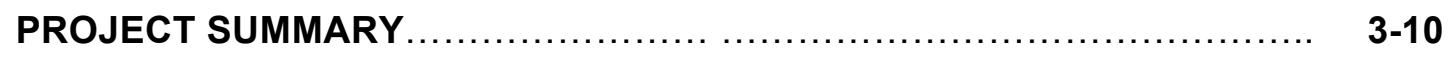

Key Research Accomplishments.......................................... 11

Reportable Outcomes................................................. 11

Conclusion.............................................................. 11

Publications............................................................... 11

References............................................................... 12

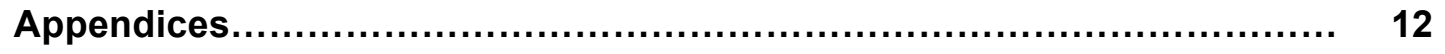




\section{INTRODUCTION:}

The overall objective is to examine whether human iPSC-GRPs (glial restricted precursors) derived from either sporadic ALS, familial (SOD1-mediated) ALS, or control subjects have the same capacity for engraftment, survival, and neuroprotective qualities following transplantation. It is not known whether iPSC-GRPs from ALS patients will in fact be normal (and thus possibly neuroprotective) or whether these iPSC-derived cells may in fact harbor ALS-specific abnormalities that may lack benefit or, potentially exacerbate disease. By comparing normal iPSC-GRPs with sALS iPSC-GRPs and fALS iPSC-GRPs we will also learn about inherent differences in astrocyte biology related to ALS, which will provide potential insights into disease mechanisms.

KEYWORDS: IPS cells, Amyotrophic Lateral Sclerosis, ALS, Astrocyte, Astrocyte Progenitor, Glial Restricted Precursor, Cell Autonomy, Stem Cell

\section{OVERALL PROJECT SUMMARY:}

\section{Aim \#1. Generation of human induced pluripotent stem cell-derived glial restricted precursors (iPSC-GRPs) from ALS subject fibroblasts}

\section{Fibroblast and iPSC lines from subjects with ALS and controls}

Total of approximately 119 subjects biopsied to date). These include subjects with familial ALS (these include SOD1, ANG, FIG4, FUS, C9ORF72, and VCP mutations), as well as subjects with sporadic ALS and control subjects.

\begin{tabular}{|c|c|c|c|}
\hline \multicolumn{2}{|c|}{ KNOWN FAMILAL MUTATIONS } & FIBROBLASTS & iPS \\
\hline SOD1 & & & \\
\hline A4V & 6 & $\mathrm{x}$ & 4 \\
\hline C38G & 1 & $\mathrm{x}$ & 1 \\
\hline E49K & 1 & $\mathrm{x}$ & 1 \\
\hline G85R & 1 & $\mathrm{x}$ & 1 \\
\hline A89V & 1 & $\mathrm{x}$ & \\
\hline D90A & 3 & $\mathrm{x}$ & 3 \\
\hline E100G & 1 & $\mathrm{x}$ & 1 \\
\hline I112T & 1 & $\mathrm{x}$ & 1 \\
\hline I113T & 4 & $\mathrm{x}$ & 1 \\
\hline N139K & 1 & $\mathrm{x}$ & 1 \\
\hline L144F/S? & 1 & $\mathrm{x}$ & 1 \\
\hline V148G & 1 & $\mathrm{x}$ & 1 \\
\hline FUS & & & \\
\hline 66 unkn var & 1 & $\mathrm{x}$ & 1 \\
\hline H517Q & 1 & $\mathrm{x}$ & 1 \\
\hline R522R & 1 & $\mathrm{x}$ & 1 \\
\hline ANG & 1 & $\mathrm{x}$ & 1 \\
\hline C9ORF72 & 9 & $\mathrm{x}$ & 3 \\
\hline FIG 4 unkn var & 1 & $\mathrm{x}$ & 1 \\
\hline TDP43 & 2 & & 2 \\
\hline VCP (pre-5ymp) & 1 & $\mathrm{x}$ & 1 \\
\hline TOTAL & 38 & & 27 \\
\hline & & & \\
\hline
\end{tabular}

\begin{tabular}{|c|c|}
\hline \multicolumn{2}{|l|}{ OTHER } \\
\hline SPORADIC & fibro \\
\hline SLOW PROGRESSING > 5 YRS & 20 \\
\hline RAPID PROGRESSION $<2$ YRS & 5 \\
\hline TYPICAL PROGRESSION 2-5 YRS & 21 \\
\hline ALS/FTD & 4 \\
\hline UNKNOWN FAMILIAL & 3 \\
\hline PLS & 10 \\
\hline LMN ONLY & 6 \\
\hline UMN ONLY & 1 \\
\hline PSEUDO BULBAR & 1 \\
\hline KENNEDY'S & 3 \\
\hline CONTROLS & 6 \\
\hline RELATED CONTROLS & 3 \\
\hline TOTAL & 83 \\
\hline
\end{tabular}

\begin{tabular}{|c|c|}
\hline \multicolumn{2}{|c|}{ iPS lines completed } \\
\hline fALS & 28 \\
\hline sporadic ALS & 18 \\
\hline other & 6 \\
\hline controls & 7 \\
\hline TOTAL & 59 \\
\hline
\end{tabular}

2. Sharing of iPSC lines with collaborators. Central to the ALSRP mission has been to generate human iPSC from a variety of ALS subjects. We have continued to expand on this effort. We have now sent iPSCs from control and ALS lines to the following institutions:

Thomas Jefferson University (Trotti and Pasinelli, PIs)

Thomas Jefferson University (Lepore, PI)

University of California, San Diego (Yeo, PI)

University of California, San Diego (Cleveland)

University of Milan, Italy (Corti, PI)

NINDS, (Fischbeck, PI)

University of Pittsburgh (Pandey, PI)

Columbia University (Maniatis, $\mathrm{PI}$ )

Harvard University (Eggan, PI)

Fondazione IRCCS Ca' Granda Ospedale Maggiore PoliclinicoUniversity of Milan, Italy (Lazzari, PI)

University of Pennsylvania (Kalb, PI) 


\section{Differentiation of iPSCs into astrocytes.}

We have now initiated an in vitro evaluation of iPSC-derived astrocytes to ascertain whether they express appropriate astrocytic markers including GFAP, the astrocyte-specific glutamate transporter GLT1, connexin 43, aquaporin 4, the cell surface marker CD44 (a marker of astrocyte precursor identity), and the intermediate filament vimentin. Our data do not indicate differences in the capacity for differentiation between SOD1 ALS and control astrocytes (Fig. 1). Similar differentiation protocols have also been demonstrated for other nonSOD1 genotypes including C9ORF72 (not shown).

Figure 1. Differentiation of SOD1-iPSCs to astroglia. Representative pictures of control (006) and SOD1-iPSC (008) derived astrocyte after 15-week differentiation showing astroglial marker expression. (A) CD44 (red) and GFAP (green) expression by differentiated cells. Thin arrows indicate GFAP+ cells. Arrowheads indicate CD44+ cells. Thick arrows indicate CD44+/GFAP+ cells. (B) Quantification of CD44+ and GFAP+ cells at different time points. (C) EAAT1 (red) expression by GFAP+ (green) astrocytes. Arrows indicate double positive cells. (D) Aquaporin 4 (AQ4, red) and EAAT2 (green) expression. Nuclei were stained with DAPI (blue). Size bar, $20 \mu \mathrm{m}$.

A
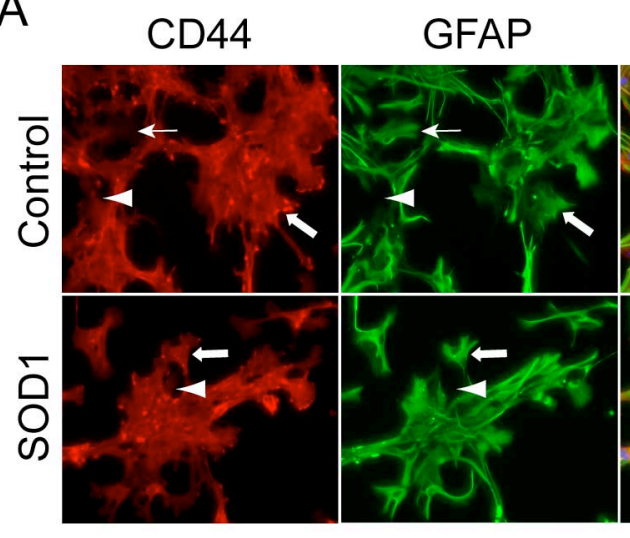

C

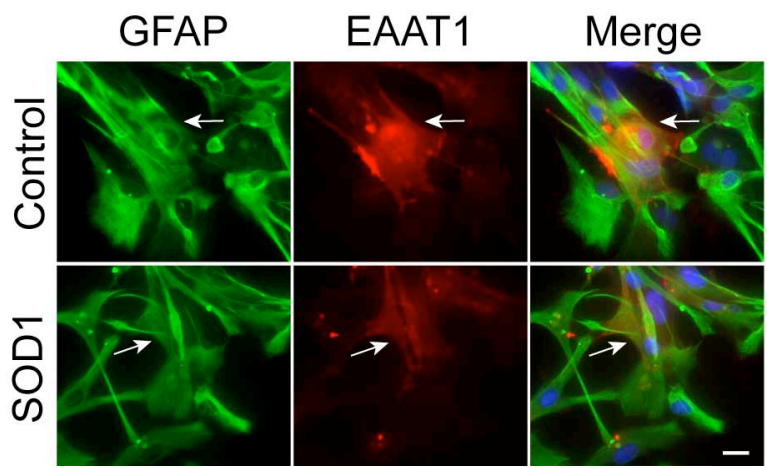

$\mathrm{B}$
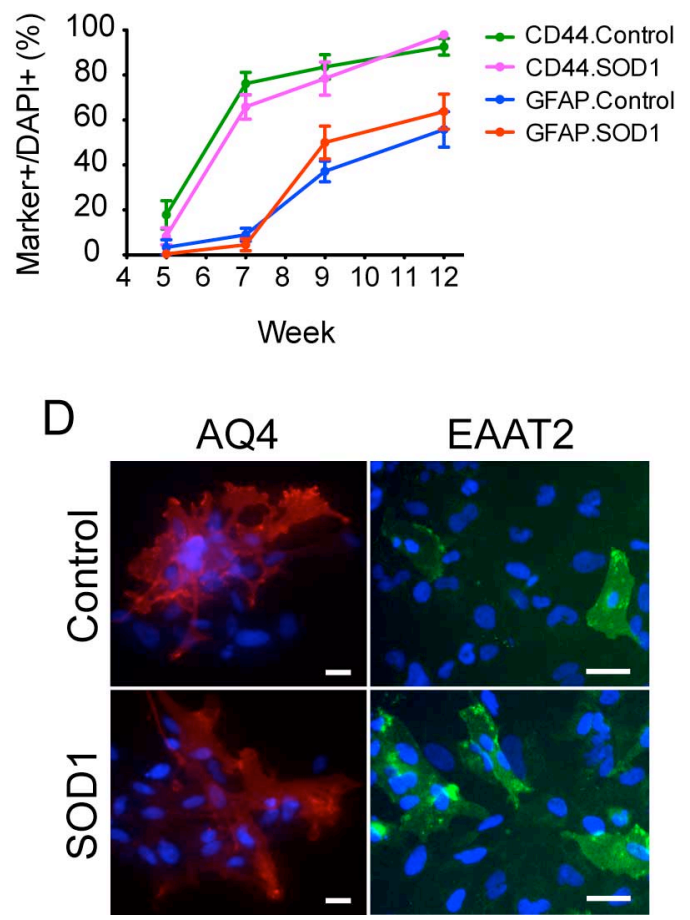

Figure 1 


\section{The demonstration of normal karyotype following} multiple passages (Figure 2).

One fundamental concern about the use of iPSC-derived astrocytes for in vitro analyses or cell therapeutics is the fidelity of the resulting line following multiple passages. Here we show the karyotypes of fALS-iPS cells. The iPS cells were analyzed between passage number 4 to 10 (P4 P10). Line 010 showed balanced translocation due to reciprocal exchange between the long-arm of chromosome 1 and the short-arm of chromosome 17. This line (010) will be removed from the library of available cells for future use.

Figure 2

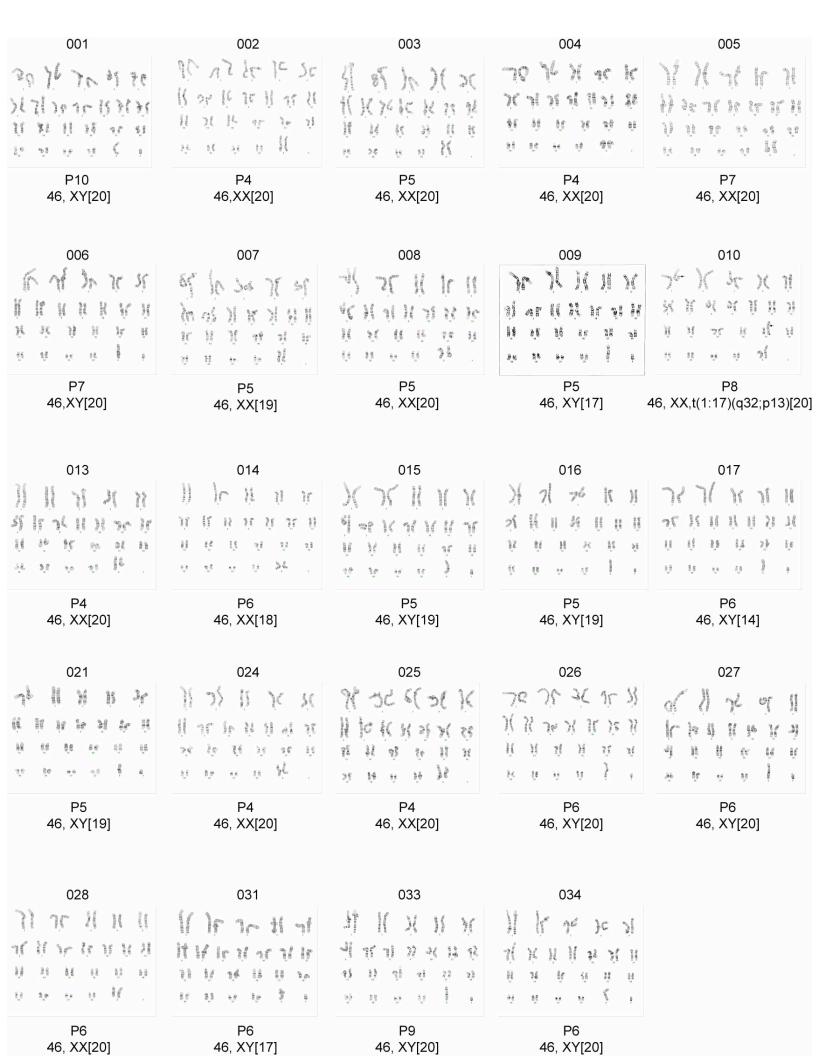

Significance: Our data demonstrate that we have derived a comprehensive list of iPSC from control, familial ALS, and sporadic ALS patients. We also demonstrate that they are karyotypically normal after numerous passages (or will be removed) and that they can be differentiated into astrocyte precursors independent of the presence of SOD1 mutations.

Aim \#2. In vivo comparison of iPS cell-derived glial restricted precursors (iPSC-GRPs) from control, sporadic ALS, and familial ALS (SOD1) following transplantation into wildtype spinal cord

\section{The detailed characterization of some IPSC lines has now been published:}

Haidet-Phillips AM, Roybon L, Gross SK, Tuteja A, Donnelly CJ, Richard JP, Ko M, Sherman A, Eggan K, Henderson CE, Maragakis NJ. Gene Profiling of Human Induced Pluripotent Stem Cell-Derived Astrocyte Progenitors Following Spinal Cord Engraftment. Stem Cells Transl Med. 2014 Mar 6. [Epub ahead of print]

\section{2. iPSC-Derived GRPs from FUS H517Q ALS do not significantly differ from control iPSC-derived GRP lines}

One question is whether iPSC-derived GRPs from ALS subjects will have different properties when compared with control iPSC-derived GRPs. This has important implications for cell therapeutics since several current human ALS "stem cell" trials internationally have relied on the harvesting of host stem cells.

To begin to address this we used a transplantation paradigm from a FUS ALS line (Line AB025).

Significance: Our initial data using the familial ALS FUS line FUS ${ }^{H 517 Q}$ would not indicate an inherent toxicity from the presence of this mutation and could suggest that (at least for FUS ALS), that autologous transplantation of iPSC-derived GRPs could be a safe neuroprotective strategy. 
Figure 3. The FUS ${ }^{\mathrm{H} 517 \mathrm{Q}}$ ALS line does not have a significant difference in its capacity for differentiation into astrocyte phenotypes when compared with control $(\mathrm{H} 13$, $11 \mathrm{a}, 18 \mathrm{c})$ lines in vitro.

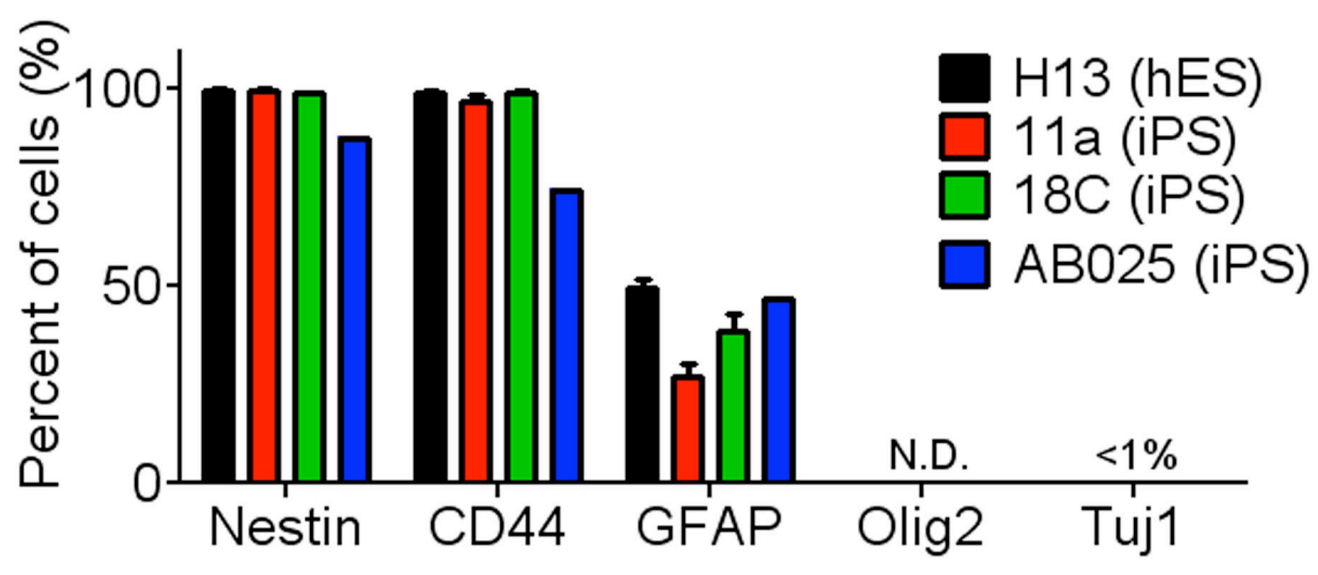

Figure 4: 12 weeks following spinal cord transplantation into the rat, the FUS ${ }^{\mathrm{H} 517 \mathrm{Q}}$ ALS line does not have a significant difference in its capacity for differentiation into astrocyte phenotypes when compared with control $(\mathrm{H} 13,11 \mathrm{a}, 18 \mathrm{c})$ lines in vivo. The majority of these cells differentiate into GFAP+ astrocytes with few (Olig2+) oligodendrocytes.

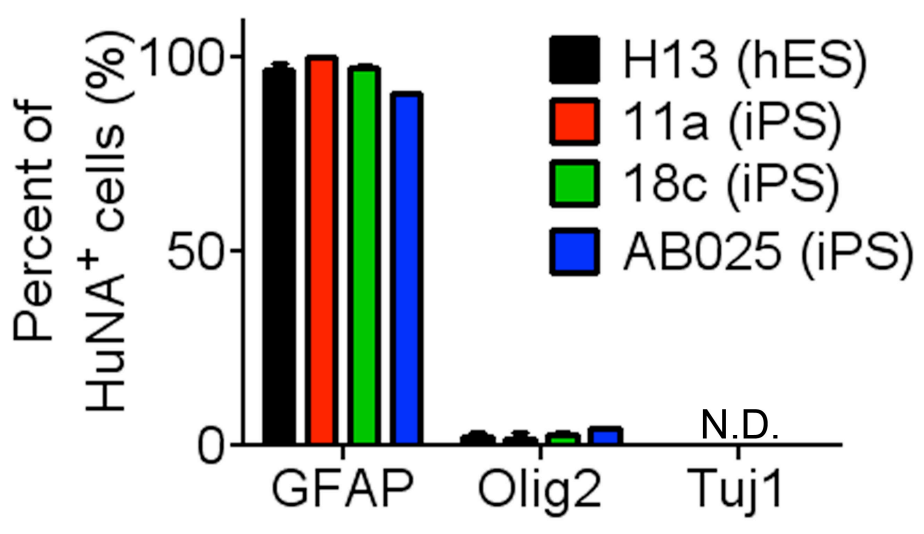

Figure 5: 12 weeks following spinal cord transplantation into the rat, the FUS ${ }^{\mathrm{H} 517 \mathrm{Q}}$ ALS line does not have a significant difference in its capacity for migration when compared with control $(\mathrm{H} 13,11 \mathrm{a}, 18 \mathrm{c})$ lines in vivo. The capacity for migration in all 4 lines is limited.

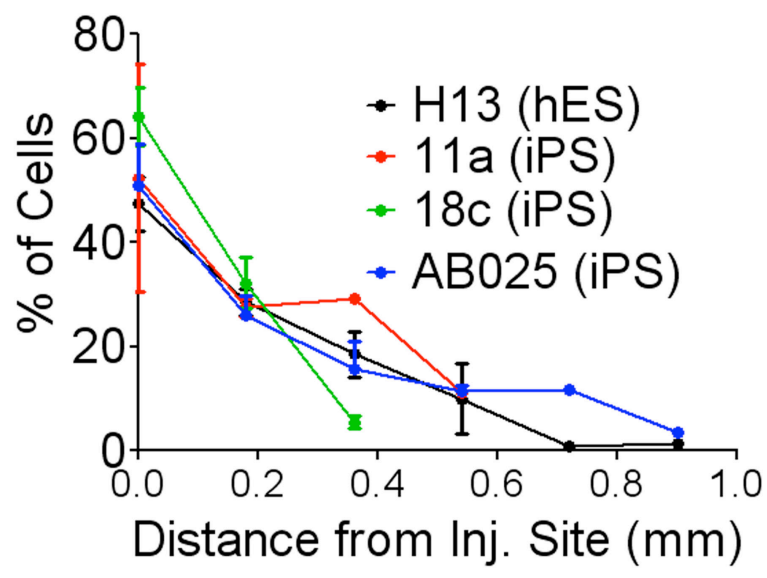

Figure 6: Following in vivo transplantation, there is limited survival of all iPSC-derived GRP subtypes including the FUS ${ }^{\mathrm{H} 517 \mathrm{Q}}$ ALS line $A B 025$. We did not appreciate any host (WT rat) motor neuron death following the transplantation of the AB025 line (not shown).

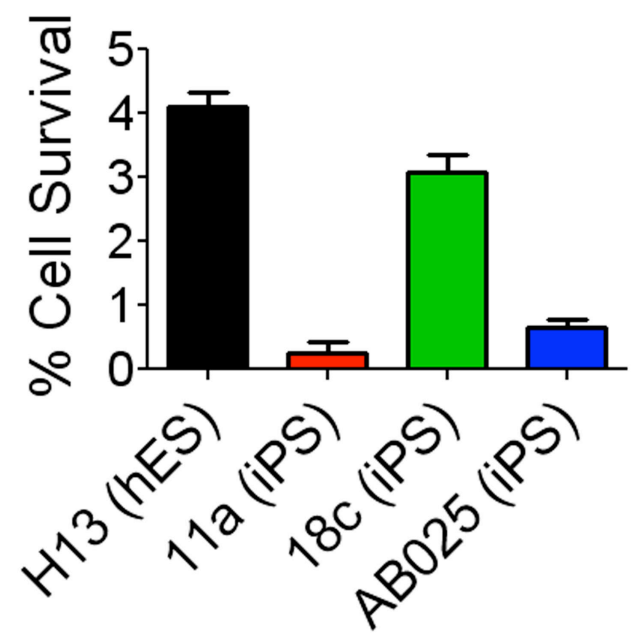


3. Generation of a homogeneous population of iPSC-derived astrocytes.

Recent developments in the generation of adult human fibroblast-derived induced pluripotent stem cells (iPSCs) has provided novel opportunities to study the mechanisms of astrocyte dysfunction in human patientderived cells. To overcome the difficulties of heterogeneity during the differentiation process from iPSCs to astroglial cells (iPS astrocytes), we chose to generate homogenous populations of iPS astrocytes using zincfinger nuclease (ZFN) technology. Enhanced green fluorescent protein (eGFP) driven by the astrocyte-specific glial fibrillary acidic protein (GFAP) promoter was inserted into the safe harbor adeno-associated virus integration site 1 (AAVS1) locus in patient- and healthy control-derived iPSCs. This work is being performed in collaboration with Dr. Rita Sattler at Johns Hopkins.

Figure 7. Homogenous GFP-iPS astrocyte population after FACS isolation

(A) Immunostaining of FACS purified astrocytes with astrocyte markers S100b, GFAP and reporter gene GFP. Scale bars, $50 \mu \mathrm{m}$.
A

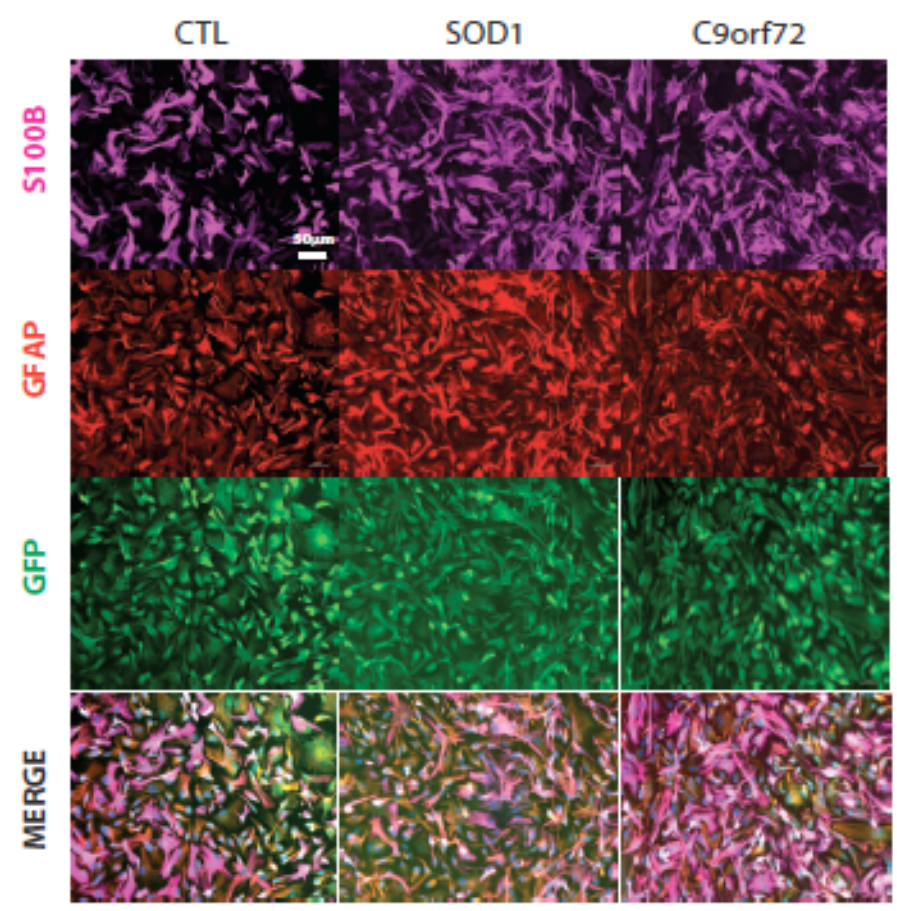

Figure 8. Engraftment of ZFN-iPSC-derived astrocytes into the wild-type rat spinal cord ventral horn. Engrafted astrocytes at the site of injection express GFP-GFAP in vivo which co-localizes with a human-specific cytoplasm marker (hCyto). The engrafted astrocytes fill the ventral horn grey matter at one month post-transplantation and express human-specific GFAP (hGFAP). The white dotted lines outline the rat spinal cord section and the spinal cord grey matter. Blue staining denotes DAPI. Co-localization of GFPGFAP and hGFAP in a single engrafted astrocyte in vivo at high magnification.

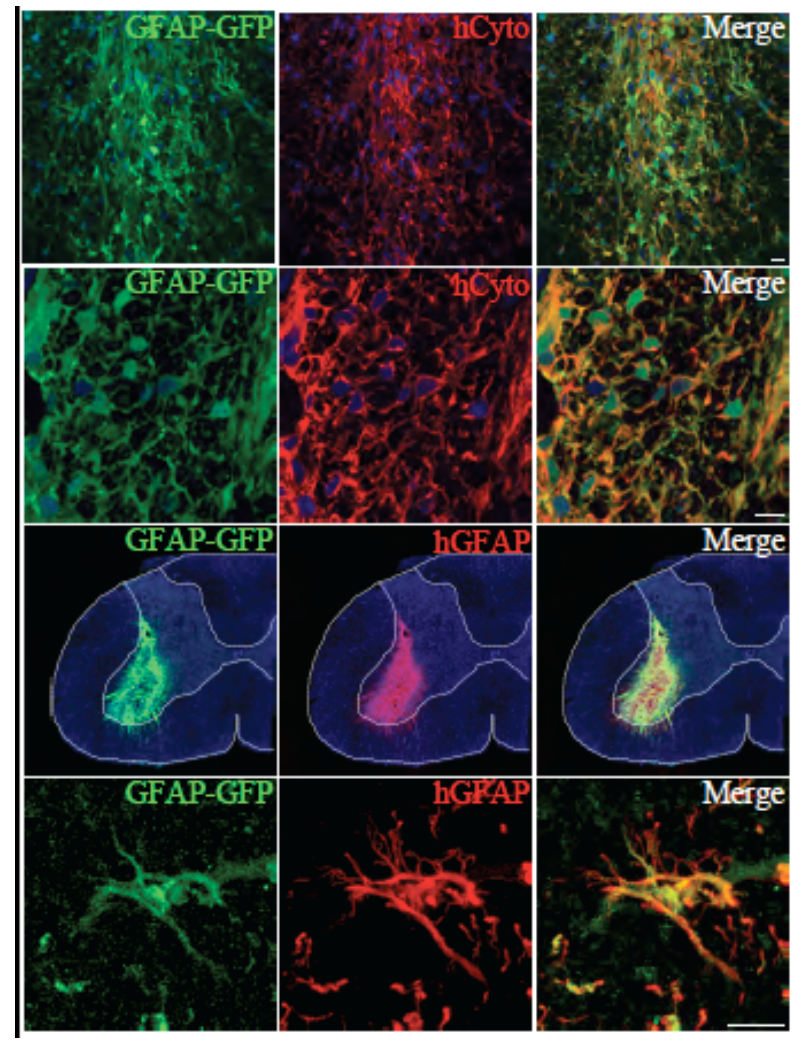




\section{Aim \#3. Determine the capacity for neuroprotection of iPSC-derived glial restricted precursors (iPSC-GRPs) following transplantation into the SOD1 ${ }^{\mathrm{G} 93 \mathrm{~A}}$ rat model of ALS.}

1. Analysis of most appropriate lines for preclinical study of iPSC-derived astrocyte progenitor cell therapies. Given the poor survival of the majority of our human iPSC-derived glial progenitors, our initial data suggested that the transplantation paradigm (including the immunosuppression strategy, sites of transplantation, numbers of cells, etc.) would not provide adequate neuroprotection and the properties of the iPSC-glial progenitor lines appeared distinct from our previous description of both rat and human fetallyderived glial progenitors.

However, we have more recently characterized a control line of iPSC which has unique properties from those described above. It appears that these cells are less differentiated and have the capacity to express both astrocyte and oligodendrocyte genes. They appear to have an improved capacity for both survival and migration (the reason for this is not yet entirely evident).

Astrocytes derived from the ciPS cell line resulted in much improved survival ( $75 \%$ at 7 weeks) compared to other lines with impressive migration of up to $6 \mathrm{~mm}$ from the site of injection. At 12 weeks post-transplantation of the ciPS cells, cell survival was quantified at $275 \%$, indicating the ciPS cells were continuing to proliferate and migrate. Indeed, staining for the proliferation marker Ki67 revealed that $19 \%$ of the HuNA+ cells were proliferating at 7 weeks post-transplantation. By 12 weeks, many of the HuNA+ cells stopped dividing with only $6 \%$ expressing Ki67.

We have identified these cells as possible candidates for the neuroprotection strategy of transplantation into SOD1 rats.
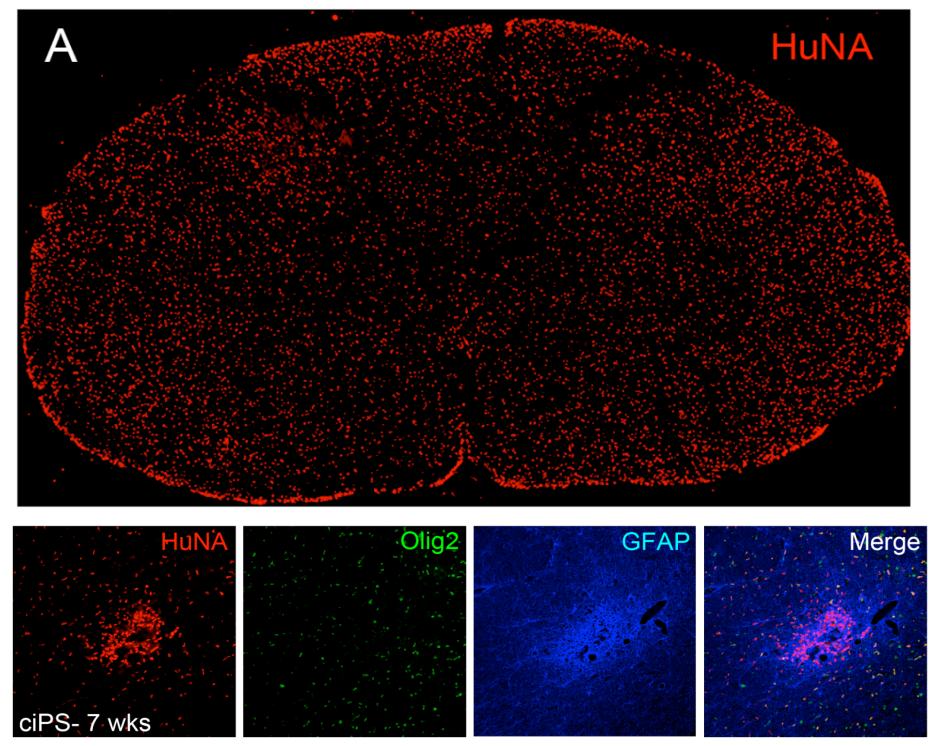

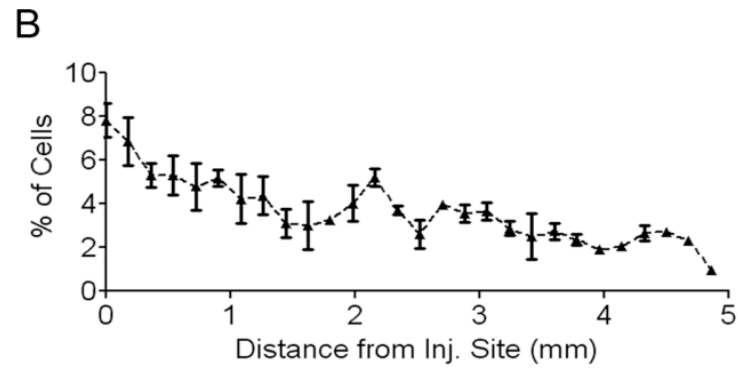

Figure 7

Figure 9. In rats receiving ciPS astrocyte transplants, HuNA+ cells could be localized after 12 weeks throughout the entire grey and white matter of the spinal cord (A). The HuNA+ ciPS cells were distributed evenly throughout the spinal cord instead of clustered at the injection site and in some sections, comprised over $50 \%$ of the DAPI+ cells in the spinal cord. Cells migrated several millimeters from transplantation site (B)

Significance: Most of the iPSC-glial progenitor cell lines studied have significant limitations for transplantation strategies with regard to cell survival and migration. These limitations are significantly different from the survival and distribution we have previously demonstrated in our utilization of human fetally-derived glial progenitor cells (Lepore et al 2011). However, we have identified a line of control iPSC-derived glial progenitor cells (the c-IPS line) that seems to have better characteristics for our transplantation studies in ALS rats. It is likely that iPSC lines will have variable properties depending on the individual donor. 


\section{Analysis of transplanted control human glial restricted precursors in ALS environment.}

In addition to studying how astrocytes from ALS patients would behave in a wildtype or SOD1 environment, we also wanted to evaluate how transplantation of control human glial restricted precursors (hGRPs) would respond to an ALS environment. Human GRPs were transplanted into the spinal cord of either an ALS mouse model or wild-type littermate mice. Mice were sacrificed for analysis at either the onset of disease course or at the endstage of disease. The transplanted GRPs were analyzed by immunohistochemistry and NanoString ${ }^{\circledR}$ gene profiling which showed no gross differences in the engraftment or gene expression of the cells.

Figure 10. Engraftment of hGRPs is independent of the SOD $1^{\text {G93A }}$ spinal cord environment. A) Expression of human nuclear antigen (HuNA) was used to identify transplanted hGRPs in the mouse spinal cord. Human GRP survival was estimated by counting the total number of $\mathrm{HuNA}^{+}$cells per spinal cord at 90 days or endstage in WT or SOD $1^{\text {G93A }}$ mice. B, C) Rostral-caudal migration of hGRPs after transplantation into the WT or SOD $1^{\mathrm{G} 93 \mathrm{~A}}$ spinal cord was quantified at 90 days (B) or endstage (C) time points by calculating the percentage of total HuNA ${ }^{+}$ cells along the distance of the spinal cord. D) Rostralcaudal migration of engrafted hGRPs as identified by HuNA immunohistochemistry in the spinal cord of endstage SOD1 ${ }^{\mathrm{G} 93 \mathrm{~A}}$ mice or age-matched WT mice. White arrows denote bilateral transplantation site. Magnification, 10X images compiled as a mosaic. All data are graphed as mean +/- SEM. $n=3-4$ mice/group, $p>$ 0.05 .

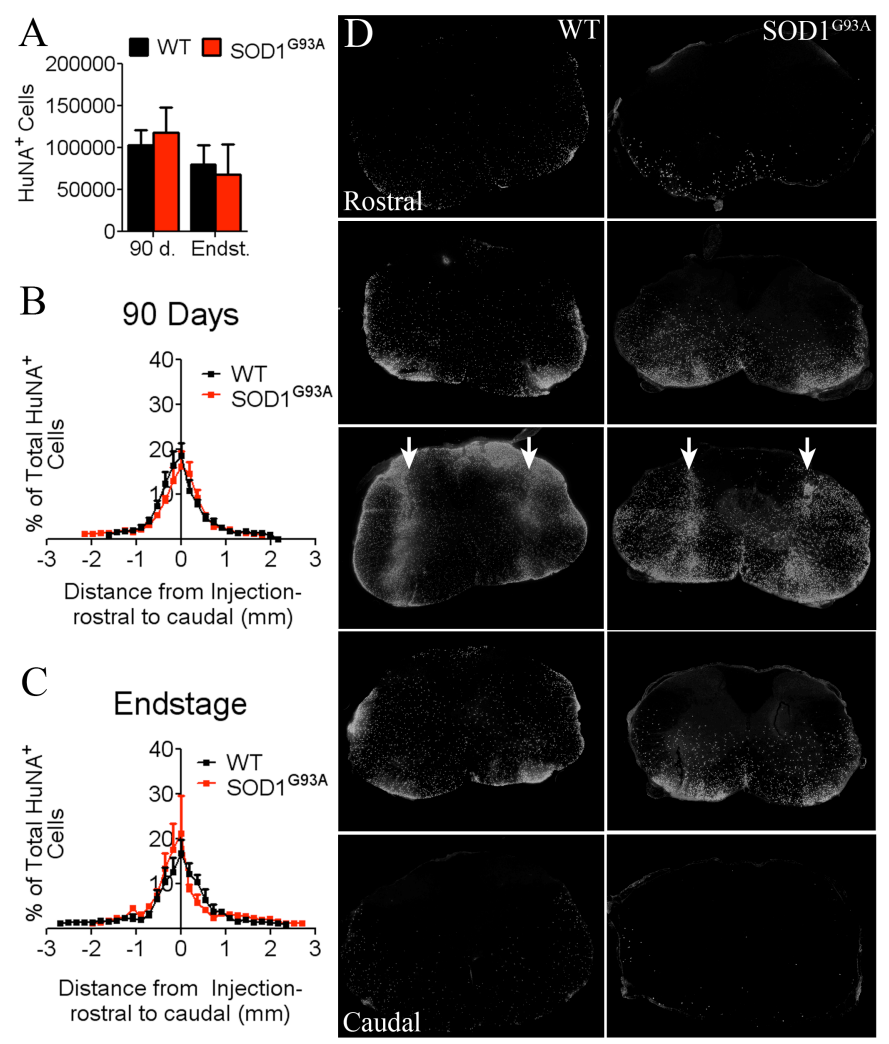


Figure 11. Astrocyte-related gene expression in engrafted cells is largely independent of the SOD $1^{\mathrm{G} 93 \mathrm{~A}}$ spinal cord environment. Human-specific gene expression was measured in hGRPs in vitro just prior to transplantation and in vivo in transplanted cells at 90 days and endstage after engraftment to the WT or SOD $1^{\mathrm{G} 93 \mathrm{~A}}$ spinal cord. A) GFAP expression in human cells engrafted to the WT versus SOD $1^{\text {G93A }}$ spinal cord. B) Expression of aquaporin 4 in human cells engrafted to the WT versus SOD $1^{\mathrm{G} 93 \mathrm{~A}}$ spinal cord. C) Connexin 43 expression in human cells engrafted to the WT versus SOD $1^{\text {G93A }}$ spinal cord. D) Expression of the astrocyte-specific gene EZR in human cells engrafted to the WT versus SOD $1^{\text {G93A }}$ spinal cord.. E) Expression of the astrocyte-specific gene F3 expression in human cells engrafted to the WT versus SOD ${ }^{\text {G93A }}$ spinal cord. F) EAAT2 expression was increased after transplantation to the SOD $1^{\text {G93A }}$ spinal cord at 90 days and endstage time points whereas EAAT2 gene expression was not changed after transplantation to the WT spinal cord at either time point. G) Expression of the astrocyte-specific gene MLC1 in human cells engrafted to the WT versus SOD $1^{\text {G93A }}$ spinal cord. H) EAAT1 expression in human cells engrafted to the WT versus SOD1 ${ }^{\text {G93A }}$ spinal cord. All data are graphed as mean $+/-$ SEM. $n=3-6$ mice/group, ${ }^{*} p<0.05$.

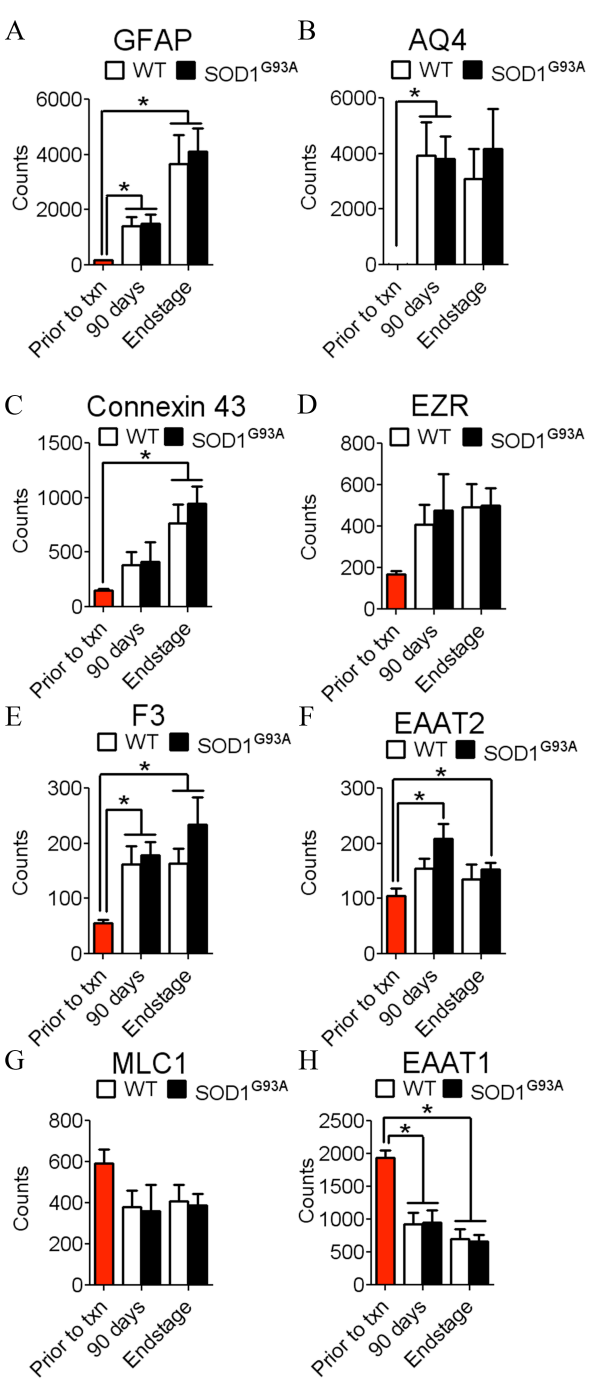

Significance: Our data indicate that human glial progenitor engraftment and gene expression is independent of the neurodegenerative ALS spinal cord environment. These data are encouraging in suggesting that control cells maintain their autonomy and may thus be neuroprotective. These findings are of interest given that human GRPs are currently in clinical development for spinal cord transplantation into ALS patients.

\section{KEY RESEARCH ACCOMPLISHMENTS:}

--Induced Pluripotent Stem Cell lines have been created from subjects with familial ALS, Sporadic ALS, and controls.

--IPS Cell-derived astrocyte progenitors have been successfully developed from subjects with familial ALS, Sporadic ALS, and controls.

--Initial transplantation experiments of iPS Cell-derived glial progenitors suggest that there is some variability among control iPS cell-derived lines with regard to survival, migration, and differentiation.

--Following transplantation, iPSC-derived glial progenitors continue to differentiate and develop more mature markers of astrocyte and oligodendrocyte identity.

--We have not yet appreciated any significant differences in the in vivo characterization of ALS iPSC-derived astroglial progenitors when compared with control astroglial progenitors.

--The complete characterization of the human iPSC-derived glial progenitors titled: "Gene profiling of human iPSC-derived astrocyte progenitors following spinal cord engraftment" has been published in Spinal Cord Translational Medicine.

--A second manuscript comparing the in vitro properties of human iPSC-derived glial progenitors from control and SOD1 subjects has been submitted: "A Comprehensive Library of Familial Human Amyotrophic Lateral Sclerosis Induced Pluripotent Stem Cells" in collaboration with Eggan, Henderson, and Rothstein. (submitted) 
--A third manuscript titled: "Human glial progenitor engraftment and gene expression is independent of the ALS environment." Is now in press at Experimental Neurology.

--In a collaboration with Dr. Rita Sattler at Johns Hopkins, she has submitted a manuscript titled: Generation of GFAP::GFP astrocyte reporter lines from human adult fibroblast-derived iPS cells using zinc-finger nuclease technology. (submitted)

\section{CONCLUSION:}

This effort has resulted in several important advances. We have now developed an extensive library of fibroblasts and iPSCs from patients with sporadic ALS, familial ALS, and control subjects. We have been able to use these cells not just for our own purposes but also as part of numerous collaborations with other investigators worldwide. We have also rigorously analyzed the characteristics of both ALS and control iPSCderived astrocyte progenitors in vitro to demonstrate (at least in the lines studied to date) that the baseline characteristics are similar. We have extended these observations to in vivo transplantation into rat spinal cords. Somewhat disappointingly, of the several control and single familial ALS lines studied, the survival and migration pattern of these cells was less than anticipated for widespread use as a therapeutic. However, one line with unique features (c-IPS) was identified with more impressive patterns of survival and migration following in vivo transplantation. This work is ongoing. This cell line that we have been using is likely the most appropriate for our future completion of therapeutic preclinical iPSC-based ALS transplantation studies. We believe that the use of iPSC-derived astrocyte progenitors from individuals will be highly variable and dependent upon the individual clone, the source of the donor, but not necessarily the presence of ALS mutations. Our most recent work underscores the utility of human fetally-derived glial restricted progenitors in maintaining cell autonomy following transplantation into the ALS spinal cord and these cells do not appear adversely affected by a neurodegenerative milieu.

\section{PUBLICATIONS (Peer Reviewed):}

Haidet-Phillips AM, Roybon L, Gross SK, Tuteja A, Donnelly CJ, Richard JP, Ko M, Sherman A, Eggan K, Henderson CE, Maragakis NJ. Gene Profiling of Human Induced Pluripotent Stem Cell-Derived Astrocyte Progenitors Following Spinal Cord Engraftment. Stem Cells Transl Med. 2014 Mar 6. [Epub ahead of print] (see Appendix)

Amanda M. Haidet-Phillips ${ }^{a}$, Arpitha Doreswamy ${ }^{a}$, Sarah K. Gross ${ }^{a}$, Xiaopei Tang ${ }^{a}$, James T. Campanelli ${ }^{b}$, Nicholas J. Maragakis ${ }^{\mathbf{a}^{*}}$. Human glial progenitor engraftment and gene expression is independent of the ALS environment. Experimental Neurology (in press). (see Appendix)

\section{INVITED ARTICLES (Related to proposal):}

1. Maragakis NJ. Stem Cells and the ALS Neurologist Amyotroph. Lateral Scler. 2010. Oct; 11(5): 41723.

2. Richard JP, Maragakis NJ. Induced pluripotent stem cells from ALS patients for disease modeling.Brain Res. 2014 Sep 16. pii: S0006-8993(14)01226-8. doi: 10.1016/j.brainres.2014.09.017. [Epub ahead of print]

\section{PRESENTATIONS 10/2013-12/2014:}

11/7/13 Speaker, Cedars-Sinai Center for Regenerative Medicine "Bedside to Bench: Stem Cells from ALS patients for understanding disease and providing cell therapeutics". Los Angeles, CA, USA

11/21/13 Speaker, Johns Hopkins University, Dept. of Neurology Grand Rounds. "Bedside to Bench: Stem cells from ALS patients for understanding disease and designing cell therapies". Baltimore, MD, USA

1/7/14 Speaker, National Institutes of Health Stem Cell Program "Clinical insights from ALS for designing cell therapies and investigating pathogeneses" Bethesda, MD, USA

3/9/14 Speaker, American Society for Neurochemistry. Colloquium: Human Glial Progenitor Cell Transplantation for in vivo ALS disease modeling and therapeutics. Long Beach, CA, USA.

9/26/14 Speaker, Fondazione Italiana di Ricerca per la SLA [Agency for Research on ALS] (AriSLA National Convention), "Using IPS Cells in ALS Research: Opportunities and Challenges", Milan, Italy

10/19/14 ALS Association Patient Workshop, "Stem Cells for Clinical Trials for ALS and IPS Cell lines for Biomarkers and Drug Discovery. Philadelphia, PA, USA 
10/20/14 ALS Association Investigator Meeting. Investigating Astrocyte-Mediated Degeneration of Upper Motor Neurons in ALS. Philadelphia, PA, USA

10/24/14 Northeast ALS Consortium Science Science Symposium. An Open- Label Study to Investigate the Safety of the Transplantation of Human Glial Restricted Progenitor Cells (hGRPs;Q-Cells) into Patients with Amyotrophic Lateral Sclerosis (ALS). Clearwater, FL, USA.

11/13/14 $9^{\text {th }}$ Brain Research Conference: Neuroprotection: Basic Mechanisms and Translational Potential. "Stem Cell Transplantation as a Neuroprotective Strategy for ALS". Washington, DC, USA.

\section{OTHER ACHIEVEMENTS:}

FUNDING BASED UPON PROPOSAL

6/30/14-6/29/16 IPSC-Derived Neurons from ALS Patients to Study Disease Progression TEDCO-Maryland Stem Cell Resarch Fund $\$ 230,000$

$\mathrm{PI}$ : Maragakis, NJ, $5 \%$

The purpose of this study is to use a variety of IPSC-derived neurons from sporadic ALS patients to study factors which influence cell vulnerability.

6/30/13-6/29/15 Human iPSC Cell-Derived Astrocytes to Study ALS and Astrocyte Connexins as a Therapeutic Target TEDCO-Maryland Stem Cell Resarch Fund Postdoctoral Fellowship Award to Dr. Akshata Almad

INVENTIONS, PATENTS: Nothing to report

REPORTABLE OUTCOMES: Induced pluripotent stem cells (see table 1)

\section{REFERENCES: NONE}

\section{APPENDICES:}

1. "Gene profiling of human iPSC-derived astrocyte progenitors following spinal cord engraftment".

2. "Human glial progenitor engraftment and gene expression is independent of the ALS environment." 


\section{Gene Profiling of Human Induced Pluripotent Stem Cell-Derived Astrocyte Progenitors Following Spinal Cord Engraftment}

Amanda M. Haidet-Phillips, Laurent Roybon, Sarah K. Gross, Alisha Tuteja, Christopher J. Donnelly, Jean-Philippe Richard, Myungsung Ko, Alex Sherman, Kevin Eggan, Christopher E. Henderson and Nicholas J. Maragakis

Stem Cells Trans Med published online March 6, 2014

The online version of this article, along with updated information and services, is located on the World Wide Web at:

http://stemcellstm.alphamedpress.org/content/early/2014/03/05/sctm.2013-0153 


\title{
Gene Profiling of Human Induced Pluripotent Stem Cell-Derived Astrocyte Progenitors Following Spinal Cord Engraftment
}

\author{
Amanda M. Haidet-Phillips, ${ }^{a}$ LaURent Roybon, ${ }^{b, c}$ Sarah K. Gross, ${ }^{a}$ Alisha Tuteja, ${ }^{a}$ \\ Christopher J. Donnelly, ${ }^{a}$ Jean-Philippe Richard, ${ }^{a}$ Myungsung Ko, ${ }^{a}$ Alex Sherman, ${ }^{a}$ \\ Kevin Eggan, ${ }^{\text {d }}$ Christopher E. Henderson, ${ }^{b}$ Nicholas J. Maragakis ${ }^{a}$ \\ Key Words. Human induced pluripotent stem cells • Stem cell transplantation - Astrocytes • \\ Gene profiling
}

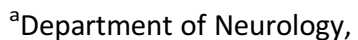
Johns Hopkins University School of Medicine, Baltimore, Maryland, USA; ${ }^{b}$ Departments of

Rehabilitation and Regenerative Medicine, Pathology and Cell Biology, Neurology, and Neuroscience, Center for Motor Neuron Biology and Disease, Columbia Stem Cell Initiative, Columbia University Medical Center, New York, New York, 'Stem Cell Laboratory for CNS Disease Modeling-MultiPark, Department of Experimental Medical Science, Lund University, Lund, Sweden; ${ }^{d}$ Howard Hughes Medical Institute, Harvard Stem Cell Institute and Department of Stem Cell and Regenerative Biology, Harvard University, Cambridge, Massachusetts, USA

Correspondence: Nicholas J. Maragakis, M.D., Department of Neurology, Johns Hopkins University School of Medicine, John G. Rangos Building, 855 North Wolfe Street, Room 248, Baltimore, Maryland 21205, USA. Telephone: 410-614-9874;

E-Mail: nmaragak@jhmi.edu

Received August 23, 2013; accepted for publication December 20, 2013.

(C)AlphaMed Press 1066-5099/2014/\$20.00/0

http://dx.doi.org/

10.5966/sctm.2013-0153

\begin{abstract}
The generation of human induced pluripotent stem cells (hiPSCs) represents an exciting advancement with promise for stem cell transplantation therapies as well as for neurological disease modeling. Based on the emerging roles for astrocytes in neurological disorders, we investigated whether hiPSC-derived astrocyte progenitors could be engrafted to the rodent spinal cord and how the characteristics of these cells changed between in vitro culture and after transplantation to the in vivo spinal cord environment. Our results show that human embryonic stem cell- and hiPSC-derived astrocyte progenitors survive longterm after spinal cord engraftment and differentiate to astrocytes in vivo with few cells from other lineages present. Gene profiling of the transplanted cells demonstrates the astrocyte progenitors continue to mature in vivo and upregulate a variety of astrocyte-specific genes. Given this mature astrocyte gene profile, this work highlights hiPSCs as a tool to investigate disease-related astrocyte biology using in vivo disease modeling with significant implications for human neurological diseases currently lacking animal models. Stem Cells Translational Medicine 2014;3:1-11
\end{abstract}

\section{INTRODUCTION}

Stem cell transplantation strategies hold considerable promise in the understanding and treatment of a variety of neurological disorders. The in vitro use of neural stem cells has already gained attraction as a platform for recreating the sequences of neural development, modeling disease phenotypes, and for potential use in drug screening against target-disease pathways. However, the correlation between the in vitro characteristics of these cells for those tasks and the in vivo characteristics of those same cells for therapeutic transplantation studies as well as more complex in vivo disease modeling has only had limited investigation.

Various stem cell sources have been evaluated for brain and/or spinal cord engraftment studies, including human embryonic stem cells (hESCs), mesenchymal stem cells, fetally derived neural stem cells, and more recently human induced pluripotent stem cells (hiPSCs) [1-4]. Human iPSCs were initially reprogrammed from adult human fibroblasts and have been shown to be capable of differentiating into neural-specific cell lineages [5]. Enthusiasm for the potential of hiPSCs in treating neurological disorders has also grown, especially for diseases involving damaged or diseased glia, including spinal cord injury, multiple sclerosis, and other demyelinating disorders $[1,6]$. The discovery that hiPSC-derived oligodendrocyte progenitors can extensively remyelinate and rescue a mouse model of congenital hypomyelination has generated promise for both adult demyelinating and degenerative disorders as well as infantile oligodendroglial disorders [7]. Indeed, the first clinical trial involving transplantation of hESC-derived oligodendrocyte progenitors into patients with spinal cord injury was approved in 2009, paving the way for future trials involving the use of hiPSCs. Since then, a second trial testing transplantation of hESC-derived retinal pigment epithelium for macular degeneration has reported no safety concerns involving the use of these cells [8].

In addition to their promise as a cellular source for transplantation therapies, hiPSCs can also be used as valuable tools in the modeling of human disease $[9,10]$. The generation of hiPSCs from living patients may be especially useful for neurological diseases for which diseased patient tissue is inaccessible through biopsy. Human iPSCs have already been generated from patients with a large variety of neurological disorders, and after differentiation toward neural cell fates, these hiPSCs have excitingly displayed diseased-related phenotypes in vitro for a number of diseases $[9,10]$.

Although the majority of hiPSC work has focused on the production of neurons or oligodendrocytes from hiPSCs, it has become evident that 
astrocytes also play critical roles in both the healthy nervous system as well as in various conditions, notably amyotrophic lateral sclerosis (ALS), Rett syndrome, and Huntington's disease [11, 12]. Specifically, astrocytes expressing disease-linked mutant genes have been shown to directly cause neurotoxicity in these diseases. Because astrocytes are either damaged or pathologically altered in these disorders, transplantation of healthy astrocytes may limit neurotoxicity and provide additional support to injured neurons. In addition to the therapeutic goals of stem cell transplantation, generation and transplantation of patient hiPSC-derived astrocytes may be useful for in vivo disease modeling. This is especially true for diseases such as sporadic ALS, in which a genetic component has not been identified as the etiology in the majority of cases. Therefore, disease modeling by transplantation of patient-derived hiPSCs into the spinal cord may currently be one of the best means to study cell-specific disease mechanisms in vivo.

The goal of our study was to develop a transplantation paradigm for the engraftment of hiPSC-derived astrocytes for diseasemodeling purposes as well as to evaluate the potential of these cells as a source for therapeutic transplantation. Because transplantation of hiPSC-derived neural stem cells yields mainly neurons or a mixture of neural cell types [13-15], we aimed to first differentiate hiPSCs into astrocyte progenitors in vitro and then evaluate their capacity to survive and engraft when transplanted into the ventral horn of the adult rodent spinal cord. In addition, a critical question to the stem cell transplantation field is whether progenitor cells continue to differentiate after transplantation and adopt mature properties in vivo, which may be essential for their potential therapeutic benefits in patients. In evaluation of the hiPSC-derived astrocyte progenitors, we used a novel human specific gene profiling approach to compare the in vivo expression profile between various stem cell lines after transplantation to the spinal cord. We also used this gene-profiling approach to compare the expression profiles of the astrocyte progenitors in vitro versus the expression profile after engraftment to evaluate how these cells mature in an in vivo environment.

Our data show that both hESC- and hiPSC-derived astrocyte progenitors are capable of engrafting and surviving in the rat spinal cord for at least 12 weeks. Immunohistochemical analysis and gene profiling of the transplanted human cells revealed the transplanted cells retain their astrocyte lineage in vivo with few cells from other neural lineages present. Additionally, gene profiling of the transplanted human cells shows that the astrocyte progenitors mature dramatically in vivo after transplantation and upregulate a variety of both structural and functional astrocyte genes. This observed maturation highlights their potential for use for in vivo disease modeling using patient-derived hiPSCs to study diseases of the brain and spinal cord.

\section{MATERIALS AND MethodS}

\section{iPSC Generation and Characterization}

Retroviruses expressing Sox2, Oct4, and KIf4 were used to reprogram fibroblasts to create the $11 \mathrm{a}$ and $18 \mathrm{c}$ iPSC lines. The characterization of these iPSC lines has been previously described [16]. Briefly, these iPSC lines were evaluated for expression of the pluripotency factors alkaline phosphatase, NANOG, OCT4, SSEA3, SSEA4, TRA-1-60, and TRA-1-81. All iPSC lines were also analyzed for the ability to form three germ layers in an in vitro assay as well as the ability to form teratomas after transplantation into immune-compromised mice. Details describing differentiation of hiPSCs are provided in the supplemental online data.

\section{Rats}

Sprague-Dawley rats (9-10 weeks old; Taconic, Hudson, NY, http://www.taconic.com) were dosed daily with cyclosporine (20 mg/kg; Novartis International, Basel, Switzerland, http:// www.novartis.com) by subcutaneous injection beginning 3 days before transplantation and continued until sacrifice. The care and treatment of animals in all procedures were conducted in strict accordance with the guidelines set by the National Institutes of Health Guide for the Care and Use of Laboratory Animals, the Guidelines for the Use of Animals in Neuroscience Research, and the Johns Hopkins University Institutional Animal Care and Use Committee. Measures were taken to minimize any potential pain or discomfort for the animals.

\section{Transplants}

Rats were anesthetized and cervical laminectomy was performed, as previously described [17]. Each rat received bilateral injections into the ventral horn at the sixth cervical spinal level (C6) for a total of two injections. Each injection contained 150,000 cells in a total of $2 \mu \mathrm{l} \mathrm{de-}$ livered using a $10-\mu \mathrm{l} \mathrm{Hamilton}$ syringe secured to a micromanipulator with microsyringe pump controller ( $1 \mu \mathrm{l} /$ minute rate) [17].

\section{NanoString Analysis}

NanoString (NanoString Technologies, Inc., Seattle, WA, http:// www.nanostring.com) analyses were performed at 12 weeks posttransplantation. Rats were perfused with $0.9 \%$ saline, and spinal cord tissue was harvested and fast-frozen in liquid nitrogen. RNA was isolated using TRIzol, followed by DNase treatment and RNA cleanup using RNeasy columns (Qiagen, Hilden, Germany, http://www. qiagen.com). As a control, RNA was also isolated using identical methods from three control human cervical spinal cords. Probe sequence and target genes used are given in supplemental online Table 1. For the NanoString assay, 100 ng of RNA was loaded per sample. For analyses comparing gene expression of transplanted cells across the spinal cord (supplemental online Table 2) as well as analysis of human spinal cord (supplemental online Fig. 7), all samples were normalized using internal positive controls, and the raw total counts after normalization were graphed. For analyses comparing gene expression between cell lines in vitro as well as analyses comparing gene expression in vitro versus in vivo (supplemental online Fig. 8; supplemental online Tables 3, 4), all samples were normalized using internal positive controls and four human-specific housekeeping genes ( $B 2 M, G A P D H, G U S B$, and OAZ1), and total counts after normalization were graphed. Before normalization, all raw values reading less than 10 total counts were eliminated from analysis because they were under the standard limit of detection.

\section{Statistical Analysis}

All data were analyzed using GraphPad Prism software (GraphPad Software, San Diego, CA, http://www.graphpad.com). Data in all graphs are represented as the mean \pm SEM. For immunohistochemistry analysis, we analyzed at least three injection sites for in vivo analysis and at least three wells for in vitro cultures. For transplantation studies, the number of animals used is represented for each cell line in Table 1, and two independent transplant sites were analyzed for all rats. 
Table 1. Stem cell lines used for rat spinal cord transplantation

\begin{tabular}{|c|c|c|c|c|c|c|c|}
\hline \multirow[b]{2}{*}{ Cell line } & \multirow[b]{2}{*}{ Cell type } & \multirow[b]{2}{*}{ Reference } & \multirow[b]{2}{*}{ Age } & \multirow[b]{2}{*}{ Sex } & \multicolumn{3}{|c|}{ Weeks until sacrifice $(n)^{a}$} \\
\hline & & & & & 2 & 7 & 12 \\
\hline H13 & hESC & Cowan et al. [18] & 0 & $M$ & 2 & 2 & 3 \\
\hline $11 \mathrm{a}$ & hiPSC & Boulting et al. [16] & 36 & $M$ & 2 & 3 & 3 \\
\hline $18 c$ & hiPSC & Boulting et al. [16] & 48 & $\mathrm{~F}$ & 2 & 3 & 3 \\
\hline
\end{tabular}

${ }^{a} n=$ number of rats receiving transplant of various cell lines.

Abbreviations: hESC, human embryonic stem cell; hiPSC, human induced pluripotent stem cell.

\section{RESULTS}

\section{Directed Differentiation of hESCs and hiPSCs to Astrocyte Progenitors}

To assess astrocyte engraftment potential from hiPSCs and hESCs, we used two hiPSC lines created from healthy individuals as well as one hESC line for in vitro astrocyte progenitor generation (Table 1). All hiPSC and hESC lines had a normal karyotype, expressed pluripotency markers, and were capable of differentiating to all three embryonic germ layers [16, 18]. Astrocytes were generated from hESCs and hiPSCs using a recently characterized protocol for astrocyte differentiation [19]. Briefly, hiPSCs and hESCs were neuralized with BMP4 and activin/TGF- $\beta$ antagonists, followed by caudalization and ventralization using retinoic acid and sonic hedgehog, respectively (Fig. 1A). By day 11 of differentiation, $75 \%-80 \%$ of the cells were neural progenitors expressing Pax6 and Sox2, indicating efficient neuralization (supplemental online Fig. 1A, 1B). As previously described [19], this protocol generates a mixture of immature Tuj $1^{+}(\beta$-tubulin) neurons and neural progenitors at early stages of differentiation before culture in glial differentiation media (supplemental online Fig. 1C, 1D). At day 30 of differentiation, the cells were transferred into glial differentiation media, including supplementation with $1 \%$ FBS. Astrocyte progenitors as defined by CD44 staining [20] were usually noticed by days 50-60 of differentiation. In addition, we stained for CD184, a newly described marker expressed by neural progenitors and astrocyte progenitors [21]. Our cells expressed CD184 by day 29 of differentiation (supplemental online Fig. 1C, 1D) and expressed the astrocyte progenitor markers CD184, CD44, S100 $\beta$, and Nestin after 100 days of differentiation, as previously described for this protocol (Fig. 1B, 1C) [19]. At this time point, between $30 \%$ and $50 \%$ of cells also expressed glial fibrillary acidic protein (GFAP) depending on the cell line (Fig. 1B, 1C). The majority of cells still expressed Nestin, $\mathrm{CD} 44, \mathrm{~S} 100 \beta$, and CD184 at the end of the differentiation process, indicating the culture was a mixture of astrocyte progenitor cells and immature $\mathrm{GAP}^{+}$astrocytes. No $\mathrm{NG}^{+}$or Olig2 ${ }^{+}$oligodendrocyte lineage cells were observed in the cultures, and rare $(<1 \%)$ Tuj $1^{+}$neurons could be identified after 100 days of differentiation, as previously described (Fig. 1C) [19]. Between 25\% and $60 \%$ of the cells expressed Ki67 after 100 days of differentiation, indicating a proportion of the cells was mitotic at the time of transplantation (Fig. 1B, 1C).

\section{Transplantation of hESC- and hiPSC-Derived Astrocyte Progenitors to the Rat Spinal Cord}

To evaluate the astrocyte progenitors' propensity for engraftment, the cells were transplanted bilaterally to the ventral horn of the cervical spinal cord of adult wild-type rats. Before the injection and for the remainder of the study, rats were given high-dose cyclosporine to prevent immune rejection of the grafted human cells. Rats were sacrificed at 2,7 , or 12 weeks post-transplantation (Table 1). All rats were observed daily, and no behavioral abnormalities were noted for the entirety of the study. At 2 weeks post-transplantation, cells could be localized in the spinal cord by staining for human-specific nuclear antigen (HuNA), and most of the transplanted cells resided within $1 \mathrm{~mm}$ rostral-caudal from the transplantation site (supplemental online Fig. 2). Evaluation of the transplanted cells at 7 weeks (supplemental online Fig. 3) and 12 weeks (Fig. $2 \mathrm{~A}-2 \mathrm{D})$ post-transplantation revealed the $\mathrm{HuNA}^{+}$cells could be localized in the spinal cord at these time points with limited $(<1 \mathrm{~mm})$ rostral-caudal migration from the transplantation site. Quantification of $\mathrm{HuNA}^{+}$cells in the spinal cord at 2, 7, and 12 weeks posttransplantation showed that the transplanted cells survived for up to 12 weeks, although survival was limited ( $<5 \%$ surviving at 12 weeks post-transplantation) (Fig. 2E). One reason that the quantified survival may be low is the limited proliferation of the cells in vivo (supplemental online Fig. 4). We also evaluated whether the transplanted $\mathrm{HuNA}^{+}$cells were expressing markers indicative of apoptosis in vivo such as cleaved caspase-3; however, we could not detect expression of these markers at even 2 weeks posttransplantation. The quantified cell survival did not dramatically change between 2 and 12 weeks post-transplantation, suggesting either that the majority of cells do not survive in the first 2 weeks post-transplant or that many never engraft at the site of transplantation and are lost at the time of surgery. The remainder of the cells are engrafted long-term. The majority of transplanted cells resided in the gray matter of the spinal cord (Fig. 2F). No large differences in the survival and migration were noted between the different lines of hESCs and hiPSCs after transplantation at any of the time points examined. Additionally, no teratoma formation was noted in any of the rats at any time point examined.

\section{Cell Lineage Characterization of Transplanted hESC- and hiPSC-Derived Astrocyte Progenitors}

To determine whether the transplanted cells retained their astrocyte lineage after engraftment, we colocalized $\mathrm{HuNA}^{+}$cells with various cell lineage markers to assess whether the human cells differentiated into $\mathrm{GFAP}^{+}$astrocytes, Tuj $1^{+}$neurons, or Olig2 ${ }^{+}$ cells of the oligodendrocyte lineage. At the time of transplantation, $30 \%-50 \%$ of the cells expressed GFAP depending on the cell line (Fig. 1C). However, after transplantation of the hiPSC lines and the $\mathrm{hESC}$ line, more than $80 \%$ of the transplanted $\mathrm{HuNA}^{+}$cells expressed GFAP at 2 weeks post-transplantation (Fig. 3A). Immunohistochemical analysis of the transplanted cells at 7 weeks (supplemental online Fig. 5A) and 12 weeks (Fig. 3B, 3C) posttransplantation showed that more than $90 \%$ of the $\mathrm{HuNA}^{+}$cells express GFAP at these time points, suggesting the majority of transplanted astrocyte progenitors differentiate within 2 weeks to $\mathrm{GFAP}^{+}$astrocytes and remain stable for at least 12 weeks. To 

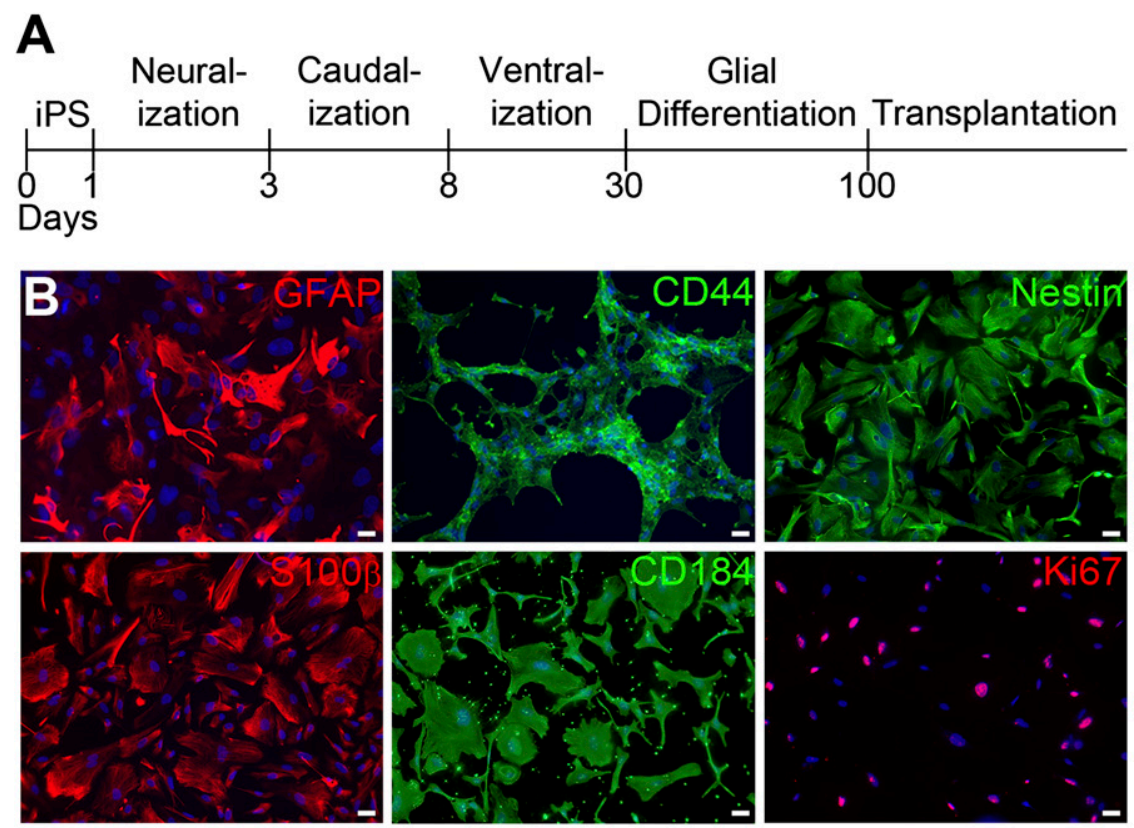

C

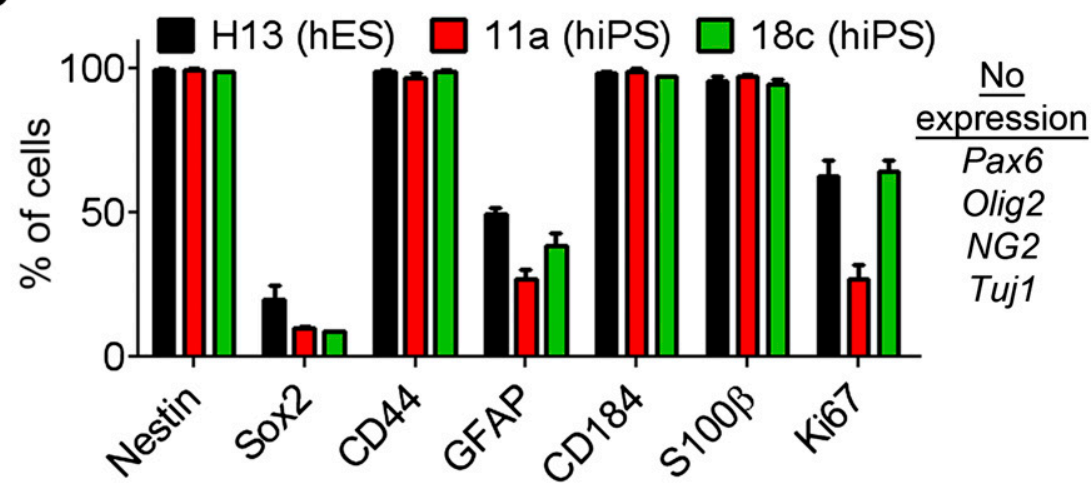

Figure 1. In vitro differentiation of human embryonic stem cells and human induced pluripotent stem cells into astrocyte progenitors. (A): Timeline for differentiation into astrocyte progenitors before transplantation. (B): Representative images of the hiPSC-derived astrocyte progenitors at the time of transplantation showing expression of astrocyte (GFAP), astrocyte progenitor (CD44, Nestin, S100 $\beta$, CD184), and proliferation (Ki67) markers. Scale bars $=10 \mu \mathrm{m}$. (C): At the time of transplantation, immunocytochemical analysis shows all cell lines express markers indicative of an astrocyte progenitor phenotype. $n=3$ wells per cell line analyzed. Error bars represent SEM. Abbreviations: GFAP, glial fibrillary acidic protein; hES, human embryonic stem cells; hiPS, human induced pluripotent stem cells; iPS, induced pluripotent stem cells.

verify the localization of the nuclear HuNA antigen with cytoplasmic markers such as GFAP, we also used an antibody specific for human mitochondria, which colocalized with GFAP (Fig. 3D). Additionally, the transplanted cells could be localized using a human-specific GFAP antibody that allowed us to observe their elaborate morphologies in vivo (Fig. 3E). The HuNA ${ }^{+}$transplanted cells also expressed the astrocyte water channel, aquaporin 4 , consistent with a mature astrocyte profile of gene expression (Fig. 3F). Few HuNA ${ }^{+} / \mathrm{Olig}^{+}$ cells were noted (Fig. 3G), and no HuNA ${ }^{+}$Tuj $^{+}{ }^{+}$cells were observed in these lines, although transplanted cells resided in close proximity to endogenous rat neurons (supplemental online Fig. 5B). Overall, the astrocyte progenitors derived from different hESC and hiPSC lines did not significantly differ in their differentiation profile post-transplantation. Because only a fraction of the cells from the hESC and hiPSC lines expressed GFAP at the time of transplantation, these data suggest that the $\mathrm{GFAP}^{-} / \mathrm{CD} 4^{+}$fraction of cells differentiated in vivo to $\mathrm{GFAP}^{+}$astrocytes within 2 weeks of transplantation. Alternatively, the $\mathrm{GFAP}^{+}$fraction of cells could have survived better after engraftment compared with the $\mathrm{GFAP}^{-}$fraction of cells. Another possibility is that the increase in GFAP reactivity indicates transition to a reactive astrocyte phenotype after transplantation. Therefore, we evaluated the transplanted cells for expression of LCN2, a recently identified marker for reactive astrocytes [22-24]. Although we could detect LCN2 in the spinal cord ventral horn of human ALS patients in which reactive astrocytosis is robust, we observed no LCN2 expression from HuNA ${ }^{+}$transplanted cells, suggesting the transplanted astrocyte progenitors did not differentiate to a reactive phenotype in vivo (supplemental online Fig. 6).

\section{In Vivo Gene Profiling of Transplanted hESC- and hiPSC-Derived Astrocyte Progenitors}

To more fully characterize the phenotype of the transplanted human cells, we sought to develop a gene-profiling system to evaluate in vivo human-specific gene expression because there exist 

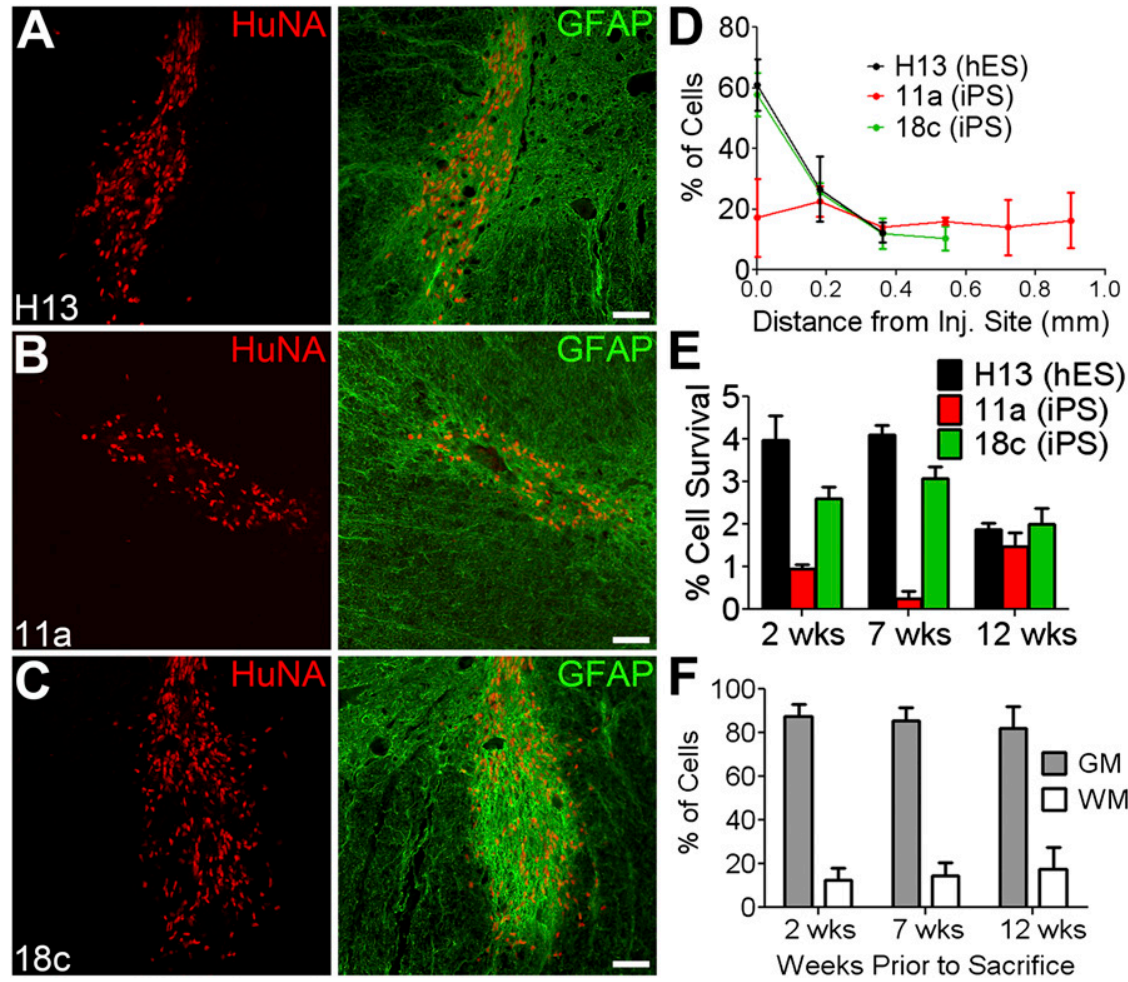

Figure 2. Characterization of human embryonic stem cell- and human induced pluripotent stem cell-derived astrocyte progenitors after transplantation to the rat spinal cord. $(\mathbf{A}-\mathbf{C})$ : Human embryonic stem cell $\mathbf{( A )}$ - and induced pluripotent stem cell $(\mathbf{B}, \mathbf{C})$-derived astrocyte progenitors can be localized by HuNA at 12 weeks post-transplantation, and many express GFAP in vivo. Scale bars $=50 \mu \mathrm{m}$. (D): Rostral-caudal cell migration from the site of injection was measured at 12 weeks post-transplantation by calculating the percentage of total HuNA ${ }^{+}$cells along the distance of the spinal cord. $n=4$ injection sites analyzed per cell line. Error bars represent SEM. (E): Cell survival at 2, 7, and 12 weeks post-transplantation was quantified by counting the total number of $\mathrm{HuNA}^{+}$cells surviving throughout the rostral-caudal extent of the spinal cord and dividing by the initial number of cells injected. $n=4-6$ injection sites analyzed per cell line. Error bars represent SEM. (F): GM/WM localization of transplanted $\mathrm{HuNA}^{+}$cells was assessed at 2,7 , and 12 weeks post-transplantation by dividing the number of HuNA ${ }^{+}$cells in GM or WM by the total number of surviving HuNA ${ }^{+}$cells present throughout the rostral-caudal extent of the spinal cord. $n=4-6$ injection sites analyzed per cell line. Error bars represent SEM. Abbreviations: GFAP, glial fibrillary acidic protein; GM, gray matter; hES, human embryonic stem cells; HuNA, human-specific nuclear antigen; Inj., injection; iPS, induced pluripotent stem cells; WM, white matter.

limited human-specific antibodies appropriate for immunohistochemical analysis of astrocytes. For these studies, we used NanoString technology, which is a probe-based method for direct RNA quantification that allows for both sensitive and specific detection of small amounts of human-specific RNAs without cDNA conversion or further amplification steps [25]. We designed a custom panel of more than 50 genes (supplemental online Table 1), including well-described genes expressed by neural progenitor cells, neurons, oligodendrocytes, and astrocytes as well as lesscharacterized genes found to be expressed specifically in astrocytes in vivo by gene-profiling methods [26]. The design of human-specific RNA probes allows for measurement of gene expression levels specifically in the transplanted human cells within the rat spinal cord to create a gene expression profile for the engrafted human astrocyte progenitors.

For each line of transplanted hESC- or hiPSC-derived astrocyte progenitors, we analyzed in vivo gene expression at 12 weeks posttransplantation. We isolated RNA for gene expression profiling from the cervical spinal cord region at the injection site, from cervical sections rostral and caudal to the injection site, as well as from a lumbar section of the spinal cord, a remote site from the area of transplant. Because we observed few transplant-derived cells migrating even into the thoracic region of the spinal cord, we chose the lumbar region as an area in which no human RNAs are present. The lumbar region was used to evaluate for any background crossreactivity of the human-specific probes with endogenous rat RNAs.

Analysis of in vivo gene expression of transplanted astrocyte progenitors from the hiPSC and hESC lines showed that the transplanted cells expressed a wide array of astrocyte lineage genes in vivo (Fig. 4A-4C; supplemental online Table 2). These genes included structural astrocyte genes such as GFAP as well as functional genes expressed by mature in vivo astrocytes such as the water channel, aquaporin 4, the gap-junction protein, Connexin 43, the membrane-associated protein, MLC1, and the glutamate transporters, EAAT1 and to a lesser extent EAAT2 in some cell lines. For many of the astrocyte lineage genes, expression was highest at the transplant site and then decreased in a gradient fashion rostral and caudal from the transplant site (Fig. 4A-4C). We also evaluated human gene expression in three control postmortem human spinal cords and found a similar pattern of astrocyte gene expression, including high GFAP expression with lower but detectable expression of other astrocyte lineage genes such as aquaporin 4 and glutamate transporters (supplemental online Fig. 7).

Although we could detect high expression levels of a variety of astrocyte-specific genes, we did not detect any neuronal-specific genes (NeuroD, $\beta$-tubulin) expressed by the transplanted cells 
A

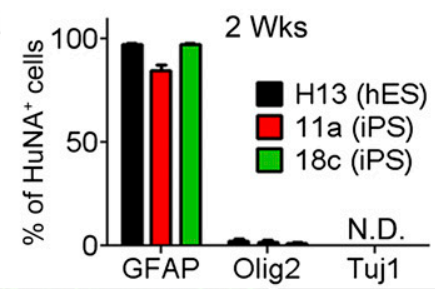

B

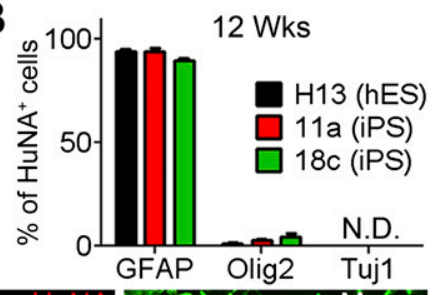

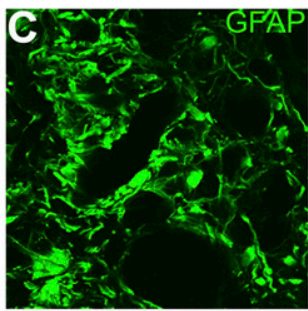
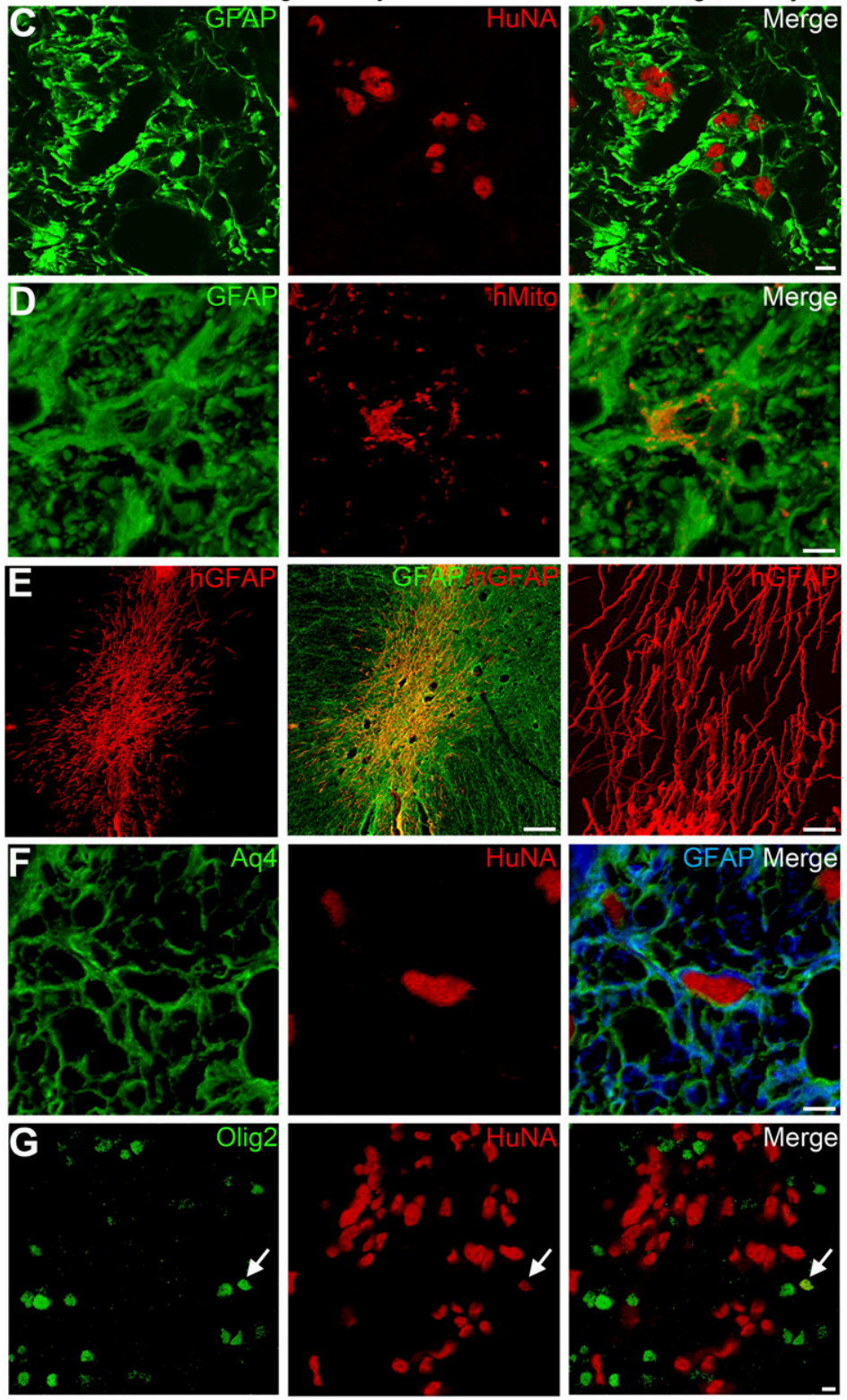

Figure 3. Transplanted human embryonic stem cell- and human induced pluripotent stem cell-derived astrocyte progenitors express astrocyte markers after transplantation to the rat spinal cord. (A, B): The percentage of HuNA ${ }^{+}$cells that also express GFAP, Olig2, or Tuj1 was quantified by immunohistochemical analysis at 2 weeks (A) and 12 weeks (B) post-transplantation. $n=4-6$ injection sites analyzed per cell line. Error bars represent SEM. (C): Transplanted HuNA ${ }^{+}$cells express GFAP and display typical astrocyte morphology at 12 weeks post-transplantation. Scale bar $=10 \mu \mathrm{m}$. (D): Transplanted human cells show colocalization of hMito and GFAP at 12 weeks post-transplantation. Scale bar $=10 \mu \mathrm{m}$. (E): The transplanted cells can be recognized using hGFAP and elaborate complex morphologies in vivo. Scale bar $=100 \mu \mathrm{m}$. The far right panel shows hGFAP expression magnified at high power. Scale bar $=10 \mu \mathrm{m}$. (F): HuNA ${ }^{+}$cells colocalizing with GFAP also express the astrocytic water channel, Aq4. Scale bar $=10 \mu \mathrm{m}$. (G): Few HuNA ${ }^{+}$cells colocalize with the oligodendrocyte marker Olig2. Arrow denotes one HuNA ${ }^{+} / \mathrm{Olig}^{+}$ cell. Scale bar $=10 \mu \mathrm{m}$. Abbreviations: Aq4, aquaporin 4; GFAP, glial fibrillary acidic protein; hES, human embryonic stem cells; hGFAP, human-specific GFAP antibody; hMito, human mitochondrial marker; HuNA, human-specific nuclear antigen; iPS, induced pluripotent stem cells; N.D., not detected. 

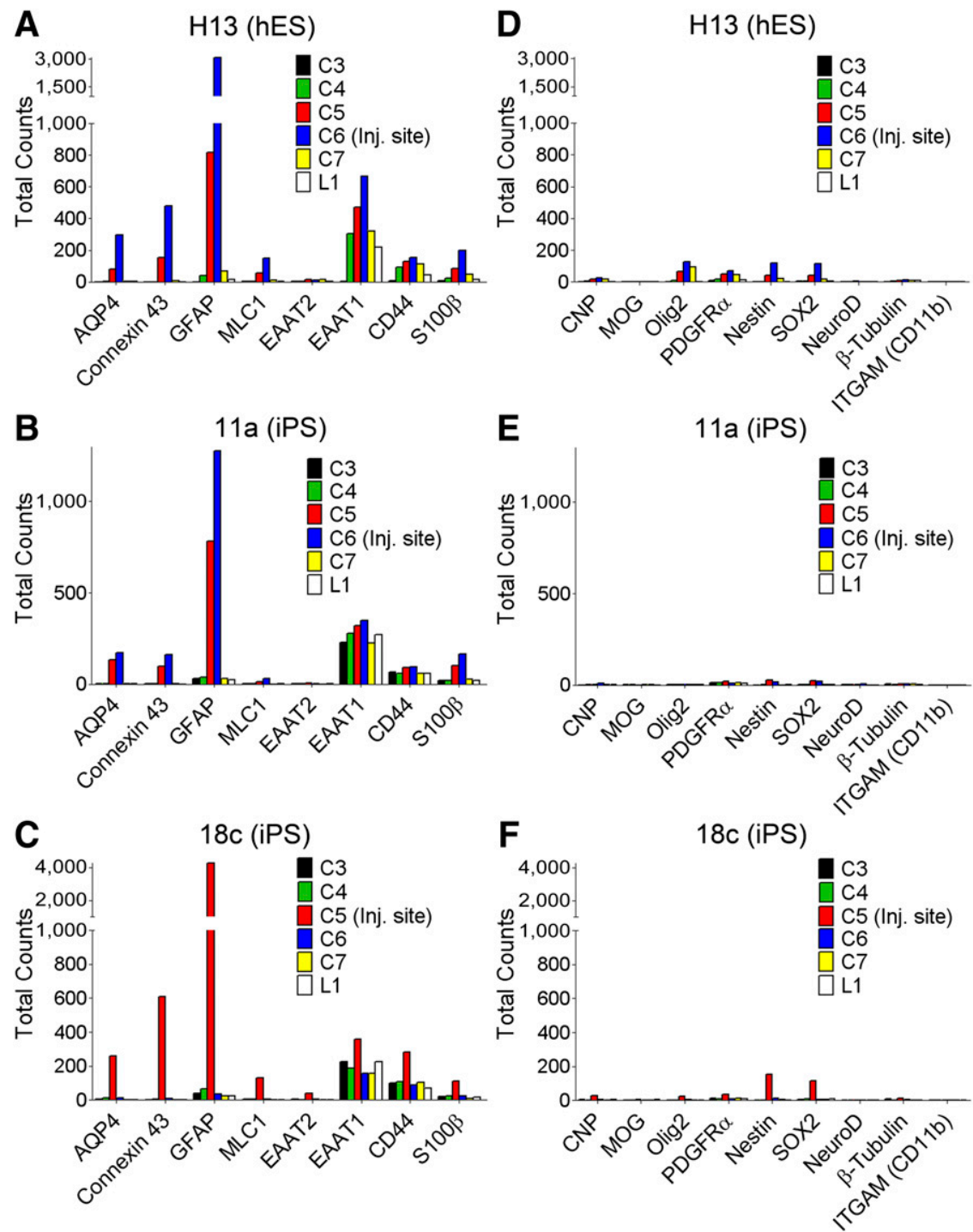

Figure 4. Human-specific in vivo gene profiling by NanoString analysis of transplanted human embryonic stem cell- and human induced pluripotent stem cell-derived astrocyte progenitors across cervical (C3-C7) and L1 lumbar segments of the spinal cord. (A-C): Gene profiling reveals expression of astrocyte lineage genes by transplanted $\mathrm{H} 13$ (A), 11a (B), and 18c (C) cells in vivo. RNA from separate spinal cord segments ranging from rostral (C3) to caudal (L1) from the site of injection was analyzed at 12 weeks post-transplantation. All samples were normalized using internal positive controls, and the raw total counts after normalization are graphed. (D, E): Gene profiling of nonastrocyte lineage genes expressed by transplanted H13 (D), 11 (E), and $18 \mathrm{c}$ (F) cells in vivo. RNA from separate spinal cord segments ranging from rostral (C3) to caudal (L1) from the site of injection was analyzed at 12 weeks post-transplantation. All samples were normalized using internal positive controls, and the raw total counts after normalization are graphed. Abbreviations: AQP4, aquaporin 4; EAAT1 excitatory amino acid transporter 1; EAAT2, excitatory amino acid transporter 2; GFAP, glial fibrillary acidic protein; hES, human embryonic stem cells; Inj., injection; iPS, induced pluripotent stem cells; MLC, megalencephalic leukoencephalopathy with subcortical cysts 1; MOG, myelin oligodendrocyte glycoprotein; NeuroD, neuronal differentiation 1; Olig2, oligodendrocyte lineage specific factor 2; PDGFR, platelet-derived growth factor receptor; SOX2, SRY (sex determining region Y)-box2.

(Fig. 4D-4F), consistent with the immunohistochemical results showing that the transplanted cells do not differentiate into neurons in vivo (Fig. 3B). Similarly, no transplant-derived expression of microglial-specific genes (ITGAM) was found (Fig. 4D-4F). However, we were able to detect human-specific transcripts for progenitor cell markers such as Nestin and Sox2, indicating some of the transplanted cells may reside in an immature progenitor state in vivo (Fig. 4D-4F). Likewise, we could also detect low levels of expression of early oligodendrocyte lineage genes such as Olig2, platelet-derived growth factor receptor- $\alpha$, and CNP $\left(2^{\prime}, 3^{\prime}\right.$-cyclic nucleotide $3^{\prime}$-phosphodiesterase), which is consistent with the immunohistochemical analysis showing that a small percentage
$(<5 \%)$ of cells differentiate toward the oligodendrocyte lineage in vivo. Mature oligodendrocyte genes related to myelin production such as myelin oligodendrocyte glycoprotein were not expressed by the transplanted cells at 12 weeks post-transplantation (Fig. 4D-4F). Overall, we did not notice large differences among the lines $(\mathrm{H} 13,11 \mathrm{a}$, and $18 \mathrm{c})$ in their in vivo gene profile after transplantation. The only noted difference was that the total level of astrocyte gene expression was lower in the 11a line compared with the $18 \mathrm{c}$ and $\mathrm{H} 13$ lines (Fig. 4A-4C). These results could indicate the 11a line did not mature as well into astrocytes as the other two cell lines. More likely though, these results reflect the slightly lower survival of this cell line after transplantation (Fig. 2E), with fewer cells 
surviving corresponding to fewer human astrocyte transcripts detected overall in the spinal cord.

\section{Gene Profiling Reveals Maturation of hESC- and hiPSC- Derived Astrocyte Progenitors Post-Transplantation}

In addition to characterizing the in vivo gene expression profile of the transplanted cells, we furthermore asked how the gene expression profile of these cells compared with their expression profile in vitro just before transplant. For therapeutic transplantation purposes, it is crucial to know whether engrafted cells continue to differentiate in vivo and adopt the properties of mature astrocytes or whether they reside in an immature state after transplantation. Immunohistochemical analysis of the differentiated hESCs and hiPSCs in vitro showed that these cells express markers indicative of an astrocyte progenitor phenotype before transplant (GFAP, CD44, Nestin, $\mathrm{S} 100 \beta, \mathrm{CD} 184$ ) (Fig. 1C). In vitro gene profiling of the astrocyte progenitors before transplant also indicates these cells express both immature stem cell markers such as Nestin, Sox2, and CD44 as well as some astrocyte lineage genes such as GFAP, Connexin 43, and EAAT1 (supplemental online Fig. 8A, 8B; supplemental online Table 3 ). These gene-profiling results are consistent with the immunohistochemical data (Fig. 1C) indicating the highest level of GFAP expression in the $\mathrm{H} 13$ line, followed by the $18 \mathrm{c}$ line, and then the 11a line, with the lowest GFAP expression level before transplant (supplemental online Fig. 8A).

We sought to determine whether the expression of these astrocyte lineage genes increases after transplantation and whether the transplanted cells begin to express a more mature profile of astrocyte lineage genes after transplant. To compare the in vitro gene expression profile with the post-transplant gene expression profile, we normalized using human-specific housekeeping genes to specifically compare the level of human-specific gene expression in vitro versus in vivo. Using this method, we found that astrocyte-specific gene expression within the transplanted cells increased dramatically (note log scale on graphs) after engraftment to the rat spinal cord (Fig. 5; supplemental online Table 4). Structural genes such as GFAP were upregulated 100 - to 500 -fold (depending on the cell line) after transplantation, and some functional genes such as EAAT1 and EAAT2 were upregulated between 30 - and 500 -fold in most of the human cell lines in vivo. Of the top 20 astrocyte-specific genes found in a previous gene-profiling report of in vivo astrocytes [26], approximately half of these genes were increased after transplant in the 11a, 18c, and H13 lines (Fig. 5). Again, we noticed no striking differences in cell maturation between the different lines after transplant, although fewer astrocyte-specific genes were above the limit of detection in the 11a line (Fig. 5B).

In addition to examining whether astrocyte-specific genes increase after transplantation, we also analyzed the expression of a variety of genes that have been shown from mouse geneprofiling studies to increase or decrease as astrocytes mature from P7 to P17 in vivo [26]. We were interested to know whether our human stem cell-derived astrocyte progenitors expressed these genes before transplantation and whether they were upregulated after transplantation. In addition, we also analyzed expression of genes shown to be enriched in cultured mouse astrocytes compared with in vivo mouse astrocytes [26] to determine whether these genes are expressed in our cell lines in vitro and, if so, whether they are downregulated after transplantation.

In general, we saw that all of our hESC- and hiPSC-derived astrocyte progenitors before transplantation express a variety of
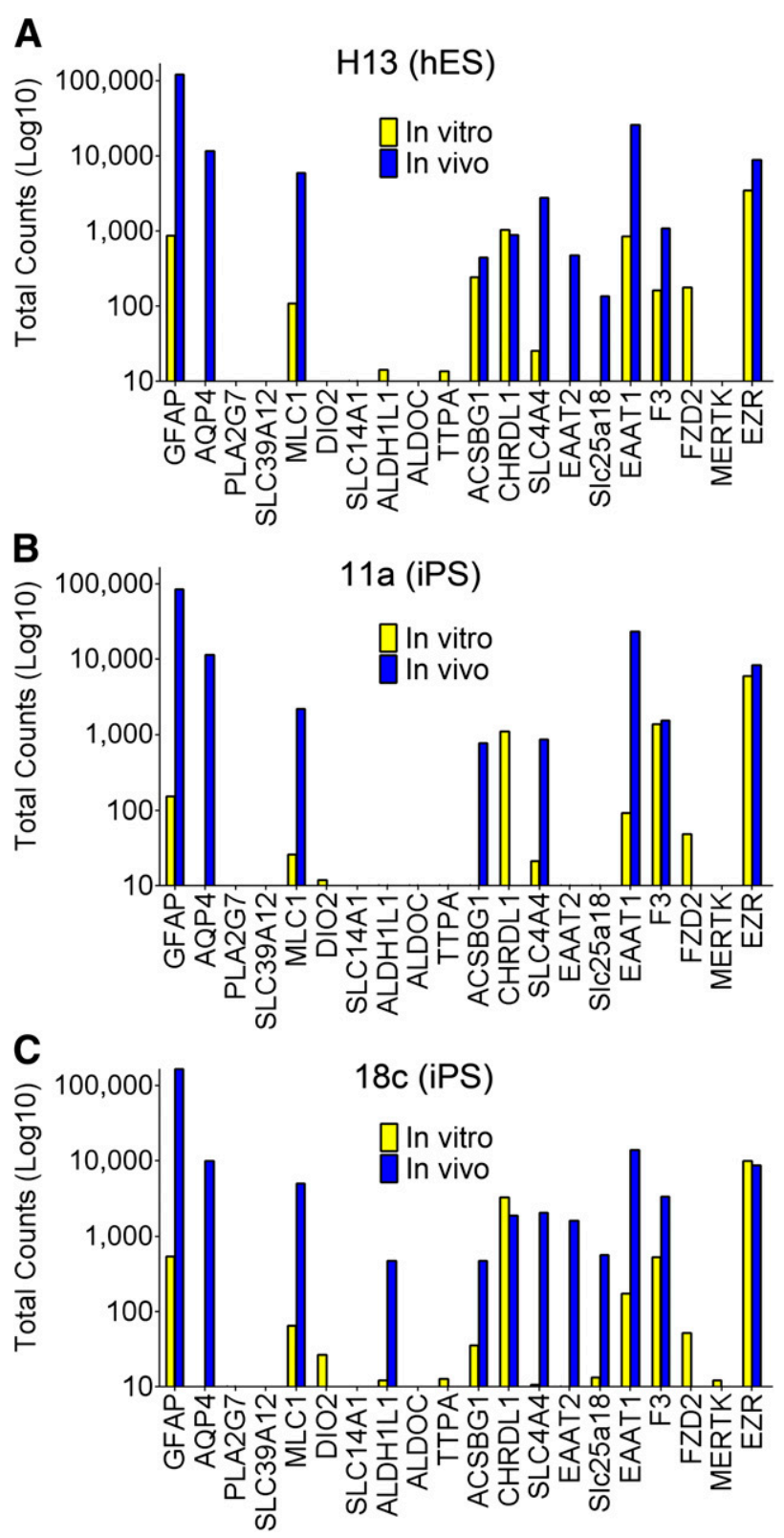

Figure 5. Human-specific gene profiling by NanoString analysis of human embryonic stem cell- and human induced pluripotent stem cellderived astrocyte progenitors for astrocyte-specific genes in vitro before transplantation and in vivo after transplantation. (A-C): Gene profiling reveals increased expression of astrocyte-specific genes by H13 (A), 11a (B), and $18 \mathrm{c}$ (C) cell lines in vivo versus in vitro. RNA was isolated from each cell line just before transplant (in vitro) as well as from the in vivo spinal cord at the site of injection 12 weeks post-transplantation. All samples were normalized using internal positive controls and four human-specific housekeeping genes (B2M, GAPDH, GUSB, OAZ1). Total counts after normalization are graphed. The lack of a blue or yellow bar indicates that gene expression was below the limit of detection. Note: a logarithmic scale is used in all graphs of this figure. Abbreviations: AQP4, aquaporin 4; GFAP, glial fibrillary acidic protein; hES, human embryonic stem cells; iPS, induced pluripotent stem cells.

genes previously shown to be enriched in in vitro cultured astrocytes (Fig. 6). However, after transplantation, all of these genes, with the exception of Anxa1, were downregulated to undetectable levels within the human cells, indicating a phenotypic maturation post-transplantation (Fig. 6). Furthermore, a variety of 
genes specifically enriched in developing astrocytes (P7) compared with mature astrocytes (P17) were also expressed in the hESCand hiPSC-derived astrocyte progenitors before transplant (Fig. 6). Similar to the expression profile for in vitro culture-related genes, after transplantation, we observed a general downregulation of these genes in the human cells, and, in two of the transplanted cell lines (11a and 18c), we could not even detect many of these development-related genes in vivo (Fig. 6). In contrast, when we analyzed genes enriched in mature mouse astrocytes (P17) compared with P7 mouse astrocytes, we observed no clear pattern of upregulation or downregulation after transplant (Fig. 6). These observations may reflect differences in the development of mouse compared with human astrocytes in vivo as well as the observation that the mouse astrocyte genes were profiled from a forebrain population that may not be a general representation of all astrocytes.

\section{DISCUSSION}

One of the most significant advances in the stem cell biology field has been the generation of hiPSCs and development of protocols allowing differentiation of hiPSCs to specific cell lineages. Human iPSCs are promising for autologous cell transplantation therapies because they can be generated from a living patient and theoretically transplanted back into the same patient without concern of immune-mediated rejection based on genetic variations between the cells and the recipient. In addition, hiPSCs can be derived from patients with neurological disorders for disease-modeling purposes that may lead to further understanding of diseases for which genetic contributors are unknown or reliable mouse models are not available.

Based on the increasingly important role for glia in neurodegenerative disorders, we focused on hiPSC-derived astrocyte progenitors and transplantation of these cells to the spinal cord. Astrocytes expressing mutant disease-linked genes have been shown to directly contribute to neurotoxicity in ALS as well as in other diseases such as Rett syndrome [11, 12]. Thus, replacement of the aberrant astrocyte population in the spinal cord may be neuroprotective in ALS and other disorders. Additionally, for the majority of ALS patients, there is no known genetic contributor to the development of the disease (sporadic ALS). This presents difficulties in the study of basic disease-related mechanisms. In vivo disease modeling through engraftment of patientderived hiPSCs to the rodent spinal cord may be one means to study astrocytes from these sporadic ALS patients in an in vivo environment. In vivo disease-modeling strategies have been attempted by transplantation of patient hiPSC-derived neurons for Huntington's disease [27], but similar measures using patient hiPSC-derived glia (rather than neurons) have not been attempted for ALS or other neurodegenerative diseases.

In this work, we investigated the propensity for engraftment of astrocyte progenitors derived from both hESC and hiPSC lines from healthy individuals as a first step toward characterizing these cells both in vitro and in vivo. Our data show that these astrocyte progenitors are capable of engrafting into the spinal cord and surviving long-term (at least 12 weeks) after transplantation. Although only a proportion of the cells expressed GFAP in vitro, post-transplantation, more than $90 \%$ of the cells expressed GFAP, indicating the astrocyte progenitors matured into astrocytes in vivo with very few cells of other lineages present. Further gene profiling at 12 weeks post-transplantation indicated the transplanted cells express a gene profile consistent with mature
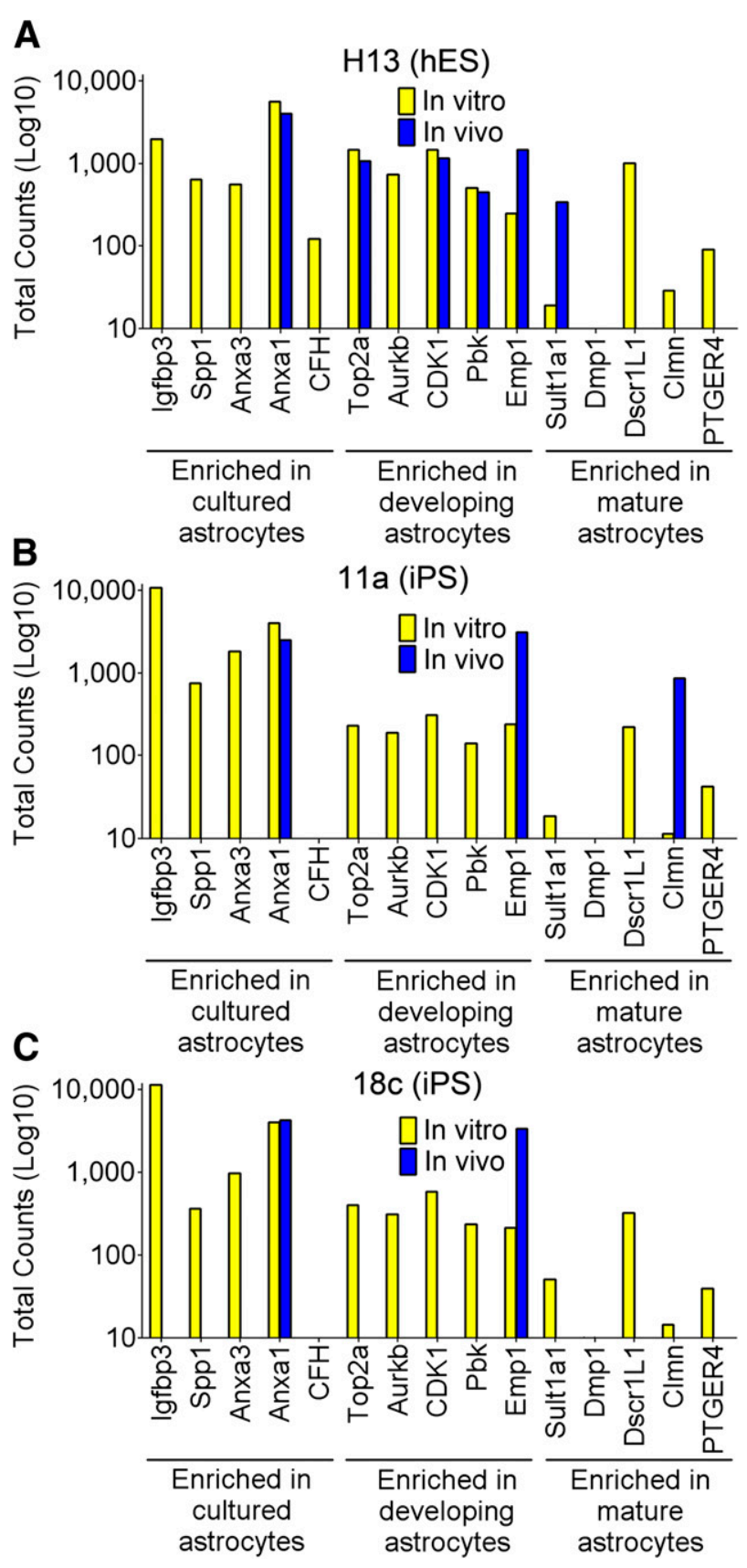

Figure 6. Human-specific gene profiling by NanoString analysis of human embryonic stem cell- and human induced pluripotent stem cell-derived astrocyte progenitors for genes involved in astrocyte development in vitro before transplantation and in vivo after transplantation. (A-C): Gene profiling reveals downregulation of many genes related to astrocyte in vitro culture and early development after transplantation of $\mathrm{H13}$ (A), 11a (B), and 18c (C). astrocyte progenitors to the spinal cord. RNA was isolated from each cell line just before transplant (in vitro) as well as from the in vivo spinal cord at the site of injection 12 weeks post-transplantation. All samples were normalized using internal positive controls and four human-specific housekeeping genes (B2M, GAPDH, GUSB, OAZ1). Total counts after normalization are graphed. The lack of a blue or yellow bar indicates that gene expression was below the limit of detection. Note: a logarithmic scale is used in all graphs of this figure. Abbreviations: hES, human embryonic stem cells; iPS, induced pluripotent stem cells. 
astrocytes in vivo, including upregulation of many astrocytespecific genes after transplant.

One challenge we encountered in transplantation of the astrocyte progenitors was their limited survival and migration after transplant. Transplantation of less differentiated human fetalderived and hiPSC-derived glial precursor cells results in much improved survival and migration, most likely a consequence of their proliferative capacity in vivo after transplant [7, 28, 29]. However, glial precursors have the ability to differentiate into astrocytes or oligodendrocytes, and this split differentiation profile was observed after transplantation of both fetal-derived and hiPSCderived cells $[7,28,29]$. The resulting mixture of astrocytes and oligodendrocytes after transplant may present challenges in analyzing the specific contributions of astrocytes or oligodendrocytes in the context of in vivo disease modeling. In contrast, in the current study, we observed more than $90 \%$ of the hESC- and hiPSC-derived astrocyte progenitors differentiating into astrocytes in vivo. Therefore, transplantation of hiPSC-derived astrocyte progenitors may be more suitable for in vivo modeling of focal astrocyte-specific influences on spinal motor neurons in diseases such as ALS. Improvement in survival and migration of the astrocyte progenitors while retaining a restricted cell fate continues to present a challenge in using these cells for therapeutic purposes. Only one other study has described attempted transplantation of hESC-derived astrocyte progenitors; however, this study did not provide any quantitative data on the survival, migration, or differentiation profile of these cells in vivo, and these transplantation studies were also limited to hESC-derived astrocyte progenitors (not hiPSCs) [30].

As a result of the limited availability of human-specific antibodies, we tested a novel method to assess human-specific gene expression in vivo after transplantation using NanoString gene profiling. This gene-profiling approach allows for rapid assessment of in vivo gene expression using customizable humanspecific probes, providing a snapshot of how the transplanted cells behave in vivo after transplantation. Using this method, we were able to show that the transplanted astrocytes express a wide array of astrocyte-specific genes in vivo, which would have been challenging by standard immunohistochemical measures.

Another goal of our work was to use gene profiling to assess how the transplanted cells change between in vitro culture versus after transplantation to the in vivo environment of the rodent spinal cord. Transcriptome analyses indicate a clear difference between astrocytes cultured in vitro versus in vivo endogenous astrocytes of the rodent forebrain [26]. Many of the perceived benefits of engrafted astrocytes rely on mature functions of these cells, which may or may not be present in the transplanted cells. For example, in ALS, astrocytes are well known to lose expression of the major glial glutamate transporter, EAAT2, causing excess glutamate to accumulate at the synapse and downstream neurotoxicity [31-33]. Our data show that the transplanted astrocyte progenitors express a variety of both structural (GFAP) and functional genes such as the water channel, aquaporin 4, the gap junction protein, Connexin 43 , and glutamate transporters. Additionally, gene profiling demonstrates that the transplanted cells undergo significant maturation after engraftment, leading to upregulation of a variety of astrocyte-specific genes and downregulation of genes involved in astrocyte development. Because we only measured the gene profile of the transplanted cells out to 12 weeks post-transplantation, the possibility also exists that these cells will continue to mature and express even higher levels of mature astrocyte genes at later time points in vivo. Still, these data highlight the potential usefulness for hiPSCs in in vivo modeling for diseases such as ALS in which astrocytes have been implicated in disease initiation and progression.

Lastly, although our understanding of hiPSCs has grown dramatically in recent years, much of this work has been limited to in vitro studies. Although Boulting et al. [16, 34-40] found considerable overlap in the neuronal differentiation propensity of hESCs and hiPSCs, several in vitro studies have suggested that hESCs differ significantly from hiPSCs and have also highlighted substantial variation between different lines of hiPSCs in gene expression and differentiation potential. We asked whether these variations exist only in vitro or whether cell line-specific differences are also present after transplantation to the spinal cord. In our work, all three cell lines that we transplanted behaved similarly in vivo with regard to survival, migration, and differentiation. We also noted no large differences between the hESC line and the two iPSC lines before or after transplant. Although our data include only three different cell lines, NanoString gene profiling may provide for a way to more quickly screen further cell lines to assess for line variability in survival, migration, and differentiation in vivo.

\section{CONCLUSION}

We have evaluated hiPSC- and hESC-derived astrocyte progenitors for their ability to engraft into the rodent spinal cord as the first step toward cell transplantation therapy and in vivo disease modeling using these cells. Although migration and initial survival were limited after transplantation of these cells, we did observe restricted differentiation to astrocytes in vivo with few cells from other lineages present. Our novel gene-profiling approach showed that hESC- and hiPSC-derived astrocyte progenitors continue to develop in vivo after transplantation and express mature astrocyte genes, suggesting the cells received in vivo environmental cues directing them toward terminal differentiation. Given the homogenous differentiation profile and mature gene expression of these cells, transplantation of patientderived hiPSC astrocyte progenitors for in vivo disease modeling or for potential therapeutics in the spinal cord is feasible. Establishment of hiPSC-derived astrocyte progenitors as a tool for in vivo disease modeling may then lead to the discovery of novel mechanisms in ALS or other neurodegenerative disorders with astrocyte dysfunction.

\section{ACKNOWLEDGMENTS}

This work was supported by the Amyotrophic Lateral Sclerosis (ALS) Association (fellowship to A.M.H.-P.), the Michael S. and Karen G. Ansari ALS Center for Cell Therapy and Regeneration Research (to N.J.M), the Department of Defense ALS Research Program (to N.J.M.), the Maryland Stem Cell Research Foundation (to N.J.M.), and $\mathrm{P}^{2} \mathrm{ALS}$ (to N.J.M.).

\section{AUthor CONTRIBUtions}

A.M.H.-P.: conception and design, collection and/or assembly of data, data analysis and interpretation, manuscript writing, final approval of manuscript; L.R.: conception and design, data analysis and interpretation, manuscript writing; S.K.G., A.T., J.-P.R., M.K., and A.S.: collection and/or assembly of data; C.J.D.: conception 
and design, collection and/or assembly of data, data analysis and interpretation; K.E. and C.E.H.: provision of study materials, final approval of manuscript; N.J.M.: conception and design, data analysis and interpretation, manuscript writing, final approval of manuscript, financial support.

\section{Disclosure of Potential Conflicts OF INTEREST}

N.J.M. has uncompensated consultant advisory roles with $Q$ Therapeutics, Inc., and compensated research funding by the National Institutes of Health.

\section{REFERENCES}

1 Lukovic D, Moreno Manzano V, Stojkovic $M$ et al. Concise review: Human pluripotent stem cells in the treatment of spinal cord injury. STEM CELLS 2012;30:1787-1792.

2 Papadeas ST, Maragakis NJ. Advances in stem cell research for amyotrophic lateral sclerosis. Curr Opin Biotechnol 2009;20:545-551.

3 Uccelli A, Laroni A, Freedman MS. Mesenchymal stem cells for the treatment of multiple sclerosis and other neurological diseases. Lancet Neurol 2011;10:649-656.

4 De Feo D, Merlini A, Laterza C et al. Neural stem cell transplantation in central nervous system disorders: From cell replacement to neuroprotection. Curr Opin Neurol 2012;25:322-333.

5 Takahashi K, Tanabe K, Ohnuki M et al. Induction of pluripotent stem cells from adult human fibroblasts by defined factors. Cell 2007; 131:861-872.

6 Goldman SA, Nedergaard M, Windrem MS. Glial progenitor cell-based treatment and modeling of neurological disease. Science 2012; 338:491-495.

7 Wang S, Bates J, Li $X$ et al. Human iPSCderived oligodendrocyte progenitor cells can myelinate and rescue a mouse model of congenital hypomyelination. Cell Stem Cell 2013; 12:252-264.

8 Schwartz SD, Hubschman JP, Heilwell G et al. Embryonic stem cell trials for macular degeneration: A preliminary report. Lancet 2012; 379:713-720.

9 Bellin M, Marchetto MC, Gage FH et al. Induced pluripotent stem cells: The new patient? Nat Rev Mol Cell Biol 2012;13:713-726.

10 Ito $D$, Okano $H$, Suzuki N. Accelerating progress in induced pluripotent stem cell research for neurological diseases. Ann Neurol 2012;72:167-174.

11 Ilieva H, Polymenidou M, Cleveland DW. Non-cell autonomous toxicity in neurodegenerative disorders: ALS and beyond. J Cell Biol 2009;187:761-772.

12 Molofsky AV, Krencik R, Ullian EM et al. Astrocytes and disease: A neurodevelopmental perspective. Genes Dev 2012;26:891-907.

13 Fujimoto $Y$, Abematsu $M$, Falk $A$ et al. Treatment of a mouse model of spinal cord injury by transplantation of human induced pluripotent stem cell-derived long-term selfrenewing neuroepithelial-like stem cells. STEM CELLS 2012;30:1163-1173.
14 Major T, Menon J, Auyeung G et al. Transgene excision has no impact on in vivo integration of human iPS derived neural precursors. PLoS One 2011;6:e24687.

15 Nori S, Okada Y, Yasuda A et al. Grafted human-induced pluripotent stem-cell-derived neurospheres promote motor functional recovery after spinal cord injury in mice. Proc Natl Acad Sci USA 2011;108:16825-16830.

16 Boulting GL, Kiskinis E, Croft GF et al. A functionally characterized test set of human induced pluripotent stem cells. Nat Biotechnol 2011;29:279-286.

17 Lepore AC, Rauck B, Dejea C et al. Focal transplantation-based astrocyte replacement is neuroprotective in a model of motor neuron disease. Nat Neurosci 2008;11:1294-1301.

18 Cowan CA, Klimanskaya I, McMahon J et al. Derivation of embryonic stem-cell lines from human blastocysts. N Engl J Med 2004; 350:1353-1356.

19 Roybon L, Lamas NJ, Garcia-Diaz A et al. Human stem cell-derived spinal cord astrocytes with defined mature or reactive phenotypes. Cell Rep 2013;4:1035-1048.

20 Liu Y, Han SS, Wu Y et al. CD44 expression identifies astrocyte-restricted precursor cells. Dev Biol 2004;276:31-46.

21 Yuan SH, Martin J, Elia J et al. Cell-surface marker signatures for the isolation of neural stem cells, glia and neurons derived from human pluripotent stem cells. PLoS One 2011;6:e17540.

22 Zamanian JL, Xu L, Foo LC et al. Genomic analysis of reactive astrogliosis. J Neurosci 2012;32:6391-6410.

23 Lee S, Park JY, Lee WH et al. Lipocalin-2 is an autocrine mediator of reactive astrocytosis. J Neurosci 2009;29:234-249.

$24 \mathrm{Bi} \mathrm{F}$, Huang $\mathrm{C}$, Tong $\mathrm{J}$ et al. Reactive astrocytes secrete Icn2 to promote neuron death. Proc Natl Acad Sci USA 2013;110:4069-4074.

25 Geiss GK, Bumgarner RE, Birditt B et al. Direct multiplexed measurement of gene expression with color-coded probe pairs. Nat Biotechnol 2008;26:317-325.

26 Cahoy JD, Emery B, Kaushal A et al. A transcriptome database for astrocytes, neurons, and oligodendrocytes: A new resource for understanding brain development and function. J Neurosci 2008;28:264-278.

27 Jeon I, Lee N, LiJY et al. Neuronal properties, in vivo effects, and pathology of a Huntington's disease patient-derived induced pluripotent stem cells. STEM CeLLS 2012;30:2054-2062.
28 Lepore AC, O'Donnell J, Kim AS et al. Human glial-restricted progenitor transplantation into cervical spinal cord of the SOD1 mouse model of ALS. PLoS One 2011;6:e25968.

29 Han $X$, Chen $M$, Wang $F$ et al. Forebrain engraftment by human glial progenitor cells enhances synaptic plasticity and learning in adult mice. Cell Stem Cell 2013;12:342-353.

30 Krencik R, Weick JP, Liu Y et al. Specification of transplantable astroglial subtypes from human pluripotent stem cells. Nat Biotechnol 2011;29:528-534.

31 Rothstein JD, Van Kammen M, Levey AI et al. Selective loss of glial glutamate transporter GLT-1 in amyotrophic lateral sclerosis. Ann Neurol 1995;38:73-84.

32 Bristol LA, Rothstein JD. Glutamate transporter gene expression in amyotrophic lateral sclerosis motor cortex. Ann Neurol 1996;39: 676-679.

33 Bendotti C, Tortarolo M, Suchak SK et al. Transgenic SOD1 G93A mice develop reduced GLT-1 in spinal cord without alterations in cerebrospinal fluid glutamate levels. J Neurochem 2001;79:737-746.

34 Doi A, Park IH, Wen B et al. Differential methylation of tissue- and cancer-specific CpG island shores distinguishes human induced pluripotent stem cells, embryonic stem cells and fibroblasts. Nat Genet 2009;41:1350-1353.

35 Ohi $Y$, Qin $H$, Hong $C$ et al. Incomplete DNA methylation underlies a transcriptional memory of somatic cells in human iPS cells. Nat Cell Biol 2011;13:541-549.

36 Zhao T, Zhang ZN, Rong Z et al. Immunogenicity of induced pluripotent stem cells. Nature 2011;474:212-215.

37 Chin MH, Pellegrini M, Plath K et al. Molecular analyses of human induced pluripotent stem cells and embryonic stem cells. Cell Stem Cell 2010;7:263-269.

38 Bock C, Kiskinis E, Verstappen G et al. Reference maps of human ES and iPS cell variation enable high-throughput characterization of pluripotent cell lines. Cell 2011;144:439-452.

39 Osafune K, Caron L, Borowiak M et al. Marked differences in differentiation propensity among human embryonic stem cell lines. Nat Biotechnol 2008;26:313-315.

40 Hu BY, Weick JP, Yu J et al. Neural differentiation of human induced pluripotent stem cells follows developmental principles but with variable potency. Proc Natl Acad Sci USA 2010; 107:4335-4340.

\section{See www.StemCellsTM.com for supporting information available online.}


Human glial progenitor engraftment and gene expression is independent

\section{of the ALS environment}

Amanda M. Haidet-Phillips ${ }^{\mathrm{a}}$, Arpitha Doreswamy ${ }^{\mathrm{a}}$, Sarah K. Gross ${ }^{\mathrm{a}}$, Xiaopei Tang ${ }^{\mathrm{a}}$, James T.

Campanelli ${ }^{\mathrm{b}}$, Nicholas J. Maragakis ${ }^{\mathrm{a}^{*}}$.

${ }^{a}$ Department of Neurology, Johns Hopkins University, 250.10 Rangos Building, 855 North

Wolfe St., Baltimore, Maryland 21205.

${ }^{\mathrm{b}} \mathrm{Q}$ Therapeutics, Inc., 615 Arapeen Drive, Suite 102, Salt Lake City, Utah 84108

Running Title: ALS environment on human glial progenitor

Word Count: 10,418

Figures: 6

Tables: 0

*Corresponding author

Nicholas J. Maragakis, M.D.

Department Neurology

Johns Hopkins University, School of Medicine

855 N. Wolfe St., Rm 248

Baltimore, MD 21205

Tel: 410-614-9874

Fax: 410-502-5459

Email:nmaragak@jhmi.edu 


\begin{abstract}
Although Amyotrophic Lateral Sclerosis (ALS) is a motor neuron disease, basic research studies have highlighted that astrocytes contribute to the disease process. Therefore, strategies which replace the diseased astrocyte population with healthy astrocytes may protect against motor neuron degeneration. Our studies have sought to evaluate astrocyte replacement using glialrestricted progenitors (GRPs), which are lineage-restricted precursors capable of differentiating into astrocytes after transplantation. The goal of our current study was to evaluate how transplantation to the diseased ALS spinal cord versus a healthy, wild-type spinal cord may affect human GRP engraftment and selected gene expression. Human GRPs were transplanted into the spinal cord of either an ALS mouse model or wild-type littermate mice. Mice were sacrificed for analysis at either the onset of disease course or at the endstage of disease. The transplanted GRPs were analyzed by immunohistochemistry and NanoString ${ }^{\circledR}$ gene profiling which showed no gross differences in the engraftment or gene expression of the cells. Our data indicate that human glial progenitor engraftment and gene expression is independent of the neurodegenerative ALS spinal cord environment. These findings are of interest given that human GRPs are currently in clinical development for spinal cord transplantation into ALS patients.
\end{abstract}

Key Words: neurodegeneration, stem cells, transplantation, astrocyte

\title{
Introduction
}

Amyotrophic Lateral Sclerosis (ALS) is a progressive, neurodegenerative disease caused by the loss of corticospinal, bulbar, and spinal motor neurons. The majority of patients lack a family 
history of the disease (characterized as sporadic ALS) while $10 \%$ of patients inherit the disease in a dominant fashion (familial ALS). Although recent efforts have identified a number of new genes linked to ALS (TDP-43, FUS, UBQLN, OPTIN, VCP, and C9ORF72) (Kabashi et al., 2008, Sreedharan et al., 2008, Kwiatkowski et al., 2009, Vance et al., 2009, Johnson et al., 2010, Maruyama et al., 2010, DeJesus-Hernandez et al., 2011, Deng et al., 2011, Renton et al., 2011), the most extensively studied gene is superoxide dismutase 1 (SOD1) since there exists a widelyused mouse model recapitulating many aspects of human ALS as a result of mutant SOD1 expression (Rosen et al., 1993, Gurney et al., 1994).

A number of studies have focused on the role of astrocytes as a mechanism of disease modification in ALS. Much of this work has focused on in vitro studies in which astrocytes derived from transgenic mice harboring the human mutant SOD1 gene are co-cultured with wildtype motor neurons (Di Giorgio et al., 2007, Nagai et al., 2007, Di Giorgio et al., 2008). This coculture system has revealed that astrocytes can induce wild-type motor neuron cell death, likely through the release of soluble factors. Subsequent studies have also demonstrated this phenomenon using autopsy-derived human astrocytes from ALS patients as well (Haidet-Phillips et al., 2011, Re et al., 2014). We have previously demonstrated that this phenomenon can be recapitulated in vivo following the engraftment of mutant SOD1 glial progenitor derivedastrocytes into wild-type rats (Papadeas et al., 2011). The engrafted astrocytes induce host wildtype motor neuron cell death, corresponding focal limb weakness, and gliosis of host astrocytes and microglia. Lastly, deletion of the mutant SOD1 gene specifically in astrocytes of the ALS mouse model leads to motor neuron protection and an extension of survival in these mice (Yamanaka et al., 2008). Collectively, these studies indicate there are cell autonomous changes that occur within astrocytes expressing ALS-linked mutations. 
However, less is known about how healthy, wild-type astrocytes might respond in a neurodegenerative environment such as the human ALS spinal cord or the spinal cord of rodent ALS models such as the SOD1 ${ }^{\mathrm{G} 93 \mathrm{~A}}$ mouse. Indeed, during the course of ALS disease progression, glutamate concentrations are elevated, cytokines and reactive oxygen species are released, and debris from injured or dying motor neurons can trigger inflammation in the ventral horn (Rothstein et al., 1990, Shaw et al., 1995, Henkel et al., 2009). This is accompanied by neuronal as well as oligodendroglial cell death and microgliosis (Kang et al., 2013, Philips et al., 2013). It is well known that the human ALS spinal cord also undergoes extensive astrocytosis manifested by changes in the glutamate transporter excitatory amino acid transporter 2 (EAAT2) and glial fibrillary acidic protein (GFAP) (Rothstein et al., 1995). Astrocytes in the SOD1 ${ }^{\text {G93A }}$ mouse spinal cord also undergo dramatic changes during the course of disease including upregulation of GFAP, morphological transformation including hypertrophy with $\mathrm{GFAP}^{+}$ spheroids, and loss of EAAT2 (GLT1 in rodents) (Bendotti et al., 2001, Rossi et al., 2008). However, these astrocytes carry the ALS-linked SOD1 mutation which has been shown to have cell-autonomous effects (Di Giorgio et al., 2007, Nagai et al., 2007, Di Giorgio et al., 2008, Yamanaka et al., 2008, Papadeas et al., 2011). Neuronal-restricted expression of mutant SOD1 led to a late onset motor phenotype and increased expression of GFAP by spinal cord wild-type astrocytes in one study (Jaarsma et al., 2008); however, parallel work reported no motor neuron degeneration or astrocytosis by neuronal-specific mutant SOD1 expression (Lino et al., 2002). Overall, it is unknown how healthy, wild-type astrocytes respond to the neurodegenerative spinal cord environment such as in the case of therapeutic transplantation.

This is particularly of interest not only to understand intrinsically how astrocytes may respond to this environment but also with an eye towards a preclinical understanding of these 
differences for translational therapeutics in ALS. Indeed, various sources of stem cells are being explored for transplantation including neural stem cells, glial-restricted progenitors (GRPs), and induced pluripotent stem cells (iPSCs) which can differentiate into astrocytes (Suzuki et al., 2007, Lepore et al., 2008b, Xu et al., 2009, Krencik et al., 2011, Glass et al., 2012, Riley et al., 2012, Feldman et al., 2014, Haidet-Phillips et al., 2014). The anticipated therapeutic effects of these cellular therapies are hypothesized to be due in part to astrocyte-related cellular functions. Thus, understanding how the neurodegenerative environment influences these cells may yield valuable information related to astrocyte function in health and disease.

We have previously demonstrated that rodent GRPs can provide therapeutic efficacy in the ALS rat model (Lepore et al., 2008b). Likewise, we have characterized engraftment and differentiation of human GRPs (hGRPs) into the SOD1 ${ }^{\text {G93A }}$ mouse model of ALS (Lepore et al., 2011). However, in our previous studies, the hGRPs were transplanted only into the diseased ALS spinal cord environment. In our current study, we used hGRPs derived from normal human subjects transplanted into the spinal cords of both wild-type mice and SOD ${ }^{\mathrm{G} 93 \mathrm{~A}}$ mice to address whether there are differences in the survival, migration, differentiation, and gene-expression profiles of these cells in this neurodegenerative environment. Here, we demonstrate that the SOD $1{ }^{\text {G93A }}$ spinal cord environment does not inherently change the engraftment of hGRPs or their gene expression profile in vivo. Thus, transplanted hGRPs retain a characteristic profile which is independent of the neurodegenerative spinal cord environment, suggesting these cells may preserve their wild-type identity after therapeutic transplantation to the neurodegenerative human ALS spinal cord.

\section{Material and Methods}

\section{Ethics Statement}


Brain tissue from fetal cadavers of gestational age from 17 to 24 weeks is used as the starting material for isolation and purification procedures of hGRPs. Tissue is procured by Procurement Specialists employed by Advanced Bioscience Resources (ABR; Alameda CA; FEIN 3005208435) following Donor ID and Informed Consent SOPs and Donor Medical Record Review procedures.

The Johns Hopkins Animal Care and Use Committee (IACUC) approved the research protocol \#MO13M403 for the transplantation studies of these cells on January 10, 2014 (expires Jan 10, 2015).

\section{Derivation and Culture of Human Glial-Restricted Progenitors (hGRPs)}

hGRPs (also referred to as Q-Cells ${ }^{\mathbb{Q}}$ ) were derived as previously described (Campanelli et al., 2008, Sandrock et al., 2010), with the addition of two passages for a total of 21 days of in vitro expansion. Briefly, fetal forebrain (17-24 weeks gestational age) was mechanically and enzymatically dissociated, followed by positive selection via magnetic-activated cell sorting with the glial progenitor-specific cell-surface antigen, $\mathrm{A}_{2} \mathrm{~B}_{5}$. Following selection, hGRPs were cultured in vitro on polyornithine-coated flasks [DMEM-F12 with L-glutamine and $15 \mathrm{mM}$ 4-(2hydroxyethyl)-1-piperazineethanesulfonic acid (Life Technologies; Carlsbad, CA), 1X N1 (Sigma-Aldrich; St. Louis, MO), 0.01\% human serum albumin (Baxter; Deerfield, IL), $20 \mathrm{ng} / \mathrm{mL}$ bFGF (Peprotech; Rocky Hill, NJ), 10 ng/mL PDGF-AA (Peprotech)] for 20 days and subsequently frozen [0.5X medium, $1 \mathrm{X}$ ProFreeze non-animal origin freezing medium (Lonza BioWhittaker; Basel, Switzerland), 7.5\% DMSO (Sigma-Aldrich)]. Frozen aliquots were thawed and immediately prepared for injections as described below (Lepore et al., 2008b).

\section{Human GRP Transplantation}


Human GRPs were suspended (in basal medium) at a concentration of $7.5 \times 10^{4}$ cells/uL. After the completion of the transplantation session, cell viability was assessed using the trypan blue assay and was always found to be greater than $75 \%$. Immune suppressed animals received transplants at 50-60 days of age. Animals were immune suppressed by intraperitoneal administration of FK-506/Rapamycin (1 mg/kg/each; LC Laboratories; Woburn, MA) daily beginning five days before grafting and continuously until sacrifice. Each mouse received 2 grafts (bilaterally at C5) of $1.5 \times 10^{5}$ cells/site (in $2 \mu \mathrm{L}$ basal media) into the ventral horn. Cells were delivered using a $10 \mu \mathrm{L}$ Hamilton Gastight syringe with an attached 30 -gauge $45^{\circ}$ beveled needle (Hamilton; Reno, NV). The injection pipette was secured to a manual micromanipulator (World Precision Instruments; Sarasota, FL) attached to an $80^{\circ}$ tilting base (Lepore et al., 2008b). The tip was lowered to a depth of $0.75 \mathrm{~mm}$ below the surface of the cord and was held in place for 2 minutes before and after cell injection. Cells were delivered under the control of a microsyringe pump controller (World Precision Instruments) at a rate of $1 \mu \mathrm{L} /$ minute.

\section{Animals}

Transgenic mice carrying the human SOD1 gene with the G93A mutation (B6SJL$\operatorname{Tg}(\mathrm{SOD} 1 *$ G93A) 1Gur/J: Stock \# 002726) or their wild-type B6SJL littermates were used . Male and female mice were obtained from The Jackson Laboratory (Bar Harbor, ME), and maintained as an in-house colony. On average, SOD ${ }^{\mathrm{G} 93 \mathrm{~A}}$ mice developed clinical disease onset at 90 days of age and reached disease endstage at approximately 125 days of age (Gurney et al., 1994). For all studies, equal numbers of males and females were included in all groups, and animals from the same litter were distributed amongst groups. All procedures were conducted in strict accordance with the guidelines set by the European Communities Counsel Directive (November 24th, 1986), the NIH Guide for the Care and Use of Laboratory Animals, the Guidelines for the 
Use of Animals in Neuroscience Research and the Johns Hopkins University IACUC, and measures were taken to minimize any potential pain or animal discomfort. Mice were housed at standard temperature $\left(21^{\circ} \mathrm{C}\right)$ and in a light controlled environment with "ad libitum" access to the food and water, and were maintained in racks of ventilated cages. In order to avoid dehydration, Hydrogel packs were provided when animals started to show disease symptoms.

\section{Tissue Processing}

Animals were sacrificed at 90 days of age or at endstage for SOD $1{ }^{\mathrm{G} 93 \mathrm{~A}}$ mice with endstage defined as the inability to right themselves during a 30 second time window. Wild-type B6SJL littermates were sacrificed at either 90 days of age or at the same time as endstage SOD $1^{\text {G93A }}$ mice in order to obtain an age-matched set of wild-type mice. Mice were deeply anaesthetized and then transcardially perfused with ice-cold $0.9 \%$ saline, followed by ice-cold $4 \%$ paraformaldehyde (Fisher Scientific; Pittsburgh, PA). Spinal cords were removed from the animal, followed by cryoprotection in $30 \%$ sucrose (Fisher) $/ 0.1 \mathrm{M}$ phosphate buffer at $4^{\circ} \mathrm{C}$ for 3 days. The tissue was embedded in Tissue Freezing Media (Triangle Biomedical Sciences), fast frozen with dry ice, and stored at ${ }^{-} 80^{\circ} \mathrm{C}$ until processed. Spinal cord tissue blocks were cut in transverse plane at $30 \mu \mathrm{m}$ thicknesses. Sections were collected on glass slides and stored at ${ }^{\circ} 20^{\circ} \mathrm{C}$ until analyzed. Subsets of spinal cord slices were collected in TBS for free-floating immunohistochemistry.

\section{Immunohistochemistry}

Tissue sections were blocked for $1 \mathrm{hr}$. in $10 \%$ goat serum with $0.3 \%$ triton-X, probed overnight with primary antibody at $4{ }^{\circ} \mathrm{C}$ in $2 \%$ goat serum with $0.3 \%$ triton-X, washed in TBS and then incubated with secondary antibody (Alexa Fluor, Life Technologies at 1:1000 or Jackson Immunoresearch at 1:200) for $2 \mathrm{hrs}$. at room temperature followed by further washing in TBS. 
Tissue sections were mounted with Prolong Gold with DAPI (Life Technologies). Primary antibodies used: Human nuclear antigen (HuNA) (Millipore \#MAB1281, 1:100), Tuj1 (Covance \#MRB-435P, 1:500), Glial Fibrillary Acidic Protein (GFAP) (DAKO \#Z0334, 1:400), GFAP (Millipore, \#AB5541, 1:300), Human-specific GFAP (Stem Cells, Inc \#STEM123, 1:500), Ki67 (Thermo Scientific \#RM-9106, 1:400), and Olig2 (Millipore \#AB9610, 1:500). Images were acquired on either a Zeiss fluorescence microscope using a Photometric Sensys KAF-1400 CCD camera (Roper Scientific) or on a Zeiss laser confocal microscope.

Transplanted cells were localized by staining for human nuclear antigen (HuNA) antibody (to identify human cells in rat spinal cord). To estimate the total number of surviving cells, spinal cord sections were stained for HuNA and DAPI and mosaic images were acquired on a Zeiss fluorescence microscope to capture the entire mouse spinal cord section in one image. Every $6^{\text {th }}$ section was imaged throughout the entire rostral-caudal extent of the spinal cord where $\mathrm{HuNA}^{+}$cells were present. The images were converted to tif files for analysis using Adobe Photoshop CS5 to further magnify the images during the quantification process. In these sections, all $\mathrm{HuNA}^{+} / \mathrm{DAPI}^{+}$cells were counted. The total number of $\mathrm{HuNA}^{+} / \mathrm{DAPI}^{+}$cells from all sections was summed and multiplied by 6 to estimate the total number of surviving cells as we have described previously (Lepore et al., 2008b, Lepore et al., 2011).

To quantify the percentage of transplanted cells differentiating toward astrocytes or oligodendrocytes, the transplanted cells were identified by HuNA immunohistochemistry and double stained for either GFAP or Olig2. Images were acquired at the site of injection as well as $1 \mathrm{~mm}$ and $2 \mathrm{~mm}$ rostral and caudal from the site of injection for analysis. For the rostral-caudal distribution analysis, images were taken both rostral and caudal from the injection site and pooled together since our previous studies have shown no differences in differentiation at rostral 
versus caudal sites. For grey/white matter differentiation analysis, images were taken at the site of injection as well as $1 \mathrm{~mm}$ and $2 \mathrm{~mm}$ rostral and caudal from the injection site and pooled together. Immunohistochemistry for GFAP was used to delineate grey/white matter borders. Images were acquired at 20X magnification on a Zeiss confocal microscope as z-stacks which were converted to orthogonal projections which allowed for sufficient resolution for quantification purposes. The images were then converted to tif files for analysis using Adobe Photoshop CS5 to further magnify the images during the quantification process. For each image, the total number of double positive $\left(\mathrm{HuNA}^{+} \mathrm{GFAP}^{+}\right.$or $\left.\mathrm{HuNA}^{+} \mathrm{Olig} 2^{+}\right)$cells was counted and divided by the total number of $\mathrm{HuNA}^{+}$cells per image to calculate the percentage of cells differentiating toward astrocytes or oligodendrocytes. The same process was used to quantify the percentage of proliferating cells using double labeling for HuNA and Ki67. Due to technical limitations of the antibody staining, separate spinal cord sections were used in some cases for $\mathrm{HuNA}^{+} \mathrm{GFAP}^{+}$and $\mathrm{HuNA}^{+} \mathrm{Olig} 2^{+}$immunohistochemistry, which accounts for about $5 \%$ of cells being double-counted. Six 20X images were acquired at the site of transplantation for analysis since the majority of cells resided at this site. For sites $1 \mathrm{~mm}$ and $2 \mathrm{~mm}$ rostral and caudal from the injection site, three $20 \mathrm{X}$ images were acquired at each site for analysis. For each group, 3-5 mice were analyzed.

\section{NanoString Analysis}

NanoString (NanoString Technologies, Inc., Seattle, WA, http://www.nanostring.com) analyses were performed for all groups at 90 days of age and endstage. NanoString probe design and sequence information has been previously described (Haidet-Phillips et al., 2014). Mice were perfused with ice-cold $0.9 \%$ saline, and spinal cord tissue was harvested and fast-frozen in liquid nitrogen. RNA was isolated using TRIzol, followed by DNase treatment and RNA cleanup using 
RNeasy columns (Qiagen, Hilden, Germany, http://www.qiagen.com). For analysis of gene expression by hGRPs in vitro, RNA was isolated from hGRPs at the time of transplantation using an identical method as described above. For the NanoString assay,100 ng of RNA was loaded per sample. All samples were normalized using internal positive controls and three housekeeping genes (B2M, GAPDH, and OAZ1) with human-specific probes. Gene expression was normalized using these human-specific housekeeping genes to discount any effects of increased proliferation of hGRPs in the endstage SOD $1{ }^{\mathrm{G} 93 \mathrm{~A}}$ spinal cord. Before normalization, all raw values reading less than 10 total counts were eliminated from analysis because they were under the standard limit of detection. Total counts, after normalization, were graphed. Raw counts prior to normalization are shown in Supporting Table 1. In terms of gene expression, a "count" is referred to as a single molecule of mRNA transcript bound by the Nanostring ${ }^{\circledR}$ probes.

\section{Statistical Analysis}

All data were analyzed using GraphPad Prism software (GraphPad Software, San Diego, CA, http://www.graphpad.com). Data in all graphs are represented as the mean +/- SEM. For immunohistochemistry analyses, 3-5 mice were analyzed per group. For NanoString analyses, 36 mice were analyzed per group. Data were analyzed by either one-way ANOVA with Bonferroni post-test or by two-tailed t-test.

\section{Results}

Glial-restricted progenitors (GRPs) are a lineage-restricted precursor cell type which are capable of differentiating along the astrocyte or oligodendrocyte lineage (Mayer-Proschel et al., 1997, Rao and Mayer-Proschel, 1997). Our previous studies have revealed that they largely differentiate into astrocytes after transplantation and their therapeutic benefit is hypothesized to 
be due to astrocyte-derived functions (Lepore et al., 2008b, Lepore et al., 2011). Human GRPs (hGRPs) were transplanted into the cervical spinal cord of wild-type (WT) or SOD1 ${ }^{\mathrm{G} 93 \mathrm{~A}}$ mice at 50-60 days of age. We sacrificed mice receiving hGRP transplants at either 90 days of age, which corresponds to clinical onset of ALS in these mice ( $\mathrm{n}=9$ for WT, $\mathrm{n}=7$ for SOD $1^{\mathrm{G} 93 \mathrm{~A}}$ ) or at endstage of disease ( $\mathrm{n}=10$ for WT, $\mathrm{n}=9$ for SOD $1^{\mathrm{G} 93 \mathrm{~A}}$ ). Since the WT mice did not develop disease, they were sacrificed on the same days as the $\mathrm{SOD} 1^{\mathrm{G} 93 \mathrm{~A}}$ mice at endstage to generate age-matched pairs for analysis. We have previously evaluated both rodent GRPs and hGRPs for neuroprotection in SOD1-based rodent models of ALS (Lepore et al., 2008b, Lepore et al., 2011); thus, in this study, we did not assess for motor neuron protection, but rather asked how the neurodegenerative spinal cord environment of the $\mathrm{SOD} 1^{\mathrm{G} 93 \mathrm{~A}}$ mouse affects the engraftment of hGRPs and their differentiation potential.

\section{hGRP survival and migration is independent of the SOD1 ${ }^{G 93 A}$ spinal cord environment}

To evaluate whether there are differences in the engraftment potential of hGRPs when transplanted into the WT versus the SOD $1{ }^{\mathrm{G} 93 \mathrm{~A}}$ spinal cord, we measured hGRP survival and migration after transplant. To identify the transplanted hGRPs in the mouse spinal cord, we used an antibody for human-specific nuclear antigen (HuNA) that allowed us to quantify the number of transplanted human cells surviving and migrating. At both 90 days of age and endstage time points, we observed hGRPs surviving and migrating rostrally and caudally from the injection sites. No significant differences were found in the survival of hGRPs in the WT versus SOD1 ${ }^{\mathrm{G} 93 \mathrm{~A}}$ spinal cord (Figure 1A) or in the distances migrated by the hGRPs posttransplantation (Figure 1B-D). Most of the transplanted hGRPs resided within $1 \mathrm{~mm}$ of the site of transplantation. However, in both WT and SOD $1{ }^{\mathrm{G} 93 \mathrm{~A}}$ spinal cord environments, some hGRPs 
migrated out $2 \mathrm{~mm}$ past the injection site at 90 days and past $3 \mathrm{~mm}$ at the endstage time point (Figure 1B-D).

\section{Proliferation of hGRPs is unchanged over disease course in SOD1 ${ }^{G 93 A}$ spinal cord}

Although the neurodegenerative spinal cord environment did not affect survival or migration of the hGRPs, we also assessed how proliferation of the transplanted cells might be influenced by potential cytokines, growth factors, or other secreted molecules present in the SOD $1^{\mathrm{G} 93 \mathrm{~A}}$ spinal cord. At both 90 days and endstage time points, few $(<10 \%)$ of the transplanted $\mathrm{HuNA}^{+}$hGRPs co-expressed the proliferation marker Ki67, indicating most of the hGRPs are not dividing post-transplantation. The percentage of hGRPs dividing during the symptomatic phase of SOD1-mediated neurodegeneration did not increase during the 90 day of age until endstage timeframe. There was a small difference in the percentage of hGRPs expressing Ki67 at endstage in the SOD ${ }^{\mathrm{G} 93 \mathrm{~A}}$ spinal cord compared to the WT spinal cord (WT $=3.0+/-0.9 \%$, $\mathrm{SOD}^{\mathrm{G} 93 \mathrm{~A}}=9.8+/-2.4 \%, \mathrm{p}<0.01, \mathrm{n}=3$ mice/group) (Figure 2). This difference in hGRP

proliferation between WT and SOD $1^{\mathrm{G} 93 \mathrm{~A}}$ was not seen in the spinal cord at 90 days of age. The differences between hGRP proliferation in $\mathrm{SOD} 1^{\mathrm{G} 93 \mathrm{~A}}$ mice when compared to WT mice at endstage may be a result of a decrease in hGRP proliferation in the WT environment (WT 90 days $=5.3+/-1.1 \%$, WT Endstage $=3.0+/-0.9 \%, \mathrm{p}>0.05, \mathrm{n}=3 \mathrm{mice} /$ group $).$ Overall, the differences in cell proliferation between the groups and the changes within each group are modest.

\section{hGRP differentiation in vivo is independent of the SOD ${ }^{G 93 A}$ spinal cord environment}

While large differences in the capacity for survival and migration of hGRPs were not observed, we also sought to evaluate whether the process of differentiation into glial subtypes 
was altered in the neurodegenerative SOD1 ${ }^{\mathrm{G} 93 \mathrm{~A}}$ spinal cord environment. Since hGRPs are capable of differentiating along the astrocyte or oligodendrocyte lineage, we quantified the percentage of transplanted $\mathrm{HuNA}^{+}$hGRPs co-expressing either the astrocyte marker, glial fibrillary acidic protein (GFAP), or the early oligodendrocyte lineage marker, Olig2. No differences were seen in the percent of hGRPs expressing this astrocyte marker in the SOD $1^{\mathrm{G} 93 \mathrm{~A}}$ spinal cord versus the WT spinal cord at either 90 days or endstage at the transplantation site (Figure 3A, C-D). Between $80-90 \%$ of the HuNA ${ }^{+}$hGRPs co-expressed GFAP at 90 days of age that stayed consistent through the endstage of disease. As we have observed in past studies, differentiation toward astrocytes was favored compared to the oligodendrocyte lineage with fewer $\mathrm{HuNA}^{+}$cells co-expressing Olig2 compared to GFAP in all study groups (Figure 3B, E-F) (Lepore et al., 2011). In addition to analyzing hGRP differentiation at the transplantation site, we also quantified differentiation of hGRPs at distant sites 1-2 mm along the rostral-caudal axis from the injection site (Supplemental Figure 1). We observed increased differentiation toward the oligodendrocyte lineage at more distant rostral-caudal sites compared to at the injection site which we have previously noted (Lepore et al., 2011). However, the genotype of the transplant recipient (WT or SOD1 ${ }^{\mathrm{G} 93 \mathrm{~A}}$ ) did not influence the percentage of $\mathrm{HuNA}^{+}$cells becoming $\mathrm{GFAP}^{+}$ astrocytes or Olig2 ${ }^{+}$oligodendrocyte-lineage cells. Similarly, the location of the transplanted cells within either the grey or white matter did not affect their differentiation toward $\mathrm{GFAP}^{+}$ astrocytes or Olig2 ${ }^{+}$cells of the oligodendrocyte lineage in either WT or SOD $1^{\mathrm{G} 93 \mathrm{~A}}$ spinal cords (Supplemental Figure 2).

Analysis using $\mathrm{HuNA}^{+} \mathrm{GFAP}^{+}$immunohistochemistry revealed that no differences exist in the percentage of hGRPs becoming astrocytes in the SOD $1{ }^{\mathrm{G} 93 \mathrm{~A}}$ spinal cord versus the WT spinal cord. To more closely examine the morphology of the hGRP-derived astrocytes in vivo, 
we localized the engrafted human astrocytes using an antibody for human-specific GFAP. Low magnification analysis of the injection site showed no alterations in how the hGRP-derived astrocytes integrate into the grey matter architecture of the SOD ${ }^{\mathrm{G} 93 \mathrm{~A}}$ spinal cord versus the WT spinal cord (Figure 4A-B). At the endstage time point, the hGRP-derived astrocytes integrated extensively into the grey matter of the spinal cord of both WT and SOD $1^{\mathrm{G} 93 \mathrm{~A}}$ mice with some cells also migrating into white matter tracts. High magnification analysis revealed the hGRPderived astrocytes develop characteristic astrocyte morphology with ramified processes extending out from the cell body (Figure 4C-D). No alterations in this typical morphology were noted even when the astrocytes developed in the neurodegenerative environment of the SOD $1^{\mathrm{G} 93 \mathrm{~A}}$ spinal cord. Qualitatively, the hGRP-derived astrocytes did not display heightened GFAP expression after engraftment into the SOD1 ${ }^{\mathrm{G} 93 \mathrm{~A}}$ spinal cord even though endogenous mouse astrocytes of the SOD $1^{\mathrm{G} 93 \mathrm{~A}}$ spinal cord upregulate GFAP at sites distant from the transplantation area, consistent with ventral horn motor neuron neurodegeneration (Supplemental Figure 3). Therefore, although host astrocytes of the SOD1 ${ }^{\mathrm{G} 93 \mathrm{~A}}$ mouse model undergo morphological changes such as hypertrophy, adoption of a spheroid-shaped cell body with thick, short processes, and upregulation of GFAP (Bendotti et al., 2001, Rossi et al., 2008), we did not observe these changes in the hGRP-derived astrocytes engrafted into the SOD $1^{\text {G93A }}$ spinal cord.

\section{Human-specific gene expression profiling analysis of the engrafted hGRPs}

Next, we evaluated the gene expression profile of the transplanted cells at 90 days of age and endstage comparing the profile in the SOD $1^{\mathrm{G} 93 \mathrm{~A}}$ spinal cord to the WT spinal cord. Although immunohistochemical measures allow for the analysis of cell morphology, gene expression profiling provides the opportunity to quantitatively assess an entire panel of genes in vivo. Using 
Nanostring ${ }^{\circledR}$ technology, we developed a panel of custom, human-specific probes to measure gene expression specifically in the transplanted human cells. This panel included well-described genes expressed by neural progenitor cells, neurons, oligodendrocytes, and astrocytes as well as less characterized genes found to be expressed specifically in astrocytes in vivo by gene-profiling methods (Cahoy et al., 2008). Nanostring ${ }^{\circledR}$ technology is a probe-based method for direct RNA analysis optimized for detection of small amounts of RNA such as in a xenograft paradigm (Geiss et al., 2008). This probe-based method allows for specific detection of RNA expression changes in the transplanted human cells separate from the endogenous host mouse cells in the spinal cord. We have previously used this approach to characterize the gene expression profile of human iPSC-derived astrocyte progenitors after transplantation to the rodent spinal cord (HaidetPhillips et al., 2014).

Gene expression was evaluated in hGRPs just prior to transplantation in vitro as well as in vivo at both 90 days of age and endstage. Since hGRPs were transplanted to the cervical region of the mouse spinal cord, RNA was isolated from the cervical region for analysis. Since the hGRPs do not migrate to the lumbar spinal cord, the lumbar region of the spinal cord served as a negative control to ensure probes did not cross-react with endogenous mouse RNA.

\section{Astrocyte-related gene expression in engrafted cells is largely independent of disease environment in the SOD1 ${ }^{G 934}$ spinal cord}

Using this method, we detected expression of a variety of astrocyte-related genes including GFAP, aquaporin-4, connexin 43, EZR, F3, EAAT1, EAAT2, and MLC1 (Figure 5). As we have previously observed, GFAP is highly expressed in the normal human spinal cord at levels much greater than many other astrocyte-related genes (Haidet-Phillips et al., 2014). The 
engrafted hGRP-derived astrocytes displayed log-fold changes in GFAP expression after transplantation to the WT and SOD1 ${ }^{\mathrm{G} 93 \mathrm{~A}}$ spinal cord at both the 90 days and endstage time points (Figure 5A) $(\mathrm{n}=3-6$ mice/group, $\mathrm{p}<0.05)$. These increases in GFAP expression likely represent the maturation from a progenitor cell type (hGRP) along the astrocyte lineage after transplantation. Interestingly, we saw no differences in GFAP expression in hGRP-derived astrocytes engrafted into the $\mathrm{SOD} 1^{\mathrm{G} 93 \mathrm{~A}}$ spinal cord versus the WT spinal cord at 90 days or endstage. These results are consistent with our immunohistochemical analysis revealing no upregulation of human-specific GFAP after engraftment to the SOD1 ${ }^{\mathrm{G} 93 \mathrm{~A}}$ spinal cord.

We also evaluated other astrocyte-related genes to determine whether they undergo changes in the hGRP-derived astrocytes in response to a neurodegenerative spinal cord environment. In addition to GFAP, the genes aquaporin-4, connexin 43, EZR, and F3 showed increases or trends toward increased expression following engraftment to the spinal cord (Figure 5B-E). However, we did not observe differences in the expression of these astrocyte-related genes in the SOD1 ${ }^{\mathrm{G} 93 \mathrm{~A}}$ spinal cord when compared to the WT spinal cord at 90 days or endstage.

Interestingly, the glutamate transporter, EAAT2, was increased only after transplantation into the SOD $1{ }^{\mathrm{G} 93 \mathrm{~A}}$ spinal cord environment, but not the WT spinal cord (Figure 5F) $(\mathrm{n}=3-6$ mice/group, $\mathrm{p}<0.05$ ). It has been well documented that EAAT2 (but not EAAT1) is lost from astrocytes during the course of disease in both rodent models of ALS as well as in the human ALS spinal cord (Rothstein et al., 1995, Bristol and Rothstein, 1996, Bendotti et al., 2001). While moderate, our observed increase in EAAT2 gene expression in the hGRP-derived astrocytes engrafted into the SOD $1^{\mathrm{G} 93 \mathrm{~A}}$ spinal cord may be a compensatory mechanism to offset the loss of this transporter observed in the neurodegenerative spinal cord. No differences were observed in the astrocyte membrane protein, MLC1, or the glutamate transporter, EAAT1, in 
hGRP-derived astrocytes in the WT versus SOD $1^{\mathrm{G} 93 \mathrm{~A}}$ spinal cord (Figure 5G-H). EAAT1 expression was detected in the hGRPs prior to transplantation as has been reported previously (Maragakis et al., 2004). This expression decreased after transplantation to the WT and SOD $1^{\mathrm{G} 93 \mathrm{~A}}$ spinal cord at 90 days and endstage $(\mathrm{n}=3-6$ mice/group, $\mathrm{p}<0.05)$. These data are consistent with glial development in that EAAT1 expression is known to peak earlier compared to the glutamate transporter, EAAT2, at least in rodents (Shibata et al., 1997, Ullensvang et al., 1997, Kugler and Schleyer, 2004, Regan et al., 2007). Additionally, the proportion of glutamate transport managed by EAAT1 versus EAAT2 varies in diverse subtypes of astrocytes (Danbolt, 2001, Regan et al., 2007).

Expression of progenitor and non-astrocyte-related genes in engrafted hGRPs is independent of the SOD $1^{G 93 A}$ spinal cord environment

In addition to examining expression of astrocyte-related genes, we also measured the expression of astrocyte-progenitor genes as well as genes expressed by other neural lineages besides astrocytes. The astrocyte precursor markers CD44 and S100 $\beta$ are expressed early in the development of astrocytes and continue to be detected in mature astrocytes as well (Liu et al., 2002, Vives et al., 2003, Liu et al., 2004). CD44 was not expressed by the hGRPs until after transplantation while S100 $\beta$ was detected in hGRPs at the time of transplantation. (Figure 6A-B). No differences in CD44 or S100ß expression were observed between hGRPs engrafted in WT versus SOD $1{ }^{\mathrm{G} 93 \mathrm{~A}}$ mice. We also measured the expression of progenitor cell markers such as nestin and sox2. No differences in expression of either of these markers were observed in hGRPs transplanted into the SOD $1{ }^{\mathrm{G} 93 \mathrm{~A}}$ spinal cord compared to the WT spinal cord.

Our immunohistochemical analysis of the transplanted hGRPs revealed that the majority of cells differentiate into astrocytes while only $20-30 \%$ of the transplanted cells become Olig2 ${ }^{+}$ 
cells of the oligodendrocyte lineage. Gene profiling analysis of the hGRPs detected expression of both Olig2 as well as platelet-derived growth factor receptor $\alpha(\operatorname{PDGFR} \alpha)$, another gene expressed by oligodendrocyte precursors (Figure 6E, F). In addition to expression of oligodendrocyte progenitor genes, the engrafted cells also expressed the early oligodendrocyte gene CNPase with no differences observed in cells transplanted to the SOD1 ${ }^{\mathrm{G} 93 \mathrm{~A}}$ spinal cord versus WT control (Figure 6G). The absence of genes involved in myelin production such as myelin oligodendrocyte protein (MOG), is consistent with the observation that cells with an oligodendroglial fate at these timepoints are not myelin producing (Figure 6H).

Furthermore, as expected, no microglial gene expression (ITGAM), nor neuronal gene expression ( $\beta$-tubulin) was detected since the hGRPs are a lineage-restricted precursor only capable of differentiating to astrocytes or oligodendrocytes (Figure 6I, J). These data indicate that even in the neurodegenerative spinal cord environment, the hGRPs retain their lineage restriction.

\section{Discussion}

Astrocytes have become increasingly recognized for their role in maintaining homeostasis in the spinal cord. Indeed, astrocyte dysfunction has been shown to contribute to pathology in several neurodegenerative diseases including the motor neuron disease ALS. Astrocytes from the SOD1 ${ }^{\mathrm{G} 93 \mathrm{~A}}$ mouse model of ALS can induce the degeneration of wild-type motor neurons in culture as well as in vivo after transplantation to the wild-type rat spinal cord (Di Giorgio et al., 2007, Nagai et al., 2007, Di Giorgio et al., 2008, Papadeas et al., 2011). Additionally, this phenomenon has been recapitulated in vitro using human cells demonstrating that astrocytes derived from ALS patient post-mortem spinal cords also cause the death of wild- 
type motor neurons in culture (Haidet-Phillips et al., 2011, Re et al., 2014). In all of these studies, astrocytes expressed ALS disease-linked mutations (or possibly carried unknown genetic modifications in the case of sporadic ALS astrocytes). Therefore, the astrocyte abnormalities are presumed to be a cell autonomous consequence from expression of the ALS-linked mutations. Conversely, in our study, we sought to address how the neurodegenerative environment of the ALS spinal cord influences wild-type astrocytes not carrying disease-linked mutations. Since astrocyte replacement therapies involving engraftment of healthy astrocytes are being considered for ALS, the manner in which the neurodegenerative environment affects healthy astrocytes is crucial to understand.

To address this question, we transplanted hGRPs derived from normal human subjects to the spinal cord of WT or SOD $1^{\mathrm{G} 93 \mathrm{~A}}$ mice. We chose to study GRPs because we have observed efficacy upon rodent GRP transplantation to the rat SOD $1{ }^{\mathrm{G} 93 \mathrm{~A}}$ ALS model and thus, human GRPs are currently undergoing preclinical studies to evaluate their safety for transplantation to human ALS patients (Lepore et al., 2008b). Our previous studies using both rodent-derived GRPs and hGRPs transplanted into rodent SOD1 ${ }^{\text {G93A }}$ ALS models have shown that these progenitors differentiate mainly into astrocytes upon transplantation with a smaller proportion becoming cells of the oligodendrocyte lineage (Lepore et al., 2008b, Lepore et al., 2011). We evaluated the profile of the hGRP-derived astrocytes at two different time points during the course of disease in the SOD $1^{\mathrm{G} 93 \mathrm{~A}}$ mice. Using both immunohistochemical methods and gene expression profiling, we compared engraftment and gene expression of the hGRPs in the WT versus SOD $1^{\mathrm{G} 93 \mathrm{~A}}$ spinal cords. Overall, no gross differences were noted in the survival, migration, and gene expression profile of the hGRPs when transplanted into the neurodegenerative SOD $1^{\mathrm{G} 93 \mathrm{~A}}$ spinal cord compared to the WT mouse spinal cord. 
The Nanostring® gene profiling approach used in our study is a powerful technique because it allows for the specific analysis of gene expression in the transplanted human cells, separate from expression changes in endogenous mouse cells of the spinal cord. One caveat to this approach is that gene expression does not always correlate with protein function. However, we have attempted to analyze genes which are not predicted to be de novo synthesized (i.e. cytokines). Instead, most of the genes analyzed are surface molecules or membrane transporters. Although we cannot predict protein function, our gene expression data suggest that hGRP gene expression is mostly independent of the neurodegenerative milieu. While astrocytosis is a well-described phenomenon in both mouse models of ALS as well as in autopsy samples of spinal cords of patients with ALS, we did not appreciate that wild-type hGRP-derived astrocytes adopted characteristics of astrocytosis such as the upregulation of GFAP, connexin-43 or aquaporin 4 which is seen in astrocytes of the SOD1 ${ }^{\mathrm{G} 93 \mathrm{~A}}$ spinal cord. These observations, with regard to GFAP expression as at least one signature of astrocytosis, are consistent with our previous observations after engraftment of rat wild-type GRPs to the SOD1 ${ }^{\mathrm{G} 93 \mathrm{~A}}$ rat spinal cord. The human-specific probes employed in this study, however, allow us to identify gene changes in human cells amongst surrounding rodent cells. These data would support, therefore, that the astroglial responses seen in the ALS spinal cord may be related in part to intrinsic properties of the astrocytes themselves as opposed to a secondary reactive process. These observations may also explain the inherent capability of ALS astrocytes to promote toxicity to wild-type motor neurons as has been described by our group and others (Di Giorgio et al., 2007, Nagai et al., 2007, Di Giorgio et al., 2008, Papadeas et al., 2011). This may be particularly relevant to cases where human ALS astrocytes, from both sporadic and SOD1-mediated ALS, have been isolated from autopsy tissues and continue to be toxic to wildtype motor neurons (Haidet-Phillips et al., 
2011, Re et al., 2014). One might expect that if this were merely a reactive process, then those ALS-derived astrocytes would not necessarily mediate the same toxicities.

It is intriguing that the only significant difference noted by Nanostring ${ }^{\circledR}$ gene profiling between engraftment to WT or SOD1 ${ }^{\mathrm{G} 93 \mathrm{~A}}$ spinal cords was in the upregulation of the glutamate transporter, EAAT2. EAAT2 is responsible for transport of the majority of the extrasynaptic glutamate in the spinal cord (Regan et al., 2007). The loss of EAAT2 has been well-documented in cases of human ALS as well as in rodent models of ALS and is hypothesized to contribute to motor neuron death through an excitotoxic mechanism (Rothstein et al., 1995, Bristol and Rothstein, 1996, Bruijn et al., 1997, Bendotti et al., 2001). Increased levels of glutamate have been found in the cerebrospinal fluid of ALS patients further supporting these findings (Rothstein et al., 1990, Shaw et al., 1995). Our gene profiling analysis revealed that the hGRPs only significantly upregulated EAAT2 expression when engrafted to the SOD $1{ }^{\text {G93A }}$ spinal cord, but not the WT spinal cord. Similar upregulation was not seen for another glutamate transporter, EAAT1, which is not lost during the course of ALS (Rothstein et al., 1995). Therefore, this EAAT2 upregulation may be a response to compensate for the EAAT2 loss observed in the ventral horn of these mice. The increases in EAAT2 gene expression may be muted by the inability to mature more fully in this mouse model since endstage of disease occurs at approximately 125 days. This lack of full EAAT2 expression may also explain why the more rapidly maturing rodent GRPs showed behavioral efficacy and neuroprotection in a SOD $1^{\text {G93A }}$ rat model but more slowly maturing human GRPs failed to show such differences (Lepore et al., 2008b, Lepore et al., 2011). Ultimately, although the increase is modest at this time point, these data suggest the hGRPs have the ability to adapt and respond to pathological events in the 
SOD1 ${ }^{\mathrm{G} 93 \mathrm{~A}}$ spinal cord such as EAAT2 loss, but they do not adopt all characteristics of the endogenous astrocytes such as GFAP upregulation during astrocytosis.

Interestingly, we did not see differences in survival between hGRPs transplanted into the wild-type spinal cord and those transplanted into the SOD $1{ }^{\mathrm{G} 93 \mathrm{~A}}$ mouse spinal cord. These findings suggest that human GRPs are not particularly susceptible to an environment filled with cytokines, secreted growth factors or other molecules released by dying motor neurons. These findings parallel those of previous in vivo transplantation studies where we did not observe differences in the survival of GRPs carrying the SOD $1{ }^{\mathrm{G} 93 \mathrm{~A}}$ mutation compared with wildtype GRPs ---when transplanted into WT rats (Papadeas et al., 2011). In that study, we wondered whether the presence of mutant SOD1 in GRPs would influence their survival when analyzed over weeks in vivo. We did not appreciate any significant differences in survival between SOD1 ${ }^{\text {G93A }}$ GRP-derived astrocytes and WT GRP-derived astrocytes. Taking these studies together, these data would suggest that neither the external neurodegenerative environment nor the presence of mutations in SOD1 within the astrocyte influences survival of GRPs or GRPderived astrocytes. This may explain why there is little observed astrocyte proliferation in ALS models during the course of the disease (Lepore et al., 2008a, Magnus et al., 2008, Kang et al., 2010).

It is important to note that although we did not see changes in hGRP survival after transplantation to the SOD ${ }^{\mathrm{G} 93 \mathrm{~A}}$ spinal cord versus the WT spinal cord, we did detect more cell division by Ki67 in the hGRPs engrafted to the $\mathrm{SOD} 1^{\mathrm{G} 93 \mathrm{~A}}$ spinal cord. Our data indicate that hGRPs, when transplanted into the WT spinal cord, decrease proliferation over time whereas $\sim 10 \%$ of hGRPs engrafted into the SOD ${ }^{\mathrm{G} 93 \mathrm{~A}}$ spinal cord continued to proliferate at endstage. The enhanced proliferation is somewhat unpredicted given that no differences in the total 
number of hGRPs surviving in the SOD $1^{\text {G93A }}$ spinal cord were noticed when compared to WT at the endstage time point. It is likely that the increase in the number of $\mathrm{Ki}^{+} 7^{+}$hGRPs is so small that no net effect is observed in the total number of $\mathrm{HuNA}^{+}$cells surviving or that the effects of enhanced proliferation would only be observed at later time points (if the SOD ${ }^{\mathrm{G} 93 \mathrm{~A}}$ mice were to survive longer).

We have previously also used human specific probes to examine the changes in astrocyte lineage genes of human iPSC-derived astrocyte progenitors during the transition from an in vitro to a WT in vivo environment using similar transplantation strategies as in the current study (Haidet-Phillips et al., 2014). Using this method, we found that astrocyte-specific gene expression within the transplanted cells increased dramatically after engraftment to the WT rat spinal cord. The current study shows that human GRPs demonstrate a similar upregulation of astrocytic genes following transplantation and long-term assessment. Secondly, it did not appear that the surrounding neurodegenerative environment influenced that profile of upregulation. Since human GRPs are derived from fetal spinal cord and forebrain, we did not have access to human GRPs carrying the SOD $1^{\mathrm{G} 93 \mathrm{~A}}$ mutation to allow for comparison of the endogenous properties of the human GRPs in vitro and in vivo. However, the use of human iPSC from ALS patients with SOD1 mutations could make a future evaluation of iPSC-derived astrocyte progenitors using these same paradigms possible.

The use of human glial progenitors in this transplantation paradigm also allows for a very specific study of glial lineages. Using cell-surface antigens to sort human GRPs, a pure population of these cells can be isolated for in vitro study (Campanelli et al., 2008, Sandrock et al., 2010). Indeed, in this study using human-specific gene probes, we did not detect the upregulation of the neuronal genes ( $\beta$-tubulin) or microglial genes (ITGAM) included in our 
profile. This was mirrored immunohistochemically with all of the transplanted human cells differentiating to either $\mathrm{GFAP}^{+}$astrocytes or Olig2 ${ }^{+}$cells of the oligodendrocyte lineage.

\section{Conclusions}

Overall, our data demonstrate that hGRPs are not grossly influenced by the neurodegenerative environment of the SOD1 ${ }^{\mathrm{G} 93 \mathrm{~A}}$ spinal cord. Although we observed slight differential upregulation of EAAT2 in hGRPs engrafted to the SOD1 ${ }^{\mathrm{G} 93 \mathrm{~A}}$ spinal cord, the hGRPs generally displayed no differences in survival, migration, or gene expression following transplantation to the SOD $1^{\mathrm{G} 93 \mathrm{~A}}$ spinal cord. Additionally, the hGRPs showed no signs of astrocytosis or morphological transformation despite their engraftment to an environment characterized by active motor neuron degeneration. These data suggest that much of the astrocyte dysfunction in ALS may be due to cell autonomous damage caused by expression of diseaselinked mutations within astrocytes rather than a consequence of the neurodegenerative environment on astrocytes. Lastly, the upregulation of EAAT2 despite a lack of astrocytosis observed in the hGRPs engrafted to the SOD1 ${ }^{\mathrm{G} 93 \mathrm{~A}}$ spinal cord is encouraging with regards to the therapeutic potential for these cells.

Acknowledgements: This study was funded in part by NIH/NIHDS (U01NS062713), Department of Defense ALS Research Program, The Milton Safenowitz Post-doctoral Fellowship from the ALS Association to A.H.P. and a Career Development Award from the Muscular Dystrophy Association to A.H.P.

N.J. Maragakis is an unpaid consultant to Q Therapeutics, Inc. and is the Principal Investigator on a NIH/NINDS U01 with Q Therapeutics, Inc. 
James T. Campanelli is the Vice President of Research and Development at Q Therapeutics, Inc. Q Cells (human glial restricted progenitors) were supplied by Q Therapeutics, Inc.

\section{References}

Bendotti C, Tortarolo M, Suchak SK, Calvaresi N, Carvelli L, Bastone A, Rizzi M, Rattray M, Mennini T (2001) Transgenic SOD1 G93A mice develop reduced GLT-1 in spinal cord without alterations in cerebrospinal fluid glutamate levels. J Neurochem 79:737-746.

Bristol LA, Rothstein JD (1996) Glutamate transporter gene expression in amyotrophic lateral sclerosis motor cortex. Ann Neurol 39:676-679.

Bruijn LI, Becher MW, Lee MK, Anderson KL, Jenkins NA, Copeland NG, Sisodia SS, Rothstein JD, Borchelt DR, Price DL, Cleveland DW (1997) ALS-linked SOD1 mutant G85R mediates damage to astrocytes and promotes rapidly progressive disease with SOD1-containing inclusions. Neuron 18:327-338.

Cahoy JD, Emery B, Kaushal A, Foo LC, Zamanian JL, Christopherson KS, Xing Y, Lubischer JL, Krieg PA, Krupenko SA, Thompson WJ, Barres BA (2008) A transcriptome database for astrocytes, neurons, and oligodendrocytes: a new resource for understanding brain development and function. J Neurosci 28:264-278.

Campanelli JT, Sandrock RW, Wheatley W, Xue H, Zheng J, Liang F, Chesnut JD, Zhan M, Rao MS, Liu Y (2008) Expression profiling of human glial precursors. BMC Dev Biol 8:102.

Danbolt NC (2001) Glutamate uptake. Prog Neurobiol 65:1-105.

DeJesus-Hernandez M, Mackenzie IR, Boeve BF, Boxer AL, Baker M, Rutherford NJ, Nicholson AM, Finch NA, Flynn H, Adamson J, Kouri N, Wojtas A, Sengdy P, Hsiung GY, Karydas A, Seeley WW, Josephs KA, Coppola G, Geschwind DH, Wszolek ZK, 
Feldman H, Knopman DS, Petersen RC, Miller BL, Dickson DW, Boylan KB, GraffRadford NR, Rademakers R (2011) Expanded GGGGCC hexanucleotide repeat in noncoding region of C9ORF72 causes chromosome 9p-linked FTD and ALS. Neuron $72: 245-256$.

Deng HX, Chen W, Hong ST, Boycott KM, Gorrie GH, Siddique N, Yang Y, Fecto F, Shi Y, Zhai H, Jiang H, Hirano M, Rampersaud E, Jansen GH, Donkervoort S, Bigio EH, Brooks BR, Ajroud K, Sufit RL, Haines JL, Mugnaini E, Pericak-Vance MA, Siddique T (2011) Mutations in UBQLN2 cause dominant X-linked juvenile and adult-onset ALS and ALS/dementia. Nature 477:211-215.

Di Giorgio FP, Boulting GL, Bobrowicz S, Eggan KC (2008) Human embryonic stem cellderived motor neurons are sensitive to the toxic effect of glial cells carrying an ALScausing mutation. Cell Stem Cell 3:637-648.

Di Giorgio FP, Carrasco MA, Siao MC, Maniatis T, Eggan K (2007) Non-cell autonomous effect of glia on motor neurons in an embryonic stem cell-based ALS model. Nat Neurosci 10:608-614.

Feldman EL, Boulis NM, Hur J, Johe K, Rutkove SB, Federici T, Polak M, Bordeau J, Sakowski SA, Glass JD (2014) Intraspinal neural stem cell transplantation in amyotrophic lateral sclerosis: phase 1 trial outcomes. Ann Neurol 75:363-373.

Geiss GK, Bumgarner RE, Birditt B, Dahl T, Dowidar N, Dunaway DL, Fell HP, Ferree S, George RD, Grogan T, James JJ, Maysuria M, Mitton JD, Oliveri P, Osborn JL, Peng T, Ratcliffe AL, Webster PJ, Davidson EH, Hood L, Dimitrov K (2008) Direct multiplexed measurement of gene expression with color-coded probe pairs. Nat Biotechnol 26:317325. 
Glass JD, Boulis NM, Johe K, Rutkove SB, Federici T, Polak M, Kelly C, Feldman EL (2012)

Lumbar intraspinal injection of neural stem cells in patients with amyotrophic lateral sclerosis: results of a phase I trial in 12 patients. Stem Cells 30:1144-1151.

Gurney ME, Pu H, Chiu AY, Dal Canto MC, Polchow CY, Alexander DD, Caliendo J, Hentati A, Kwon YW, Deng HX, et al. (1994) Motor neuron degeneration in mice that express a human $\mathrm{Cu}, \mathrm{Zn}$ superoxide dismutase mutation. Science 264:1772-1775.

Haidet-Phillips AM, Hester ME, Miranda CJ, Meyer K, Braun L, Frakes A, Song S, Likhite S, Murtha MJ, Foust KD, Rao M, Eagle A, Kammesheidt A, Christensen A, Mendell JR, Burghes AH, Kaspar BK (2011) Astrocytes from familial and sporadic ALS patients are toxic to motor neurons. Nat Biotechnol 29:824-828.

Haidet-Phillips AM, Roybon L, Gross SK, Tuteja A, Donnelly CJ, Richard JP, Ko M, Sherman A, Eggan K, Henderson CE, Maragakis NJ (2014) Gene profiling of human induced pluripotent stem cell-derived astrocyte progenitors following spinal cord engraftment. Stem Cells Transl Med 3:575-585.

Henkel JS, Beers DR, Zhao W, Appel SH (2009) Microglia in ALS: The Good, The Bad, and The Resting. J Neuroimmune Pharmacol.

Jaarsma D, Teuling E, Haasdijk ED, De Zeeuw CI, Hoogenraad CC (2008) Neuron-specific expression of mutant superoxide dismutase is sufficient to induce amyotrophic lateral sclerosis in transgenic mice. J Neurosci 28:2075-2088.

Johnson JO, Mandrioli J, Benatar M, Abramzon Y, Van Deerlin VM, Trojanowski JQ, Gibbs JR, Brunetti M, Gronka S, Wuu J, Ding J, McCluskey L, Martinez-Lage M, Falcone D, Hernandez DG, Arepalli S, Chong S, Schymick JC, Rothstein J, Landi F, Wang YD, Calvo A, Mora G, Sabatelli M, Monsurro MR, Battistini S, Salvi F, Spataro R, Sola P, 
Borghero G, Galassi G, Scholz SW, Taylor JP, Restagno G, Chio A, Traynor BJ (2010)

Exome sequencing reveals VCP mutations as a cause of familial ALS. Neuron 68:857864.

Kabashi E, Valdmanis PN, Dion P, Spiegelman D, McConkey BJ, Vande Velde C, Bouchard JP, Lacomblez L, Pochigaeva K, Salachas F, Pradat PF, Camu W, Meininger V, Dupre N, Rouleau GA (2008) TARDBP mutations in individuals with sporadic and familial amyotrophic lateral sclerosis. Nat Genet 40:572-574.

Kang SH, Fukaya M, Yang JK, Rothstein JD, Bergles DE (2010) NG2+ CNS glial progenitors remain committed to the oligodendrocyte lineage in postnatal life and following neurodegeneration. Neuron 68:668-681.

Kang SH, Li Y, Fukaya M, Lorenzini I, Cleveland DW, Ostrow LW, Rothstein JD, Bergles DE (2013) Degeneration and impaired regeneration of gray matter oligodendrocytes in amyotrophic lateral sclerosis. Nat Neurosci 16:571-579.

Krencik R, Weick JP, Liu Y, Zhang ZJ, Zhang SC (2011) Specification of transplantable astroglial subtypes from human pluripotent stem cells. Nat Biotechnol 29:528-534.

Kugler P, Schleyer V (2004) Developmental expression of glutamate transporters and glutamate dehydrogenase in astrocytes of the postnatal rat hippocampus. Hippocampus 14:975-985.

Kwiatkowski TJ, Jr., Bosco DA, Leclerc AL, Tamrazian E, Vanderburg CR, Russ C, Davis A, Gilchrist J, Kasarskis EJ, Munsat T, Valdmanis P, Rouleau GA, Hosler BA, Cortelli P, de Jong PJ, Yoshinaga Y, Haines JL, Pericak-Vance MA, Yan J, Ticozzi N, Siddique T, McKenna-Yasek D, Sapp PC, Horvitz HR, Landers JE, Brown RH, Jr. (2009) Mutations in the FUS/TLS gene on chromosome 16 cause familial amyotrophic lateral sclerosis. Science 323:1205-1208. 
Lepore AC, Dejea C, Carmen J, Rauck B, Kerr DA, Sofroniew MV, Maragakis NJ (2008a) Selective ablation of proliferating astrocytes does not affect disease outcome in either acute or chronic models of motor neuron degeneration. Exp Neurol 211:423-432.

Lepore AC, O'Donnell J, Kim AS, Williams T, Tuteja A, Rao MS, Kelley LL, Campanelli JT, Maragakis NJ (2011) Human glial-restricted progenitor transplantation into cervical spinal cord of the SOD1 mouse model of ALS. PLoS One 6:e25968.

Lepore AC, Rauck B, Dejea C, Pardo AC, Rao MS, Rothstein JD, Maragakis NJ (2008b) Focal transplantation-based astrocyte replacement is neuroprotective in a model of motor neuron disease. Nat Neurosci 11:1294-1301.

Lino MM, Schneider C, Caroni P (2002) Accumulation of SOD1 mutants in postnatal motoneurons does not cause motoneuron pathology or motoneuron disease. J Neurosci $22: 4825-4832$.

Liu Y, Han SS, Wu Y, Tuohy TM, Xue H, Cai J, Back SA, Sherman LS, Fischer I, Rao MS (2004) CD44 expression identifies astrocyte-restricted precursor cells. Dev Biol 276:3146.

Liu Y, Wu Y, Lee JC, Xue H, Pevny LH, Kaprielian Z, Rao MS (2002) Oligodendrocyte and astrocyte development in rodents: an in situ and immunohistological analysis during embryonic development. Glia 40:25-43.

Magnus T, Carmen J, Deleon J, Xue H, Pardo AC, Lepore AC, Mattson MP, Rao MS, Maragakis NJ (2008) Adult glial precursor proliferation in mutant SOD1G93A mice. Glia 56:200208. 
Maragakis NJ, Dietrich J, Wong V, Xue H, Mayer-Proschel M, Rao MS, Rothstein JD (2004) Glutamate transporter expression and function in human glial progenitors. Glia 45:133143.

Maruyama H, Morino H, Ito H, Izumi Y, Kato H, Watanabe Y, Kinoshita Y, Kamada M, Nodera H, Suzuki H, Komure O, Matsuura S, Kobatake K, Morimoto N, Abe K, Suzuki N, Aoki M, Kawata A, Hirai T, Kato T, Ogasawara K, Hirano A, Takumi T, Kusaka H, Hagiwara K, Kaji R, Kawakami H (2010) Mutations of optineurin in amyotrophic lateral sclerosis. Nature 465:223-226.

Mayer-Proschel M, Kalyani AJ, Mujtaba T, Rao MS (1997) Isolation of lineage-restricted neuronal precursors from multipotent neuroepithelial stem cells. Neuron 19:773-785.

Nagai M, Re DB, Nagata T, Chalazonitis A, Jessell TM, Wichterle H, Przedborski S (2007) Astrocytes expressing ALS-linked mutated SOD1 release factors selectively toxic to motor neurons. Nat Neurosci 10:615-622.

Papadeas ST, Kraig SE, O'Banion C, Lepore AC, Maragakis NJ (2011) Astrocytes carrying the superoxide dismutase 1 (SOD1G93A) mutation induce wild-type motor neuron degeneration in vivo. Proc Natl Acad Sci U S A 108:17803-17808.

Philips T, Bento-Abreu A, Nonneman A, Haeck W, Staats K, Geelen V, Hersmus N, Kusters B, Van Den Bosch L, Van Damme P, Richardson WD, Robberecht W (2013) Oligodendrocyte dysfunction in the pathogenesis of amyotrophic lateral sclerosis. Brain 136:471-482.

Rao MS, Mayer-Proschel M (1997) Glial-restricted precursors are derived from multipotent neuroepithelial stem cells. Dev Biol 188:48-63. 
Re DB, Le Verche V, Yu C, Amoroso MW, Politi KA, Phani S, Ikiz B, Hoffmann L, Koolen M, Nagata T, Papadimitriou D, Nagy P, Mitsumoto H, Kariya S, Wichterle H, Henderson CE, Przedborski S (2014) Necroptosis Drives Motor Neuron Death in Models of Both Sporadic and Familial ALS. Neuron.

Regan MR, Huang YH, Kim YS, Dykes-Hoberg MI, Jin L, Watkins AM, Bergles DE, Rothstein JD (2007) Variations in promoter activity reveal a differential expression and physiology of glutamate transporters by glia in the developing and mature CNS. J Neurosci 27:66076619.

Renton AE, Majounie E, Waite A, Simon-Sanchez J, Rollinson S, Gibbs JR, Schymick JC, Laaksovirta H, van Swieten JC, Myllykangas L, Kalimo H, Paetau A, Abramzon Y, Remes AM, Kaganovich A, Scholz SW, Duckworth J, Ding J, Harmer DW, Hernandez DG, Johnson JO, Mok K, Ryten M, Trabzuni D, Guerreiro RJ, Orrell RW, Neal J, Murray A, Pearson J, Jansen IE, Sondervan D, Seelaar H, Blake D, Young K, Halliwell N, Callister JB, Toulson G, Richardson A, Gerhard A, Snowden J, Mann D, Neary D, Nalls MA, Peuralinna T, Jansson L, Isoviita VM, Kaivorinne AL, Holtta-Vuori M, Ikonen E, Sulkava R, Benatar M, Wuu J, Chio A, Restagno G, Borghero G, Sabatelli M, Heckerman D, Rogaeva E, Zinman L, Rothstein JD, Sendtner M, Drepper C, Eichler EE, Alkan C, Abdullaev Z, Pack SD, Dutra A, Pak E, Hardy J, Singleton A, Williams NM, Heutink P, Pickering-Brown S, Morris HR, Tienari PJ, Traynor BJ (2011) A hexanucleotide repeat expansion in C9ORF72 is the cause of chromosome 9p21-linked ALS-FTD. Neuron 72:257-268.

Riley J, Federici T, Polak M, Kelly C, Glass J, Raore B, Taub J, Kesner V, Feldman EL, Boulis NM (2012) Intraspinal stem cell transplantation in amyotrophic lateral sclerosis: a phase I 
safety trial, technical note, and lumbar safety outcomes. Neurosurgery 71:405-416; discussion 416.

Rosen DR, Siddique T, Patterson D, Figlewicz DA, Sapp P, Hentati A, Donaldson D, Goto J, O'Regan JP, Deng HX, et al. (1993) Mutations in Cu/Zn superoxide dismutase gene are associated with familial amyotrophic lateral sclerosis. Nature 362:59-62.

Rossi D, Brambilla L, Valori CF, Roncoroni C, Crugnola A, Yokota T, Bredesen DE, Volterra A (2008) Focal degeneration of astrocytes in amyotrophic lateral sclerosis. Cell Death Differ 15:1691-1700.

Rothstein JD, Tsai G, Kuncl RW, Clawson L, Cornblath DR, Drachman DB, Pestronk A, Stauch BL, Coyle JT (1990) Abnormal excitatory amino acid metabolism in amyotrophic lateral sclerosis. Ann Neurol 28:18-25.

Rothstein JD, Van Kammen M, Levey AI, Martin LJ, Kuncl RW (1995) Selective loss of glial glutamate transporter GLT-1 in amyotrophic lateral sclerosis. Ann Neurol 38:73-84.

Sandrock RW, Wheatley W, Levinthal C, Lawson J, Hashimoto B, Rao M, Campanelli JT (2010) Isolation, characterization and preclinical development of human glial-restricted progenitor cells for treatment of neurological disorders. Regen Med 5:381-394.

Shaw PJ, Forrest V, Ince PG, Richardson JP, Wastell HJ (1995) CSF and plasma amino acid levels in motor neuron disease: elevation of CSF glutamate in a subset of patients. Neurodegeneration 4:209-216.

Shibata T, Yamada K, Watanabe M, Ikenaka K, Wada K, Tanaka K, Inoue Y (1997) Glutamate transporter GLAST is expressed in the radial glia-astrocyte lineage of developing mouse spinal cord. J Neurosci 17:9212-9219. 
Sreedharan J, Blair IP, Tripathi VB, Hu X, Vance C, Rogelj B, Ackerley S, Durnall JC, Williams KL, Buratti E, Baralle F, de Belleroche J, Mitchell JD, Leigh PN, Al-Chalabi A, Miller CC, Nicholson G, Shaw CE (2008) TDP-43 mutations in familial and sporadic amyotrophic lateral sclerosis. Science 319:1668-1672.

Suzuki M, McHugh J, Tork C, Shelley B, Klein SM, Aebischer P, Svendsen CN (2007) GDNF secreting human neural progenitor cells protect dying motor neurons, but not their projection to muscle, in a rat model of familial ALS. PLoS One 2:e689.

Ullensvang K, Lehre KP, Storm-Mathisen J, Danbolt NC (1997) Differential developmental expression of the two rat brain glutamate transporter proteins GLAST and GLT. Eur J Neurosci 9:1646-1655.

Vance C, Rogelj B, Hortobagyi T, De Vos KJ, Nishimura AL, Sreedharan J, Hu X, Smith B, Ruddy D, Wright P, Ganesalingam J, Williams KL, Tripathi V, Al-Saraj S, Al-Chalabi A, Leigh PN, Blair IP, Nicholson G, de Belleroche J, Gallo JM, Miller CC, Shaw CE (2009) Mutations in FUS, an RNA processing protein, cause familial amyotrophic lateral sclerosis type 6. Science 323:1208-1211.

Vives V, Alonso G, Solal AC, Joubert D, Legraverend C (2003) Visualization of S100B-positive neurons and glia in the central nervous system of EGFP transgenic mice. J Comp Neurol 457:404-419.

Xu L, Ryugo DK, Pongstaporn T, Johe K, Koliatsos VE (2009) Human neural stem cell grafts in the spinal cord of SOD1 transgenic rats: differentiation and structural integration into the segmental motor circuitry. J Comp Neurol 514:297-309. 
Yamanaka K, Chun SJ, Boillee S, Fujimori-Tonou N, Yamashita H, Gutmann DH, Takahashi R, Misawa H, Cleveland DW (2008) Astrocytes as determinants of disease progression in inherited amyotrophic lateral sclerosis. Nat Neurosci 11:251-253.

\section{Figure Legends}

Figure 1. Engraftment of hGRPs is independent of the SOD $1^{\mathrm{G} 93 \mathrm{~A}}$ spinal cord environment. A) Expression of human nuclear antigen (HuNA) was used to identify transplanted hGRPs in the mouse spinal cord. Human GRP survival was estimated by counting the total number of HuNA ${ }^{+}$ cells per spinal cord at 90 days or endstage in WT or SOD ${ }^{\mathrm{G} 93 \mathrm{~A}}$ mice. B, C) Rostral-caudal migration of hGRPs after transplantation into the WT or SOD $1^{\text {G93A }}$ spinal cord was quantified at 90 days $(\mathrm{B})$ or endstage $(\mathrm{C})$ time points by calculating the percentage of total $\mathrm{HuNA}^{+}$cells along the distance of the spinal cord. D) Rostral-caudal migration of engrafted hGRPs as identified by HuNA immunohistochemistry in the spinal cord of endstage SOD $1^{\mathrm{G} 93 \mathrm{~A}}$ mice or age-matched WT mice. White arrows denote bilateral transplantation site. Magnification, 10X images compiled as a mosaic. All data are graphed as mean +/- SEM. $n=3-4$ mice/group, $p>0.05$.

Figure 2. Proliferation of engrafted hGRPs is modestly enhanced in the SOD $1{ }^{\mathrm{G} 93 \mathrm{~A}}$ spinal cord at endstage, but not 90 days. A, B) Human GRPs localized by human nuclear antigen (HuNA) immunohistochemistry were double-labeled with Ki67 to identify dividing hGRPs in the WT (A) or SOD1 ${ }^{\mathrm{G} 93 \mathrm{~A}}$ (B) spinal cord at the endstage time point. Scale bars $=10 \mu \mathrm{m}$. Magnification, $40 \mathrm{X}$. 
C) The percentage of proliferating hGRPs was measured by quantifying the proportion of total $\mathrm{HuNA}^{+}$cells co-expressing the proliferation marker Ki67 at 90 days or endstage time points. Data are graphed as mean $+/$ - SEM. $\mathrm{n}=3$ mice/group, ${ }^{*} \mathrm{p}<0.01$.

Figure 3. Differentiation of hGRPs after transplantation to the WT or SOD $1^{\mathrm{G} 93 \mathrm{~A}}$ spinal cord. A) The percentage of hGRPs differentiating to $\mathrm{GFAP}^{+}$astrocytes at the site of injection was measured by quantifying the proportion of human nuclear antigen $(\mathrm{HuNA})^{+}$cells co-expressing the astrocyte marker GFAP by immunohistochemistry at 90 days and endstage in the WT and SOD1 ${ }^{\mathrm{G} 93 \mathrm{~A}}$ spinal cord. $\mathrm{p}>0.05$ between all groups, $\mathrm{n}=3$ mice/group. B) The percentage of hGRPs differentiating to Olig2 ${ }^{+}$cells of the oligodendrocyte lineage at the site of injection was measured by quantifying the proportion of $\mathrm{HuNA}^{+}$cells co-expressing Olig2 by immunohistochemistry at 90 days and endstage in the WT and SOD $1{ }^{\mathrm{G} 93 \mathrm{~A}}$ spinal cord. ${ }^{*} \mathrm{p}<0.05$, $\mathrm{n}=3$ mice/group. C, D) Representative images demonstrating the majority of engrafted $\mathrm{HuNA}^{+}$ cells are expressing the astrocyte marker, GFAP, after transplantation to either the WT (C) or $\mathrm{SOD}^{\mathrm{G} 93 \mathrm{~A}}$ (D) spinal cord at endstage. Scale bars $=10 \mu \mathrm{m}$. Magnification, 100X. E, F) Representative images demonstrating some of the engrafted $\mathrm{HuNA}^{+}$are expressing the oligodendrocyte lineage marker Olig2 after transplantation to either the WT (E) or SOD1 ${ }^{\mathrm{G} 93 \mathrm{~A}}$ (F) spinal cord at endstage. Arrows denote several $\mathrm{HuNA}^{+}$cells co-labeling for Olig2. Scale bars $=$ $10 \mu \mathrm{m}$. Magnification, 100X. All data are graphed as mean +/- SEM.

Figure 4. The SOD $1^{\mathrm{G} 93 \mathrm{~A}}$ spinal cord environment does not induce gross morphological changes in hGRP-derived astrocytes. A, B) The spinal cord ventral horn at the site of injection was analyzed using an antibody to human-specific GFAP (hGFAP) to detect the hGRP-derived 
astrocytes. A polyclonal antibody recognizing both human and mouse GFAP was used as a reference to identify the spinal cord borders as well as distinguish the spinal cord grey versus white matter (denoted by white dotted lines). At the endstage time point, the hGRP-derived astrocytes fill the ventral horn grey matter of both WT (A) and SOD1 ${ }^{\mathrm{G} 93 \mathrm{~A}}$ (B) spinal cords. Scale bars $=100 \mu \mathrm{m}$. Magnification, 20X images compiled as a mosaic. C, D) High magnification analysis of hGRP-derived astrocytes in the WT (C) or SOD ${ }^{\mathrm{G} 93 \mathrm{~A}}$ (D) spinal cord reveals no changes in astrocyte cell body or ramified cellular process morphology by human-specific GFAP (hGFAP) immunohistochemistry. Scale bars $=10 \mu \mathrm{m}$. Magnification, 40X (C), 100X (D).

Figure 5. Astrocyte-related gene expression in engrafted cells is largely independent of the SOD1 ${ }^{\mathrm{G} 93 \mathrm{~A}}$ spinal cord environment. Human-specific gene expression was measured in hGRPs in vitro just prior to transplantation and in vivo in transplanted cells at 90 days and endstage after engraftment to the WT or SOD $1{ }^{\mathrm{G} 93 \mathrm{~A}}$ spinal cord. A) GFAP expression in human cells engrafted to the WT versus SOD1 ${ }^{\mathrm{G} 93 \mathrm{~A}}$ spinal cord. B) Expression of aquaporin 4 in human cells engrafted to the WT versus SOD1 ${ }^{\mathrm{G} 93 \mathrm{~A}}$ spinal cord. C) Connexin 43 expression in human cells engrafted to the WT versus SOD1 ${ }^{\mathrm{G} 93 \mathrm{~A}}$ spinal cord. D) Expression of the astrocyte-specific gene EZR in human cells engrafted to the WT versus SOD1 ${ }^{\mathrm{G} 93 \mathrm{~A}}$ spinal cord.. E) Expression of the astrocytespecific gene $\mathrm{F} 3$ expression in human cells engrafted to the WT versus SOD ${ }^{\mathrm{G} 93 \mathrm{~A}}$ spinal cord. F) EAAT2 expression was increased after transplantation to the SOD1 ${ }^{\mathrm{G} 93 \mathrm{~A}}$ spinal cord at 90 days and endstage time points whereas EAAT2 gene expression was not changed after transplantation to the WT spinal cord at either time point. G) Expression of the astrocyte-specific gene MLC1 in human cells engrafted to the WT versus SOD1 ${ }^{\mathrm{G} 93 \mathrm{~A}}$ spinal cord. H) EAAT1 expression in human 
cells engrafted to the WT versus SOD1 ${ }^{\mathrm{G} 93 \mathrm{~A}}$ spinal cord. All data are graphed as mean $+/-$ SEM. $\mathrm{n}$ $=3-6$ mice/group, $* \mathrm{p}<0.05$.

Figure 6. Expression of progenitor and non-astrocyte-related genes in engrafted hGRPs is independent of the SOD $1^{\mathrm{G} 93 \mathrm{~A}}$ spinal cord environment. Human-specific gene expression was measured in hGRPs in vitro just prior to transplantation and in vivo in transplanted cells at 90 days and endstage after engraftment to the WT or SOD $1^{\mathrm{G} 93 \mathrm{~A}}$ spinal cord. A) Expression of the astrocyte progenitor marker CD44 in human cells engrafted to the WT versus SOD1 ${ }^{\mathrm{G} 93 \mathrm{~A}}$ spinal cord. B) Expression of the astrocyte progenitor marker S100 $\beta$ in human cells engrafted to the WT versus SOD1 ${ }^{\mathrm{G} 93 \mathrm{~A}}$ spinal cord. C) Expression of the progenitor marker nestin in human cells engrafted to the WT versus SOD $1^{\text {G93A }}$ spinal cord. D) Expression of the progenitor marker Sox2 in human cells engrafted to the WT versus SOD ${ }^{\mathrm{G} 93 \mathrm{~A}}$ spinal cord. E) Expression of the oligodendrocyte lineage marker Olig2 in human cells engrafted to the WT versus SOD1 ${ }^{\text {G93A }}$ spinal cord. F) Expression of the oligodendrocyte lineage marker PDGFR $\alpha$ in human cells engrafted to the WT versus SOD1 ${ }^{\mathrm{G} 93 \mathrm{~A}}$ spinal cord. G) Expression of the oligodendrocyte lineage marker CNPase in human cells engrafted to the WT versus SOD1 ${ }^{\mathrm{G} 93 \mathrm{~A}}$ spinal cord. H) The engrafted human cells did not express the mature oligodendrocyte marker MOG at any time point analyzed. I) The engrafted human cells did not express the microglial-specific gene ITGAM at any time point analyzed. J) The engrafted human cells did not express the neuronalspecific gene $\beta$-tubulin at any time point analyzed. All data are graphed as mean $+/-$ SEM. ${ }^{*} p<$ 0.05, $\mathrm{n}=3-6 \mathrm{mice} /$ group. 


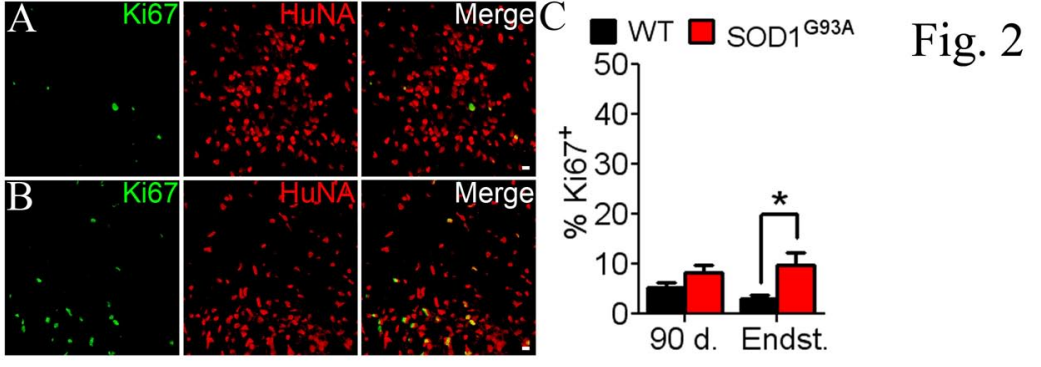


$\mathrm{A}_{100} \square \mathrm{WT} \square \mathrm{SOD}_{1}{ }^{\mathrm{G} 93 \mathrm{~A}} \mathrm{~B}$
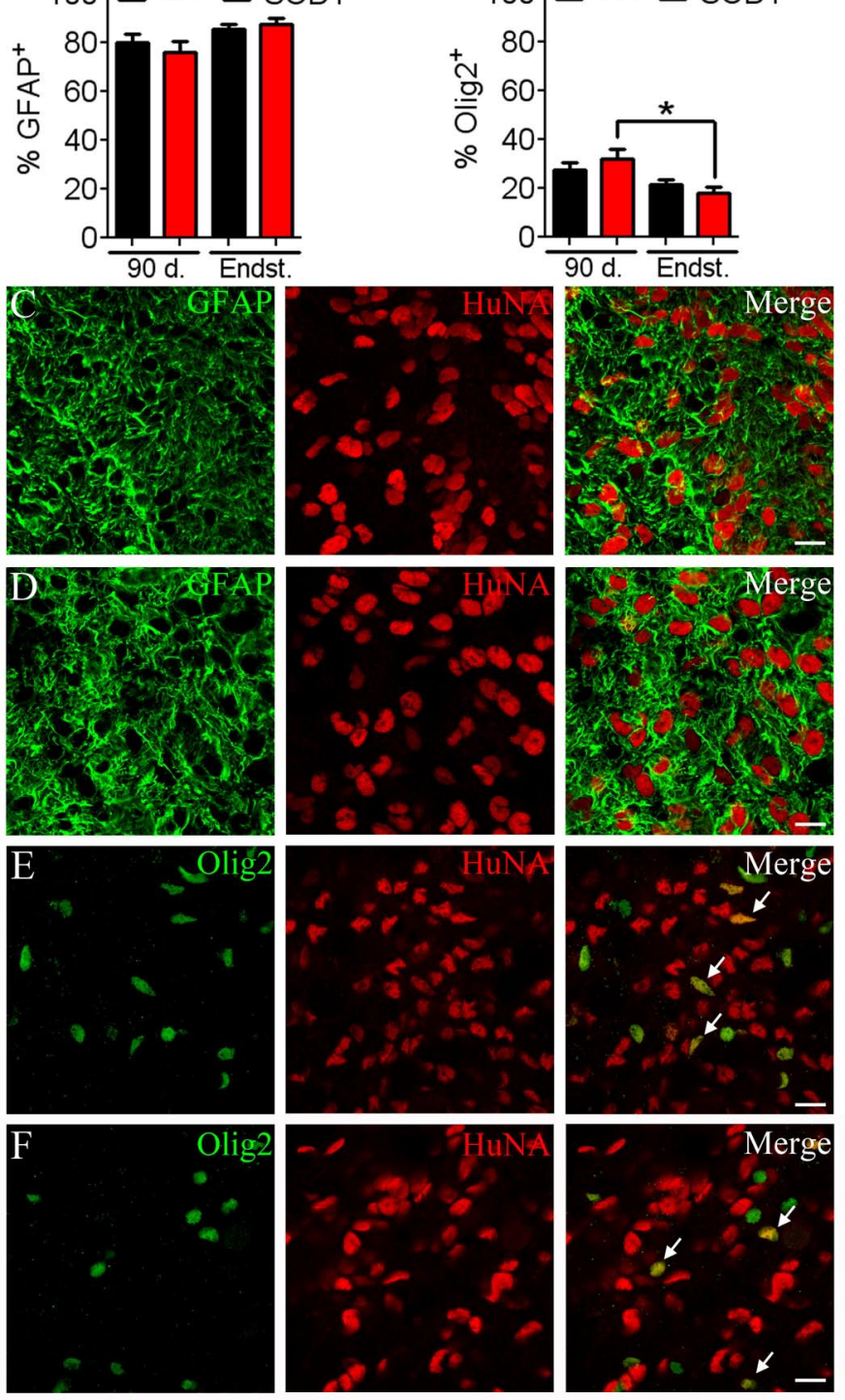

100 WT $\square$ SOD ${ }^{\text {G93A }}$

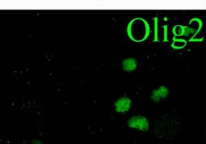

F \\ F}




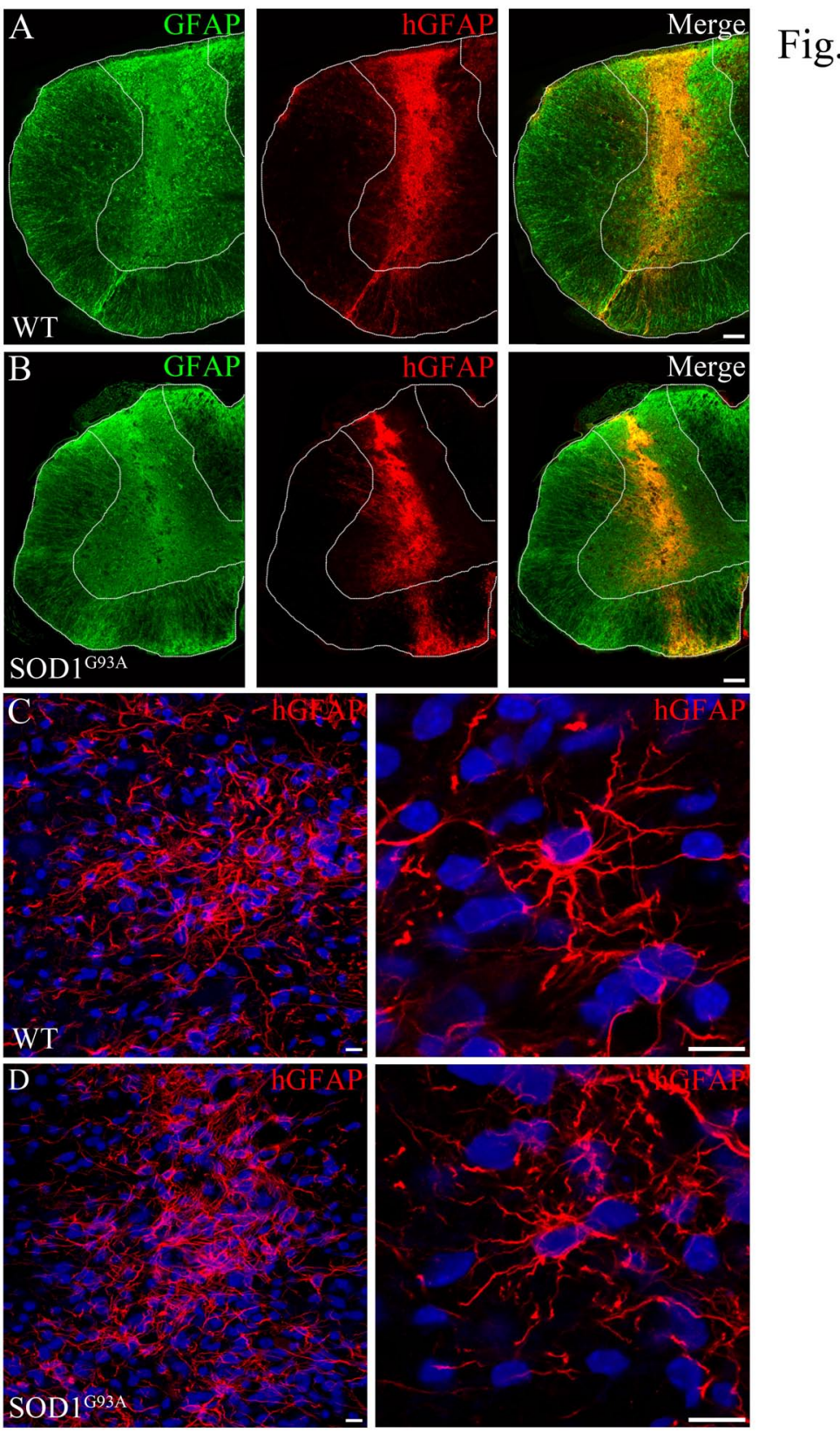


$\mathrm{A} \quad \boldsymbol{W T} \square_{\mathrm{SOD} 1^{\mathrm{G9} A}} \quad \mathrm{~B}$

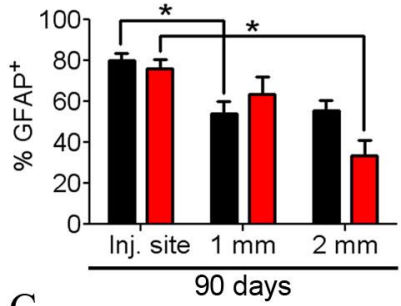

$\square$ WT $\square$ SOD1 ${ }^{\text {G93A }}$

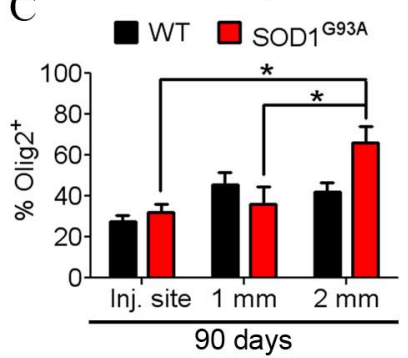

90 days $\square$ WT $\square$ SOD $1^{\text {G93A }}$

100

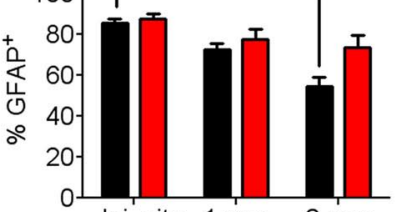

Inj. site $1 \mathrm{~mm} \quad 2 \mathrm{~mm}$

D

\section{Endstage}

Supp.

Figure 1 $\square$ WT $\square$ SOD1 $^{\mathrm{G} 93 \mathrm{~A}}$

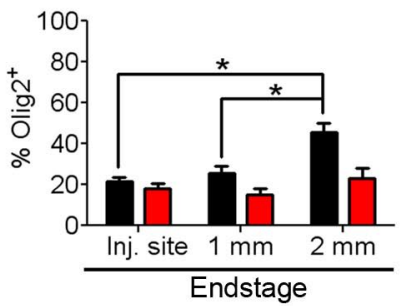




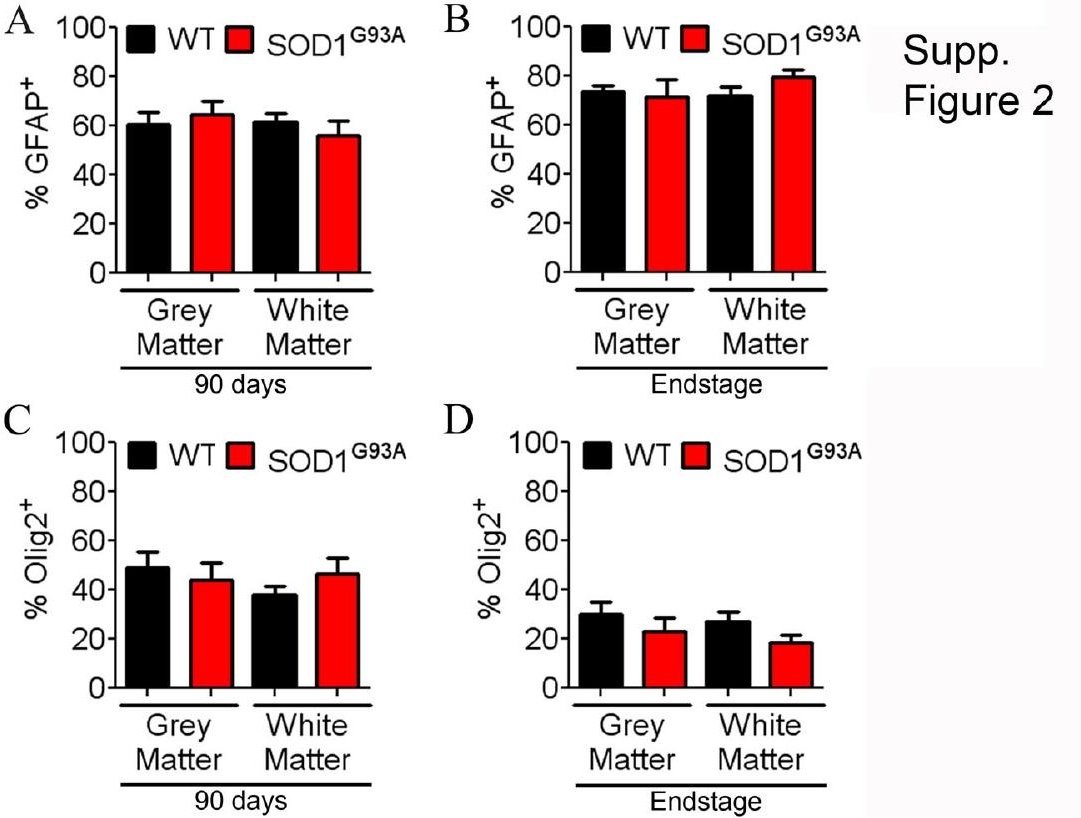




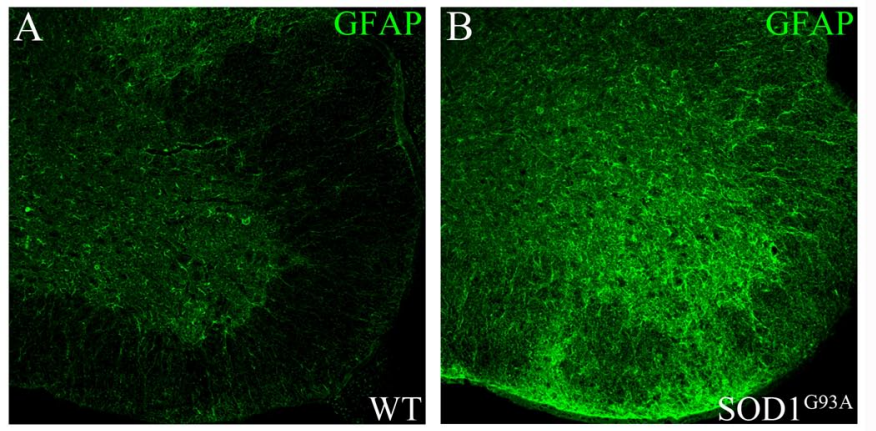

Supp.

Fig. 3 
Supporting Table 1. Raw values (prior to normalization) for NanoString ${ }^{\circledR}$ gene profiling of hGRPs in vitro prior to transplantation and in vivo post-transplantation.

\begin{tabular}{|c|c|c|c|c|c|c|c|c|c|c|c|}
\hline Gene Name & Accession \# & Class Name & $\begin{array}{c}\text { Mouse } \\
\text { SC region } \\
\text { Genotype } \\
\text { Age at sacrifice }\end{array}$ & $\begin{array}{c}8 \text { Red } \\
\text { Lumbar } \\
\text { WT } \\
90 \text { days }\end{array}$ & $\begin{array}{c}9 \text { Blue } \\
\text { Lumbar } \\
\text { WT } \\
90 \text { days }\end{array}$ & $\begin{array}{l}10 \text { Black } \\
\text { Lumbar } \\
\text { SOD1 } \\
90 \text { days }\end{array}$ & $\begin{array}{l}12 \text { None } \\
\text { Lumbar } \\
\text { SOD1 } \\
90 \text { days }\end{array}$ & $\begin{array}{c}14 \text { Red } \\
\text { Lumbar } \\
\text { WT } \\
\text { Endstage }\end{array}$ & $\begin{array}{c}17 \text { Red } \\
\text { Lumbar } \\
\text { WT } \\
\text { Endstage }\end{array}$ & $\begin{array}{c}4 \text { Red } \\
\text { Lumbar } \\
\text { SOD1 } \\
\text { Endstage }\end{array}$ & $\begin{array}{c}5 \text { Red } \\
\text { Lumbar } \\
\text { SOD1 } \\
\text { Endstage }\end{array}$ \\
\hline AQP4 & NM_004028.3 & Endogenous & & 615 & 1008 & 1007 & 1526 & 214 & 324 & 2109 & 108 \\
\hline B2M & NM_004048.2 & Endogenous & & 1 & 3 & 1 & 1 & 2 & 1 & 1 & 2 \\
\hline CD44 & NM_001001392.1 & Endogenous & & 7 & 3 & 4 & 5 & 1 & 3 & 20 & 1 \\
\hline $\mathrm{CNP}$ & NM_033133.4 & Endogenous & & 1 & 5 & 2 & 1 & 2 & 1 & 2 & 1 \\
\hline Connexin 43 & NM_000165.3 & Endogenous & & 1 & 4 & 28 & 33 & 1 & 1 & 19 & 2 \\
\hline EZR & NM_003379.4 & Endogenous & & 3 & 3 & 1 & 3 & 2 & 1 & 3 & 1 \\
\hline F3 & NM_001993.3 & Endogenous & & 2 & 2 & 1 & 1 & 1 & 1 & 2 & 1 \\
\hline GAPDH & NM_002046.3 & Endogenous & & 434 & 544 & 366 & 546 & 215 & 231 & 282 & 62 \\
\hline GFAP & NM_002055.4 & Endogenous & & 1 & 2 & 7 & 14 & 1 & 1 & 8 & 1 \\
\hline ITGAM & NM_000632.3 & Endogenous & & 1 & 3 & 1 & 1 & 2 & 1 & 1 & 1 \\
\hline MLC1 & NM_015166.3 & Endogenous & & 1 & 7 & 3 & 4 & 1 & 2 & 2 & 1 \\
\hline MOG & NM_001008228.2 & Endogenous & & 1 & 1 & 1 & 1 & 1 & 2 & 1 & 1 \\
\hline NES & NM_006617.1 & Endogenous & & 1 & 1 & 35 & 41 & 1 & 1 & 35 & 3 \\
\hline OAZ1 & NM_004152.2 & Endogenous & & 12 & 15 & 22 & 23 & 11 & 8 & 22 & 2 \\
\hline OLIG2 & NM_005806.2 & Endogenous & & 1 & 1 & 5 & 10 & 1 & 1 & 13 & 1 \\
\hline PDGFRA & NM_006206.3 & Endogenous & & 1 & 10 & 3 & 2 & 1 & 1 & 2 & 1 \\
\hline S100B & NM_006272.1 & Endogenous & & 3 & 2 & 4 & 3 & 2 & 1 & 3 & 1 \\
\hline SLC1A3 (EAAT1) & NM_004172.4 & Endogenous & & 1 & 2 & 4 & 2 & 1 & 2 & 4 & 1 \\
\hline SOX 2 & NM_003106.2 & Endogenous & & 2 & 1 & 4 & 3 & 1 & 3 & 3 & 1 \\
\hline Slc1a2 (EAAT2) & NM_004171.3 & Endogenous & & 1 & 1 & 17 & 23 & 1 & 1 & 24 & 1 \\
\hline TUBB3 (beta-tubulin) & NM_006086.2 & Endogenous & & 1 & 2 & 1 & 3 & 2 & 1 & 1 & 1 \\
\hline NEG_A & ERCC_00096.1 & Negative & & 6 & 7 & 4 & 9 & 3 & 3 & 10 & 2 \\
\hline NEG_B & ERCC_00041.1 & Negative & & 1 & 2 & 4 & 6 & 3 & 4 & 3 & 1 \\
\hline NEG_C & ERCC_00019.1 & Negative & & 2 & 2 & 6 & 8 & 1 & 1 & 7 & 1 \\
\hline NEG_D & ERCC_00076.1 & Negative & & 2 & 3 & 3 & 15 & 1 & 1 & 6 & 1 \\
\hline NEG_E & ERCC_00098.1 & Negative & & 8 & 13 & 9 & 15 & 4 & 5 & 7 & 1 \\
\hline NEG_F & ERCC_00126.1 & Negative & & 7 & 8 & 6 & 5 & 3 & 1 & 4 & 1 \\
\hline NEG_G & ERCC_00144.1 & Negative & & 1 & 1 & 1 & 2 & 1 & 1 & 1 & 1 \\
\hline NEG_H & ERCC_00154.1 & Negative & & 4 & 3 & 1 & 2 & 1 & 1 & 3 & 2 \\
\hline POS_A & ERCC_00117.1 & Positive & & 16648 & 25968 & 20758 & 23859 & 11248 & 14521 & 24660 & 2882 \\
\hline POS_B & ERCC_00112.1 & Positive & & 5842 & 9081 & 6929 & 8535 & 3708 & 4738 & 9041 & 651 \\
\hline POS_C & ERCC_00002.1 & Positive & & 1856 & 3134 & 2398 & 2910 & 1222 & 1553 & 3136 & 181 \\
\hline POS_D & ERCC_00092.1 & Positive & & 429 & 687 & 483 & 619 & 305 & 349 & 681 & 44 \\
\hline POS_E & ERCC_00035.1 & Positive & & 61 & 82 & 68 & 89 & 59 & 58 & 94 & 9 \\
\hline POS_F & ERCC_00034.1 & Positive & & 23 & 48 & 32 & 35 & 22 & 31 & 37 & 1 \\
\hline
\end{tabular}


Supporting Table 1. Raw values (prior to normalization) for NanoString ${ }^{\circledR}$ gene profiling of hGRPs in vitro prior to transplantation and in vivo post-transplantation.

\begin{tabular}{|c|c|c|c|c|c|c|c|c|c|c|c|}
\hline Gene Name & Accession \# & Class Name & $\begin{array}{c}\text { Mouse } \\
\text { SC region } \\
\text { Genotype } \\
\text { Age at sacrifice }\end{array}$ & $\begin{array}{c}8 \text { Red } \\
\text { Cervical } \\
\text { WT } \\
90 \text { days }\end{array}$ & $\begin{array}{c}9 \text { Blue } \\
\text { Cervical } \\
\text { WT } \\
90 \text { days }\end{array}$ & $\begin{array}{c}10 \text { Red } \\
\text { Cervical } \\
\text { WT } \\
90 \text { days }\end{array}$ & $\begin{array}{l}10 \text { Green } \\
\text { Cervical } \\
\text { WT } \\
90 \text { days }\end{array}$ & $\begin{array}{l}10 \text { None } \\
\text { Cervical } \\
\text { WT } \\
90 \text { days }\end{array}$ & $\begin{array}{l}10 \text { Black } \\
\text { Cervical } \\
\text { SOD1 } \\
90 \text { days }\end{array}$ & $\begin{array}{l}12 \text { None } \\
\text { Cervical } \\
\text { SOD1 } \\
90 \text { days }\end{array}$ & $\begin{array}{c}11 \text { Red } \\
\text { Cervical } \\
\text { SOD1 } \\
90 \text { days }\end{array}$ \\
\hline AQP4 & NM_004028.3 & Endogenous & & 3189 & 3001 & 5458 & 1129 & 3405 & 4038 & 2328 & 2171 \\
\hline B2M & NM_004048.2 & Endogenous & & 792 & 138 & 2262 & 229 & 1976 & 1686 & 354 & 493 \\
\hline CD44 & NM_001001392.1 & Endogenous & & 88 & 17 & 67 & 27 & 56 & 65 & 46 & 34 \\
\hline $\mathrm{CNP}$ & NM_033133.4 & Endogenous & & 308 & 49 & 813 & 45 & 296 & 659 & 238 & 59 \\
\hline Connexin 43 & NM_000165.3 & Endogenous & & 214 & 37 & 1630 & 93 & 891 & 1400 & 137 & 91 \\
\hline EZR & NM_003379.4 & Endogenous & & 266 & 60 & 1627 & 124 & 776 & 1517 & 147 & 146 \\
\hline F3 & NM_001993.3 & Endogenous & & 184 & 17 & 490 & 50 & 332 & 413 & 70 & 83 \\
\hline GAPDH & NM_002046.3 & Endogenous & & 2513 & 1223 & 3736 & 670 & 1873 & 3045 & 961 & 796 \\
\hline GFAP & NM_002055.4 & Endogenous & & 1399 & 115 & 4770 & 477 & 2881 & 3902 & 608 & 571 \\
\hline ITGAM & NM_000632.3 & Endogenous & & 2 & 3 & 6 & 3 & 1 & 1 & 2 & 1 \\
\hline MLC1 & NM_015166.3 & Endogenous & & 218 & 66 & 1316 & 148 & 705 & 1133 & 102 & 123 \\
\hline MOG & NM_001008228.2 & Endogenous & & 11 & 6 & 62 & 3 & 31 & 40 & 16 & 7 \\
\hline NES & NM_006617.1 & Endogenous & & 294 & 76 & 755 & 92 & 408 & 655 & 134 & 153 \\
\hline OAZ1 & NM_004152.2 & Endogenous & & 217 & 79 & 461 & 76 & 247 & 380 & 104 & 101 \\
\hline OLIG2 & NM_005806.2 & Endogenous & & 670 & 73 & 1532 & 67 & 534 & 1086 & 181 & 112 \\
\hline PDGFRA & NM_006206.3 & Endogenous & & 670 & 91 & 1463 & 81 & 619 & 1162 & 207 & 84 \\
\hline S100B & NM_006272.1 & Endogenous & & 218 & 27 & 489 & 36 & 212 & 358 & 86 & 37 \\
\hline SLC1A3 (EAAT1) & NM_004172.4 & Endogenous & & 714 & 175 & 3047 & 287 & 1997 & 2453 & 324 & 459 \\
\hline SOX2 & NM_003106.2 & Endogenous & & 443 & 65 & 1174 & 115 & 518 & 975 & 160 & 163 \\
\hline Slc1a2 (EAAT2) & NM_004171.3 & Endogenous & & 125 & 38 & 435 & 65 & 237 & 468 & 99 & 83 \\
\hline TUBB3 (beta-tubulin) & NM_006086.2 & Endogenous & & 18 & 7 & 71 & 5 & 25 & 53 & 10 & 10 \\
\hline NEG_A & ERCC_00096.1 & Negative & & 12 & 5 & 6 & 3 & 4 & 6 & 2 & 9 \\
\hline NEG_B & ERCC_00041.1 & Negative & & 8 & 9 & 7 & 4 & 3 & 7 & 4 & 4 \\
\hline NEG_C & ERCC_00019.1 & Negative & & 1 & 1 & 4 & 1 & 1 & 5 & 4 & 4 \\
\hline NEG_D & ERCC_00076.1 & Negative & & 5 & 7 & 1 & 2 & 1 & 10 & 3 & 6 \\
\hline NEG_E & ERCC_00098.1 & Negative & & 9 & 10 & 8 & 7 & 8 & 8 & 9 & 7 \\
\hline NEG_F & ERCC_00126.1 & Negative & & 13 & 10 & 10 & 6 & 5 & 4 & 10 & 9 \\
\hline NEG_G & ERCC_00144.1 & Negative & & 3 & 1 & 5 & 1 & 2 & 1 & 1 & 1 \\
\hline NEG_H & ERCC_00154.1 & Negative & & 3 & 1 & 5 & 1 & 2 & 1 & 1 & 4 \\
\hline POS_A & ERCC_00117.1 & Positive & & 37241 & 40162 & 36442 & 19017 & 33409 & 23888 & 29219 & 32402 \\
\hline POS_B & ERCC_00112.1 & Positive & & 12456 & 13393 & 12157 & 5782 & 11427 & 7322 & 9319 & 10756 \\
\hline POS_C & ERCC_00002.1 & Positive & & 4018 & 4534 & 3930 & 1829 & 3877 & 2381 & 2965 & 3615 \\
\hline POS_D & ERCC_00092.1 & Positive & & 823 & 911 & 837 & 388 & 791 & 534 & 623 & 770 \\
\hline POS_E & ERCC_00035.1 & Positive & & 157 & 146 & 138 & 66 & 98 & 124 & 107 & 124 \\
\hline POS_F & ERCC_00034.1 & Positive & & 59 & 50 & 53 & 27 & 47 & 33 & 42 & 42 \\
\hline
\end{tabular}


Supporting Table 1. Raw values (prior to normalization) for NanoString ${ }^{\circledR}$ gene profiling of hGRPs in vitro prior to transplantation and in vivo post-transplantation.

\begin{tabular}{|c|c|c|c|c|c|c|c|c|c|c|c|}
\hline Gene Name & Accession \# & Class Name & $\begin{array}{c}\text { Mouse } \\
\text { SC region } \\
\text { Genotype } \\
\text { Age at sacrifice }\end{array}$ & $\begin{array}{c}7 \text { Red } \\
\text { Cervical } \\
\text { WT } \\
\text { Endstage }\end{array}$ & $\begin{array}{c}7 \text { Blue } \\
\text { Cervical } \\
\text { WT } \\
\text { Endstage }\end{array}$ & $\begin{array}{c}14 \text { Red } \\
\text { Cervical } \\
\text { WT } \\
\text { Endstage }\end{array}$ & $\begin{array}{c}16 \text { Black } \\
\text { Cervical } \\
\text { WT } \\
\text { Endstage }\end{array}$ & $\begin{array}{c}17 \text { Red } \\
\text { Cervical } \\
\text { WT } \\
\text { Endstage }\end{array}$ & $\begin{array}{c}3 \text { Blue } \\
\text { Cervical } \\
\text { SOD1 } \\
\text { Endstage }\end{array}$ & $\begin{array}{c}3 \text { None } \\
\text { Cervical } \\
\text { SOD1 } \\
\text { Endstage }\end{array}$ & $\begin{array}{c}4 \text { Red } \\
\text { Cervical } \\
\text { SOD1 } \\
\text { Endstage }\end{array}$ \\
\hline AQP4 & NM_004028.3 & Endogenous & & 1247 & 2336 & 1873 & 4549 & 7551 & 13960 & 1455 & 3699 \\
\hline B2M & NM_004048.2 & Endogenous & & 955 & 175 & 2400 & 3523 & 5578 & 15564 & 79 & 543 \\
\hline $\mathrm{CD} 44$ & NM_001001392.1 & Endogenous & & 53 & 25 & 44 & 108 & 238 & 971 & 36 & 121 \\
\hline CNP & NM_033133.4 & Endogenous & & 84 & 14 & 394 & 682 & 1134 & 1805 & 12 & 21 \\
\hline Connexin 43 & NM_000165.3 & Endogenous & & 490 & 70 & 896 & 1713 & 4313 & 10367 & 64 & 298 \\
\hline EZR & NM_003379.4 & Endogenous & & 287 & 53 & 528 & 1158 & 2871 & 4988 & 22 & 254 \\
\hline F3 & NM_001993.3 & Endogenous & & 116 & 26 & 168 & 364 & 780 & 2330 & 7 & 140 \\
\hline GAPDH & NM_002046.3 & Endogenous & & 671 & 1325 & 1569 & 2684 & 3877 & 7483 & 578 & 1046 \\
\hline GFAP & NM_002055.4 & Endogenous & & 3884 & 286 & 2989 & 7064 & 16547 & 51630 & 264 & 2353 \\
\hline ITGAM & NM_000632.3 & Endogenous & & 1 & 4 & 2 & 1 & 1 & 3 & 2 & 1 \\
\hline MLC1 & NM_015166.3 & Endogenous & & 225 & 34 & 616 & 1134 & 1836 & 3651 & 16 & 175 \\
\hline MOG & NM_001008228.2 & Endogenous & & 12 & 4 & 17 & 58 & 93 & 134 & 3 & 3 \\
\hline NES & NM_006617.1 & Endogenous & & 63 & 11 & 225 & 393 & 663 & 1314 & 25 & 92 \\
\hline OAZ1 & NM_004152.2 & Endogenous & & 84 & 43 & 188 & 358 & 575 & 1119 & 27 & 53 \\
\hline OLIG2 & NM_005806.2 & Endogenous & & 119 & 16 & 335 & 878 & 1491 & 2500 & 14 & 46 \\
\hline PDGFRA & NM_006206.3 & Endogenous & & 131 & 15 & 622 & 795 & 1243 & 1883 & 6 & 15 \\
\hline S100B & NM_006272.1 & Endogenous & & 175 & 27 & 215 & 404 & 1032 & 1943 & 12 & 111 \\
\hline SLC1A3 (EAAT1) & NM_004172.4 & Endogenous & & 363 & 52 & 1287 & 2115 & 2832 & 5157 & 31 & 289 \\
\hline SOX 2 & NM_003106.2 & Endogenous & & 112 & 21 & 353 & 743 & 1298 & 2451 & 12 & 84 \\
\hline Slc1a2 (EAAT2) & NM_004171.3 & Endogenous & & 87 & 10 & 218 & 367 & 529 & 1260 & 16 & 64 \\
\hline TUBB3 (beta-tubulin) & NM_006086.2 & Endogenous & & 4 & 3 & 17 & 29 & 58 & 145 & 2 & 11 \\
\hline NEG_A & ERCC_00096.1 & Negative & & 1 & 13 & 3 & 10 & 6 & 9 & 4 & 8 \\
\hline NEG_B & ERCC_00041.1 & Negative & & 1 & 2 & 4 & 8 & 10 & 13 & 4 & 5 \\
\hline NEG_C & ERCC_00019.1 & Negative & & 1 & 3 & 1 & 2 & 3 & 11 & 9 & 5 \\
\hline NEG_D & ERCC_00076.1 & Negative & & 1 & 1 & 1 & 1 & 4 & 15 & 3 & 10 \\
\hline NEG_E & ERCC_00098.1 & Negative & & 4 & 8 & 8 & 13 & 12 & 9 & 6 & 10 \\
\hline NEG_F & ERCC_00126.1 & Negative & & 3 & 11 & 1 & 3 & 6 & 11 & 4 & 12 \\
\hline NEG_G & ERCC_00144.1 & Negative & & 1 & 1 & 3 & 2 & 1 & 1 & 1 & 1 \\
\hline NEG_H & ERCC_00154.1 & Negative & & 2 & 5 & 4 & 5 & 2 & 4 & 1 & 3 \\
\hline POS_A & ERCC_00117.1 & Positive & & 11757 & 40394 & 24681 & 33395 & 34119 & 28818 & 17029 & 32926 \\
\hline POS_B & ERCC_00112.1 & Positive & & 3540 & 13024 & 7512 & 10519 & 10738 & 9984 & 5653 & 11222 \\
\hline POS_C & ERCC_00002.1 & Positive & & 1143 & 4409 & 2410 & 3495 & 3440 & 3389 & 1771 & 3782 \\
\hline POS_D & ERCC_00092.1 & Positive & & 255 & 898 & 506 & 749 & 731 & 667 & 404 & 768 \\
\hline POS_E & ERCC_00035.1 & Positive & & 41 & 165 & 98 & 141 & 147 & 124 & 73 & 137 \\
\hline POS_F & ERCC_00034.1 & Positive & & 19 & 60 & 39 & 45 & 52 & 37 & 20 & 66 \\
\hline
\end{tabular}


Supporting Table 1. Raw values (prior to normalization) for NanoString ${ }^{\circledR}$ gene profiling of hGRPs in vitro prior to transplantation and in vivo post-transplantation.

\begin{tabular}{|c|c|c|c|c|c|c|c|c|c|}
\hline Gene Name & Accession \# & Class Name & $\begin{array}{c}\text { Mouse } \\
\text { SC region } \\
\text { Genotype } \\
\text { Age at sacrifice }\end{array}$ & $\begin{array}{c}5 \text { Red } \\
\text { Cervical } \\
\text { SOD1 } \\
\text { Endstage }\end{array}$ & $\begin{array}{c}16 \text { Red } \\
\text { Cervical } \\
\text { SOD1 } \\
\text { Endstage }\end{array}$ & $\begin{array}{c}16 \text { Blue } \\
\text { Cervical } \\
\text { SOD1 } \\
\text { Endstage }\end{array}$ & $\begin{array}{c}\text { hGRPs } \\
\text { in vitro } \\
\# 1\end{array}$ & $\begin{array}{c}\text { hGRPs } \\
\text { in vitro } \\
\# 2\end{array}$ & $\begin{array}{c}\text { hGRPs } \\
\text { in vitro } \\
\# 3\end{array}$ \\
\hline AQP4 & NM_004028.3 & Endogenous & & 8785 & 2239 & 7165 & 259 & 12 & 45 \\
\hline $\mathrm{B} 2 \mathrm{M}$ & NM_004048.2 & Endogenous & & 12896 & 1770 & 4692 & 15322 & 536 & 2162 \\
\hline CD44 & NM_001001392.1 & Endogenous & & 490 & 50 & 393 & 103 & 10 & 21 \\
\hline $\mathrm{CNP}$ & NM_033133.4 & Endogenous & & 1041 & 378 & 1206 & 1936 & 83 & 348 \\
\hline EZR & NM_003379.4 & Endogenous & & 3346 & 464 & 1973 & 2964 & 157 & 442 \\
\hline F3 & NM_001993.3 & Endogenous & & 1726 & 144 & 939 & 1273 & 36 & 165 \\
\hline GAPDH & NM_002046.3 & Endogenous & & 6440 & 2092 & 4773 & 34451 & 1776 & 5772 \\
\hline GFAP & NM_002055.4 & Endogenous & & 24341 & 1892 & 15232 & 3674 & 155 & 529 \\
\hline ITGAM & NM_000632.3 & Endogenous & & 7 & 1 & 7 & 5 & 2 & 5 \\
\hline MLC1 & NM_015166.3 & Endogenous & & 2233 & 494 & 1656 & 9435 & 560 & 1705 \\
\hline MOG & NM_001008228.2 & Endogenous & & 42 & 9 & 87 & 19 & 1 & 5 \\
\hline NES & NM_006617.1 & Endogenous & & 894 & 268 & 889 & 5521 & 407 & 1002 \\
\hline OLIG2 & NM_005806.2 & Endogenous & & 1305 & 354 & 1702 & 4653 & 216 & 764 \\
\hline PDGFRA & NM_006206.3 & Endogenous & & 1751 & 647 & 1282 & 9745 & 450 & 1248 \\
\hline S100B & NM_006272.1 & Endogenous & & 1184 & 164 & 744 & 5417 & 226 & 735 \\
\hline SLC1A3 (EAAT1) & NM_004172.4 & Endogenous & & 3580 & 1123 & 3074 & 37923 & 1658 & 5169 \\
\hline SOX2 & NM_003106.2 & Endogenous & & 1703 & 362 & 1361 & 6155 & 267 & 882 \\
\hline Slc1a2 (EAAT2) & NM_004171.3 & Endogenous & & 908 & 187 & 580 & 1725 & 102 & 289 \\
\hline TUBB3 (beta-tubulin) & NM_006086.2 & Endogenous & & 75 & 9 & 98 & 241 & 29 & 66 \\
\hline NEG_A & ERCC_00096.1 & Negative & & 8 & 6 & 5 & 5 & 4 & 9 \\
\hline NEG_B & ERCC_00041.1 & Negative & & 12 & 11 & 6 & 5 & 4 & 3 \\
\hline NEG_C & ERCC_00019.1 & Negative & & 12 & 10 & 11 & 4 & 1 & 2 \\
\hline NEG_D & ERCC_00076.1 & Negative & & 16 & 7 & 7 & 7 & 1 & 2 \\
\hline NEG_E & ERCC_00098.1 & Negative & & 14 & 10 & 11 & 18 & 4 & 11 \\
\hline NEG_F & ERCC_00126.1 & Negative & & 7 & 7 & 14 & 7 & 5 & 9 \\
\hline NEG_G & ERCC_00144.1 & Negative & & 4 & 5 & 1 & 3 & 6 & 5 \\
\hline NEG_H & ERCC_00154.1 & Negative & & 5 & 4 & 7 & 5 & 6 & 7 \\
\hline POS_A & ERCC_00117.1 & Positive & & 29439 & 32987 & 31818 & 27890 & 21221 & 37079 \\
\hline POS_B & ERCC_00112.1 & Positive & & 9796 & 10562 & 9879 & 9250 & 5968 & 10756 \\
\hline POS_E & ERCC_00035.1 & Positive & & 122 & 137 & 126 & 125 & 77 & 139 \\
\hline POS_F & ERCC_00034.1 & Positive & & 51 & 28 & 42 & 38 & 25 & 62 \\
\hline
\end{tabular}

